\title{
WLS: um serviço aberto de ligações hipermídia para Web baseado em XML
}

\author{
Renato de Freitas Bulcão Neto
}

Orientadora:

Profa. Dra. Maria da Graça Campos Pimentel

Dissertação apresentada ao Instituto de Ciências Matemáticas e de Computação ICMC-USP, como parte dos requisitos para obtenção do título de Mestre em Ciências de Computação e Matemática Computacional.

USP - São Carlos

Novembro/2001

Versão Revisada)

Disto do Orientador: $456 / 10 / 2001$




\section{Dedicatória}

Dedico aos meus pais e irmãs pelo amor, carinho e compreensão que sempre me depositaram ao longo desta minha jornada. 


\section{Agradecimentos}

Agradeço o apoio da FAPESP (00/10931-1), a todos os amigos e parentes que sempre me transmitiram uma palavra de incentivo, a Graça Pimentel, a Mário, João e Érika, a Alê \& Toño, a Cláudia, Juninho e Renan, a Daniela, Elis e Camila. 


\section{Resumo}

Um serviço de ligações oferece funcionalidades hipermídia a aplicações que devem suportar ligações entre seus documentos, mantendo-os em seus formatos nativos. Este trabalho apresenta a definição da infra-estrutura do Serviço Aberto de Ligações Hipermídia para Web, chamado WLS (Web Linking Service). A infra-estrutura do WLS compreende uma base externa de ligações, um protocolo de comunicação entre o WLS e aplicações que o utilizam, e um conjunto de funções, sob a forma de uma API que têm acesso a sua base de ligações. Ao utilizar padrões baseados na tecnologia XML, o WLS fornece funcionalidades hipermídia para que aplicações XML se tornem hipermídia habilitadas, segundo uma abordagem de sistemas hipermídia abertos. 


\begin{abstract}
A linking service provides hypermedia functionalities to applications that must support links among their documents, keeping them in their native formats. This work presents the definition of the infrastructure of an Open Hypermedia Linking Service for the Web, called WLS (Web Linking Service). The infrastructure includes an external linkbase, a communication protocol among the WLS and its target applications, and a set of operations, defined as an API, that have access to its linkbase. By using XML-based standards, WLS provides hypermedia functionalities to any XML applications, according to an open hypermedia systems approach.
\end{abstract}




\section{Sumário}

1 Introdução 1

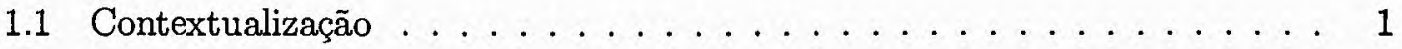

1.2 Motivação . . . . . . . . . . . . . . . . . . . 2

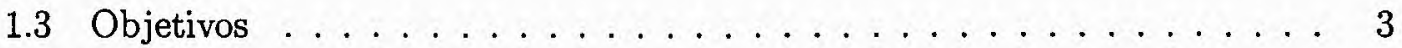

1.4 Resultados . . . . . . . . . . . . . . . . . . . . 3

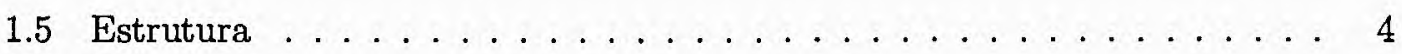

2 Sistemas Hipermídia Abertos 5

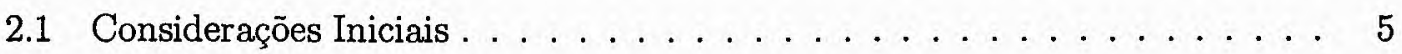

2.2 Endereços Embutidos versus Objetos de Ligação . . . . . . . . . . . . 6

2.3 Requisitos de Aplicações em OHSs $\ldots \ldots \ldots \ldots$. . . . . . . . . 7

2.4 Comunidade de Pesquisa de OHS $\ldots \ldots \ldots \ldots \ldots$

2.5 Modelo de Referência Hipertexto de Dexter . . . . . . . . . . . . . . 10

2.6 Protocolo Hipermídia Aberto - OHP . . . . . . . . . . 11

2.7 Principais OHSs . . . . . . . . . . . . . . . 13

2.7.1 SLS - Serviço de Ligação da Sun . . . . . . . . . . . . . 14

2.7 .2 Microcosm . . . . . . . . . . . . . . 16 
2.7.3 DHM - Devise Hypermedia . . . . . . . . . . . . 19

2.8 Considerações Finais . . . . . . . . . . . . . . . . 22

3 Papel de Padrões XML em OHSs 23

3.1 Considerações Iniciais . . . . . . . . . . . . . . . . . . 23

3.2 XML - Linguagem de Marcação Extensível . . . . . . . . . . . . . . . 24

3.3 XSL - Linguagem de Folha de Estilo Extensível . . . . . . . . . . . 25

3.4 XLink - Linguagem de Ligação XML . . . . . . . . . . . . . . . . 26

3.5 XPointer - Linguagem de Ponteiros XML . . . . . . . . . . . . . . 28

3.6 RDF - Framework para Descrição de Recursos . . . . . . . . . . . . 29

3.7 Considerações Finais $\ldots \ldots \ldots \ldots \ldots \ldots \ldots$. . . . . . . . . . . . . . .

4 Implementações de Serviços de Ligação $\quad 33$

4.1 Considerações Iniciais . . . . . . . . . . . . . . . . . 33

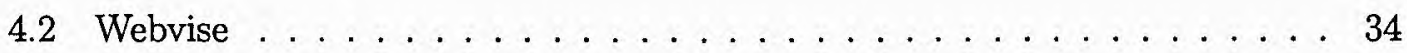

4.2 .1 Arquitetura do Webvise . . . . . . . . . . . . . 34

4.2.2 Webvise-cliente e Aplicações Integradas . . . . . . . . . . . 37

4.2 .3 Protocolo OHP XML . . . . . . . . . . . . . . . . . . . . 39

4.2 .4 Características do Webvise . . . . . . . . . . . . . 41

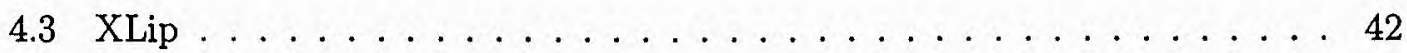

4.3.1 XLip e Ligação/Ancoragem XML . . . . . . . . . . . . . . . 42

4.3.2 Características do XLip ................ 45

4.4 Considerações Finais . . . . . . . . . . . . . . 46 
5 Projeto e Implementação do WLS $\quad 47$

5.1 Considerações Iniciais . . . . . . . . . . . . . . . . . . . 47

5.2 Modelagem do WLS . . . . . . . . . . . . . . . . 48

5.3 Arquitetura do WLS . . . . . . . . . . . . . . . 51

5.4 Implementação do WLS . . . . . . . . . . . . . 53

5.5 Operaçôes Suportadas pelo WLS . . . . . . . . . . . . . . . 57

5.6 Considerações Finais $\ldots \ldots \ldots$. . . . . . . . . . . . . . 60

$\begin{array}{lll}6 \text { Conclusões } & 61\end{array}$

6.1 Contribuições . . . . . . . . . . . . . . . . . . . 62

6.2 Trabalhos Futuros . . . . . . . . . . . . . . . . . . . 62

6.3 Considerações Finais . . . . . . . . . . . . . . . . . . 63

$\begin{array}{ll}\text { A Esquema RDF para o WLS } & 71\end{array}$ 


\section{Lista de Figuras}

2.1 Estruturas de ligação na Web e em OHSs (Grønbæk et al., 1997) . . . . . . 7

2.2 Sistema de camadas do Modelo Dexter (Halasz and Schwartz, 1990) . . . 10

2.3 Modelo de dados navegacional segundo OHP (Grønbæk, 1998) . . . . . . 12

2.4 Arquitetura do Serviço de Ligação da Sun (Pearl, 1989) . . . . . . . . . . 14

2.5 Painel de comandos do SLS e ligação na aplicação textedit (Pearl, 1989) . . 15

2.6 Arquitetura do Microcosm (Davis et al., 1994) . . . . . . . . . . 16

2.7 Percurso de ligação no DLS Microcosm (Carr et al., 1995) . . . . . . . 19

2.8 Framework DHM (Grønbæk and Trigg, 1999) . . . . . . . . . . . 20

2.9 Criação e percurso de ligações no DHM (Grønbæk and Trigg, 1999) . . . . 21

3.1 Declaração RDF segundo a representação de grafo . . . . . . . . . . . 30

4.1 Arquitetura do OHS Webvise, adaptado de (Grønbæk et al., 1999) . . . . 35

4.2 Interface da aplicação Webvise-cliente . . . . . . . . . . . . . 37

4.3 Criação de ligação ancorada no MSIE . . . . . . . . . . . . . . 38

4.4 Criação de ligação global no Microsoft Word . . . . . . . . . . . . . 39

4.5 Interface da aplicação XLink Tree . . . . . . . . . . . . . 43

4.6 Percurso de ligação simples interna com XLip/XLink Tree . . . . . . . 44 
4.7 Percurso de ligação estendida bidirecional externa com XLip/XLink Tree . 44

5.1 Modelo de dados conceitual do WLS . . . . . . . . . . . . 48

5.2 Arquitetura do WLS e comunicação com aplicações XML . . . . . . . . . 52 


\section{Lista de Tabelas}

2.1 Infra-estrutura Web versus Infra-estrutura em OHSs (Grønbæk et al., 1997) 9

3.1 Documentos estruturados na Web ................... 25

5.1 Tipos semânticos pré-definidos para ligações no WLS . . . . . . . . . 50

5.2 Algumas operaçōes definidas na API do WLS . . . . . . . . . . 57 


\section{Capítulo 1}

\section{Introdução}

\subsection{Contextualização}

Os precursores da tecnologia hipermídia - Bush, Nelson e Engelbart (Bush, 1945; Engelbart, 1984; Nelson, 1974) - formularam uma grande visão que incluía o suporte a estruturas hipermídia globais distribuídas. Estas estruturas incluiriam todo o conhecimento gerado ao longo do tempo e auxiliariam as pessoas na busca, navegação, reuso e crescimento desse imenso hiperdocumento, chamado por Nelson de Docuverse. Contudo, ao longo da história dos sistemas hipertexto, verificou-se o desenvolvimento de uma grande quantidade de sistemas com diferentes propósitos, funcionalidades, terminologias e modelos estruturais, dificultando a distribuição e o intercâmbio de dados entre os mesmos. Tais sistemas são caracterizados como fechados ${ }^{1}$ ou monolíticos.

Nesse ínterim, surge o Modelo de Referência Hipertexto de Dexter, uma agregação das melhores concepções de projeto de vários sistemas hipertexto de $1^{2}$ e $2^{2}$ gerações (Halasz and Schwartz, 1990). Sua finalidade é fornecer uma base de princípios para a especificação das estruturas de dados que implementam a informação interligada e a interação entre o usuário e o sistema hipertexto (Halasz and Schwartz, 1994). O princípio básico do Modelo Dexter é a separação explícita entre a estrutura ${ }^{2}$ e o conteúdo dos documentos gerenciados pelas aplicações de um ambiente computacional.

\footnotetext{
${ }^{1} \mathrm{Um}$ sistema hipermídia fechado impõe um formato de modelo de dados a aplicações, obrigando-as a se adaptarem a este formato.

${ }^{2}$ Conjunto de âncoras e ligações.
} 
Ao final dos anos 80 e início dos anos 90, sobretudo com o advento do Modelo Dexter, observou-se uma crescente mudança do projeto de sistemas hipermídia fechados para sistemas hipermídia abertos. Um Sistema Hipermídia Aberto (OHS - Open Hypermedia System) consiste em um componente middleware que oferece funcionalidades hipermídia a aplicações de um ambiente computacional (Wiil, 1997). Ao utilizarem os serviços de um OHS, aplicações podem tornar-se "hipermídia habilitadas" suportando, assim, a criação de ligações entre seus documentos, mantendo-os em seus formatos nativos. Ainda segundo Wiil (1997), para se tornarem hipermídia habilitadas, aplicações precisam ser extensíveis para que as funcionalidades hipermídia estejam disponíveis na interface do usuário, e precisam também ser capazes de comunicar solicitações hipermídia ao OHS através de um protocolo de comunicação.

A partir da experiência adquirida durante o desenvolvimento dos OHSs Microcosm (Davis et al., 1992) e Multicard (Rizk and Sauter, 1992), e da necessidade de interoperabilidade entre aplicações hipermídia habilitadas, Davis et al. (1996) propuseram um protocolo de comunicação, denominado Protocolo Hipermídia Aberto (OHP - Open Hypermedia Protocol). Este protocolo, composto por um conjunto de mensagens, define uma forma padrão de comunicação entre OHSs e suas aplicações integradas. ${ }^{3}$ OHSs são empregados em vários domínios de aplicação, incluindo: bibliotecas digitais, suporte computacional a projetos de engenharia, desenvolvimento de software e ambiente educacional.

\subsection{Motivação}

Para Bieber et al. (1997), os benefícios alcançados com a adição de funcionalidades hipermídia a aplicações que não são hipermídia habilitadas consistem em fornecer acesso navegacional e contextual às informações gerenciadas por estas aplicações, possibilitando que o encadeamento do conhecimento que estas informações representam se aproxime das estruturas cognitivas humanas.

Segundo Malcolm et al. (1991), as principais motivações para o desenvolvimento de OHSs consistem na necessidade de reduzir o esforço de autoria em aplicações hipermídia de grande escala, e de torná-las mais fáceis de serem modificadas, personalizadas e estendidas.

Ainda, a maioria dos OHSs discutidos na literatura oferece funcionalidades hipermídia a conjuntos específicos de aplicações (editores de texto, planilhas eletrônicas, ferramen-

\footnotetext{
${ }^{3}$ Aplicaçōes integradas a OHSs são utilizadas como sinônimo para aplicaçōes hipermídia habilitadas.
} 
tas $\mathrm{CAD}$, etc.) e não apresenta informações detalhadas de scus projetos e respectivas implementações. Nesse contexto, extensões não podem scr rcalizadas em scus conjuntos de aplicaçõcs integradas, o que limita scu emprcgo (para integração de informações) cm aplicações de tercciros.

O presente trabalho está inserido no contcxto do Projeto InCA-SERVE ${ }^{4}$ do Programa de Cooperação Internacional entre ProTeM-CC/CNPq/Brasil c NSF/EUA (Pimentel and Abowd, 1999). Esse projeto envolve parceria de grupos de pesquisadores do GeorgiaTech, Atlanta, EUA, e do Instituto de Ciências Matemáticas e de Computação da Universidade de São Paulo (ICMC-USP). Um conjunto de aplicações de cunho colaborativo vem scndo descnvolvido no contexto desse projeto, scndo que cstas aplicaçõcs não apresentam qualquer tipo de integração.

\subsection{Objetivos}

O objetivo deste trabalho consiste na definição da infra-cstrutura de um scrviço aberto de ligaçõos hipcrmídia para Web baseado em XML, denominado WLS (Web Linking Service). A infra-cstrutura hipermídia do WLS deve atender aos scguintes requisitos:

1. disponibilização de funcionalidades hipermídia a aplicações para que estas se tornem hipcrmídia habilitadas;

2. integração de um conjunto em aberto de aplicações hipcrmídia habilitadas; $\mathrm{e}$

3. disponibilização do scrviço $\mathrm{cm}$ ambiente Web através da utilização de tecnologias hipermídia atuais.

\subsection{Resultados}

Como resultado alcançado pelo presente trabalho, tem-sc o descnvolvimento do serviço aberto de ligações hipcrmídia WLS para Web que gerencia uma base independente de âncoras c ligações. A partir desta base de dados, o WLS fornece funcionalidades hipcrmídia a aplicaçōes que utilizam o formato XML (Extensible Markup Language) (Bray

\footnotetext{
${ }^{4}$ Infrastructure for Capture and Access - Infrastructure for Store, Extend, Retrieve and Visualize of Evolitionary Information.
} 
et al., 1998) na cstruturação de seus documentos gerenciados, por excmplo, as aplicações que compõem o ambiente computacional do Projeto InCA-SERVE.

A disponibilização de funcionalidades hipermídia a aplicações XML ć suportada através da implementação de mensagens (instanciadas como operações) do Protocolo Hipermídia Abcrto (OHP). A integração de aplicações XML hipermídia habilitadas ć obtida atravćs da implementação do serviço de ligações WLS na forma de uma API (Application Programming Interface). A disponibilização do WLS em ambientc Web sc dá atravćs da utilização de padrões baseados na tecnologia XML.

\subsection{Estrutura}

Este capítulo apresentou o contexto no qual se insere este trabalho, a motivação para o seu descnvolvimento, os objetivos propostos e os resultados alcançados. O Capítulo 2 introduz conceitos relacionados a OHSs, destaca a importância do Protocolo Hipcrmídia Aberto (OHP), e discorre sobre alguns dos principais OHSs encontrados na literatura. $O$ Capítulo 3 rclaciona a família de padrões XML ao desenvolvimento de OHSs. O Capítulo 4 descreve implementações de serviços de ligação semelhantes ao proposto neste trabalho. $\mathrm{O}$ Capítulo 5 apresenta as decisões de projeto relacionadas ao serviço de ligações WLS, bem como aspectos de sua implementação. Por fim, o Capítulo 6 apresenta a conclusão deste trabalho, discutindo suas contribuições para o cstado da arte e propostas para trabalhos futuros. 


\section{Capítulo 2}

\section{Sistemas Hipermídia Abertos}

\subsection{Considerações Iniciais}

Na década de 90, alguns aspectos da visão de estruturas hipermídia genéricas e globalmente acessíveis previstas pelos precursores da hipermídia se tornaram realidade através da Web. Devido à simplicidade de sua infra-estrutura, a Web fornece pouco suporte à criação dinâmica de ligações, bem como à colaboração sobre tais ligações. Assim, ao longo da década, desenvolveram-se pesquisas que visavam estender a infra-estrutura da Web com serviços que armazenam as informações de ligação externamente ao conteúdo dos documentos (Grønbæk et al., 1997).

Nesse contexto, observa-se que, ao longo da história dos sistemas hipermídia, existe uma nítida mudança do projeto de sistemas hipermídia fechados para sistemas hipermídia abertos. Um Sistema Hipermídia Aberto consiste em um middleware, cujo componente central é o serviço de ligações, que oferece funcionalidades hipermídia a aplicações de um ambiente computacional, permitindo a criação de ligações entre documentos gerenciados por essas aplicações, sem alterá-los (Davis et al., 1996).

O presente trabalho tem por objetivo a definição da infra-estrutura do serviço de ligações hipermídia WLS (Web Linking Service), que visa oferecer funcionalidades hipermídia a aplicações XML em ambiente Web que desejem tornar-se hipermídia habilitadas. Este capítulo introduz conceitos relacionados à teoria de OHSs, discute sobre requisitos de aplicações em OHSs, a importância do Modelo Dexter e sua relação com o Protocolo Hipermídia Aberto e, por fim, apresenta alguns dos principais OHSs. 


\subsection{Endereços Embutidos versus Objetos de Ligação}

Um importante requisito $\mathrm{em}$ sistemas hipermídia ć a distinção entre estrutura e conteúdo. Conteúdo se refere à informação armazenada no documento gerenciado por uma aplicação. Estrutura corresponde ao conjunto de âncoras e ligações que intcrligam contcúdos de documentos. A partir desses dois conceitos, consegue-se distinguir sistemas hipermídia fechados de sistemas hipermídia abertos.

Um sistcma fechado é aquele que impõe um formato de modelo de dados específico a suas aplicações integradas, visto que suas aplicações precisam ser personalizadas para participarem deste tipo de ambiente. A partir dessa perspectiva, a Web é considerada um sistema hipermídia fechado por impor o formato HTML (Raggett et al., 1998) às aplicações que desejem integrar-se a sua infra-estrutura. Quando o documento gerenciado por uma aplicação não está no formato HTML, cle precisa ser primeiramente convertido para esse formato antes de ser utilizado no contexto da Web. Como conseqüências imediatas, têm-se que aplicações integradas:

- não podem ser facilmente estendidas com novos tipos de documentos, exigindo, no mínimo, um extenso processo de reescrita da maioria dessas aplicações (van Ossenbruggen et al., 1998);

- são impedidas de reconhecer ligações hipermídia codificadas $\mathrm{cm}$ outro formato que não scja cm HTML; c

- não podem definir a forma de apresentação de novos tipos de documentos.

Em contrapartida, um sistema hipermídia aberto impõe apenas um formato cspecífico da estrutura hipermídia a suas aplicações integradas. Conseqüentemente,

1. documentos manipulados por aplicações hipermídia habilitadas permanecem em scus formatos nativos;

2. podem ser utilizadas estruturas de ligação comuns entre diferentes formatos de documentos; c

3. podem ser definidas formas alternativas de apresentação do conteúdo dos documentos manipulados pelas aplicações integradas sob a forma de folhas de estilo. 
A Figura 2.1 ilustra as abordagens de sistemas de estruturas embutidas utilizada na Web (à esquerda) e de estruturas externas ao conteúdo dos documentos manipulados por aplicações integradas a OHSs. Na abordagem utilizada na Web, âncoras e ligações são armazenadas no conteúdo dos documentos manipulados pelas aplicações integradas à infra-estrutura Web. Além disto, as ligações são unidirecionais e binárias. Na abordagem utilizada em OHSs, informações sobre âncoras e ligações são armazenadas e acessadas separadamente do conteúdo dos componentes ligados. Desta forma, ligações podem ser bidirecionais e ter grau de conexão ponto-multiponto e vice-versa.
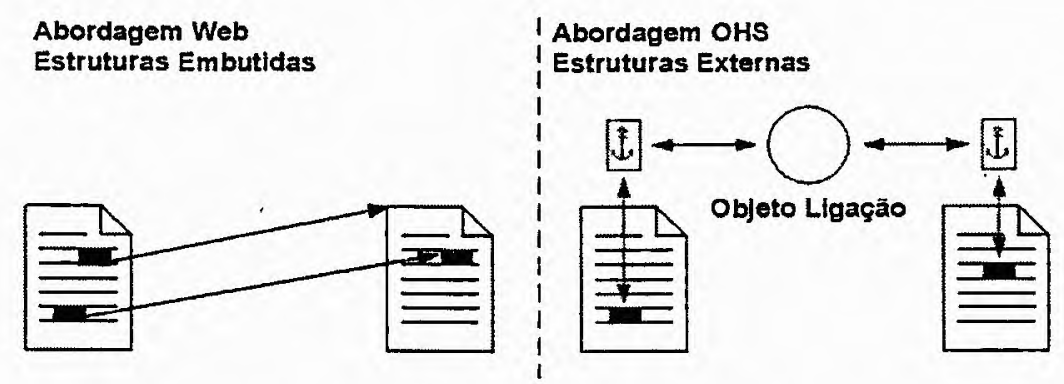

Figura 2.1: Estruturas de ligação na Web e em OHSs (Grønbæk et al., 1997)

\subsection{Requisitos de Aplicações em OHSs}

Aplicações integrantes de sistemas hipermídia abertos gerenciam seu próprio conjunto de documentos e usufruem de funcionalidades hipermídia fornecidas pelo servidor de ligações hipermídia, elemento central de OHSs. São apresentados a seguir um conjunto de requisitos que essas aplicações devem atender para participar de OHSs. Um estudo mais detalhado destes requisitos pode ser encontrado em Miotto (2001).

1. Separação explícita entre estrutura e conteúdo da informação: característica básica de aplicações em OHSs. Nenhuma informação sobre ligações deve estar embutida no conteúdo de documentos, permitindo que estes documentos sejam analisados, processados e manipulados pelas aplicações que os criaram em seus formatos originais.

2. Documentos em diferentes formatos: as funcionalidades hipermídia fornecidas podem ser utilizadas por um conjunto em aberto de aplicações, cada qual com seu formato de documento. 
3. Bases de ligações externas: informações sobre ligações são mantidas em bases de ligações cxtcrnas que podem ser públicas, como na Web, ou privadas, na qual um usuário leitor pode configurar seu próprio conjunto de ligações.

4. Ligações "de" e "para" informações read-only: uma vez quc âncoras e ligaçõcs são supcrpostas ao conteúdo de documentos em tempo de aprescntação, é possívcl que ligaçõcs sejam criadas em documentos de diferentes origens, incluindo read-only.

5. Ligações em termos da semântica da informação: ligações a informações com a mesma semântica podem ser suportadas nas aplicações em OHSs independentcmente da identidade dos documentos que encapsulam essas informaçõcs.

6. Documentos multi-relacionados: aplicações em OHSs podem suportar difc-

- rentes tipos de ligações, segundo Davis et al. (1994), tais como:

Específicas. Possucm uma única âncora-fonte c uma única âncora-destino, gcralmentc utilizadas para fornecer informações detalhadas sobre um assunto espccífico. São as ligações suportadas pela infra-cstrutura da Web.

Bidirecionais. Ligações específicas que podem ser navegadas $\mathrm{cm}$ ambas as dircções, não havendo distinção entre âncoras-fonte e destino.

Locais. Uma vez inseridas, são rcfletidas automaticamente $\mathrm{cm}$ toda ocorrência da âncora-fonte no documento de origcm. Podem ser utilizadas para relacionar uma cxplicação a uma palavra usada de modo particular $\mathrm{cm}$ um documento.

Globais. Uma vez inseridas, são refletidas automaticamentc $\mathrm{cm}$ toda ocorrência $\mathrm{da}$ âncora-fontc $\mathrm{cm}$ todo documento que for visualizado. Podem scr utilizadas para relacionar uma explicação de um termo técnico cm um glossário.

Computadas. Permitem que algum texto seja selecionado a partir de um documento de origem e sejam encontrados outros documentos que contêm uma alta ocorrência das palavras significativas na scleção. Dessa forma, são gcradas ligações de forma automática para esses documentos.

7. Distribuição: aplicaçõcs em OHSs podem ser armazenadas e exccutadas cm difcrentes máquinas em uma rede local ou através de diferentes domínios da Internet. Desta forma, durantc a especificação dessas aplicações, questõcs rclacionadas à distribuição de contcúdo e de estruturas de ligação devem scr considcradas.

8. Cooperação: tanto conteúdo quanto estrutura de aplicações $\mathrm{em}$ OHSs podem scr descnvolvidos de mancira cooperativa assíncrona ou sincronamentc. 
A Tabela 2.1 apresenta de forma reduzida as diferenças de projeto entre as aplicações que utilizam a infra-estrutura Web e aquelas que utilizam a abordagem de OHSs:

Tabela 2.1: Infra-estrutura Web versus Infra-estrutura cm OHSs (Grønbæk ct al., 1997)

\begin{tabular}{|l|l|l|}
\hline & Infra-estrutura Web & Infra-estrutura em OHSs \\
\hline \hline Servidor de ligações & Inexistentc & Elemento central \\
\hline Armazenamento de ligações & Embutidas no conteúdo & Extcrnas ao conteúdo \\
\hline Tipo de conexão & Binárias & N-árias \\
\hline Semântica de ligaçōes & Sem tipos e atributos & Com tipos c atributos \\
\hline Direção de ligaçōes & Unidirecionais & Bidirecionais \\
\hline Domínio de ligações & Privadas & Públicas c privadas \\
\hline Ancoragem & Textual, na maioria & Figuras, áudio c vídeo, inclusive \\
\hline Versionamento de ligações & Página inteira & Conteúdo c cstrutura \\
\hline Cooperação sobre ligaçōes & Assíncrona & Assíncrona c síncrona \\
\hline Distribuição & Apenas de conteúdo & Ligações e âncoras, inclusive \\
\hline
\end{tabular}

\subsection{Comunidade de Pesquisa de OHS}

Mediantc a nccessidade de diretrizes e padrões para a intcroperabilidade cntrc OHSs c suas aplicações integradas, a comunidade de pesquisa cm OHSs criou o Grupo de Trabalho de Sistcmas Hipcrmídia Abcrtos (OHSWG - Open Hypermedia Systems Working Group) (OHSWG, 2001). As atividades do OHSWG são divididas em três frentes de pesquisa: Grupo de Cenários, Grupo de Arquiteturas de Refcrência c Grupo de Protocolos.

O Grupo de Cenários tem como propósito apresentar exemplos práticos da utilização de OHŚs cm diversos domínios de aplicação, incluindo bibliotecas digitais, projetos de engcnharia, engenharia de software c ambiente educacional (Grønbæk ct al., 2000; Hall ct al., 1993; Trigg and Grønbak, 1997; Wiil, 1995). Cenários diversos podem ser encontrados cm Grønbæk and Trigg (1999) e no site Web do OHSWG (OHSWG, 2001).

O Grupo de Arquiteturas de Reforência tem por finalidade definir uma arquitetura de referência para OHSs. A comunidade de OHSs decidiu utilizar o Modelo Dexter (Halasz and Schwartz, 1990) como ponto de partida para a maioria das decisões relacionadas ao projeto de OHSs por este representar a agregação das concepções de projeto dos principais sistcmas hipcrtexto de $1^{\text {a }}$ e $2^{\text {a }}$ gerações. Além do Modelo Dexter, existcm outros modelos c arquiteturas propostos para OHSs, como a arquitctura cm camadas do Framework DHM (Devise Hypermedia Framework) (Grønbxk et al., 1994), que cstendeu o Modelo Dexter original. 
O Grupo de Protocolos trata dos aspectos de comunicação entre OHSs e suas aplicações integradas. A partir da experiência adquirida durante o desenvolvimento dos OHSs Microcosm (Davis et al., 1992) e Multicard (Rizk and Sauter, 1992), e da necessidade de interoperabilidade entre aplicações hipermídia habilitadas, Davis et al. (1996) propuseram um protocolo de comunicação, denominado Protocolo Hipermídia Aberto (OHP - Open Hypermedia Protocol). Em especial, o grupo de protocolos do OHSWG está diretamente relacionado ao presente trabalho, uma vez que é necessária a definição de um protocolo de comunicação entre o serviço de ligação WLS e suas aplicações integradas.

\subsection{Modelo de Referência Hipertexto de Dexter}

O Modelo de Referência Hipertexto de Dexter resulta na composição das melhores decisões de projeto dos principais sistemas hipertexto existentes até o final da década de 80 . Este modelo estabelece que a arquitetura de um sistema hipertexto deve ser organizada em três camadas: apresentação, armazenamento e componentes, conforme descrito na Figura 2.2. O Modelo Dexter enfatiza a camada de armazenamento, uma vez que esta modela a estrutura de rede ligações/nós básica, essência do sistema hipertexto.

\begin{tabular}{|c|c|c|c|c|}
\hline $\begin{array}{l}\text { CAMADA DE } \\
\text { APRESENTAÇAO } \\
\text { Apresentaçåo do } \\
\text { hipertexto, interaçăo } \\
\text { com o usuário }\end{array}$ & 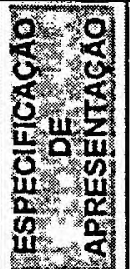 & $\begin{array}{c}\text { CAMADA DE } \\
\text { ARMAZENAMENTO } \\
\text { Banco de dados } \\
\text { contendo uma rede de } \\
\text { nós e ligaços }\end{array}$ & 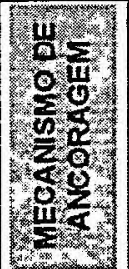 & $\begin{array}{l}\text { CAMADA DE } \\
\text { COMPONENTES } \\
\text { Estrutura/conteúdo } \\
\text { internos aos nós } \\
\text {. }\end{array}$ \\
\hline
\end{tabular}

Figura 2.2: Sistema de camadas do Modelo Dexter (Halasz and Schwartz, 1990)

A camada de componentes se preocupa com a estrutura e o conteúdo internos dos componentes da rede hipertexto. Componentes podem ser atômicos (nós), ligações ou composições (conjunto de componentes que forma um grafo acíclico dirigido).

O enfoque da camada de armazenamento reside nos mecanismos através dos quais ligações e nós são agregados para formar a malha de hipertexto. Halasz and Schwartz (1994) descrevem a camada de armazenamento com destaque para as entidades correlatas, como componente atômico, ligação, de composição, âncora e ponto final (Endpoint); os campos associados a estas entidades; e as funções de resolução de localização de componentes e de âncoras. 
A interface entre as camadas de armazenamento e de componentes comprcende o mecanismo de ancoragem, utilizado para o endereçamento das localidades ou ítens internos de um componente individual.

Funcionalidades de acesso, visualização e manipulação da malha de hipertexto são capturadas pela camada de apresentação. Tais funcionalidades capturam a essência dos aspectos interativos e dinâmicos dos sistemas hipertexto, mas não tentam cobrir os detalhes da interação do usuário com o hipertexto.

A interface entre as camadas de armazenamento e de apresentação é obtida através das especificações de apresentação que representam mecanismos através dos quais um componente deve ser cxibido ao usuário juntamente com a malha de hipertexto associada.

O Modelo Dexter tem sido utilizado para o desenvolvimento de padrões de intercâmbio de hipertexto. Fatores que podem influenciar no intercâmbio estão relacionados com as noções de composição e direção e scmântica das ligações suportadas pelos sistemas, conforme discutido em Leggett and Schnase (1994).

\subsection{Protocolo Hipermídia Aberto - OHP}

O OHP ć um protocolo padrão de comunicação bidirecional ponto-a-ponto, através do qual OHSs e suas aplicações integradas podem se comunicar através do envio c recebimento de mensagens.

A partir de análises realizadas sobre as extensões do Modelo Dexter em Grønback and Trigg (1996) c dos modelos de dados formulados em Davis et al. (1996), Grønbæk (1998) propôs o modelo de dados navegacional do OHP. O objetivo deste modelo, assumido como padrão pelo OHSWG, consiste cm garantir máxima interoperabilidade entre diferentes OHSs tanto na interface de comunicação quanto no intercâmbio de estruturas hipermídia entre OHSs. O modelo de dados navegacional do OHP é apresentado na Figura 2.3.

A hicrarquia de classes apresentada na Figura 2.3 mostra as classes gerais que contêm propriedades compartilhadas por todos os objetos definidos no modelo. Os objetos hipermídia das classes especializadas (Context, Link, Endpoint, Anchor, Node, Computation c PSpec) herdam os atributos das classes gerais c possucm atributos específicos a sua localização física (localização de conteúdo e localização de âncoras). 


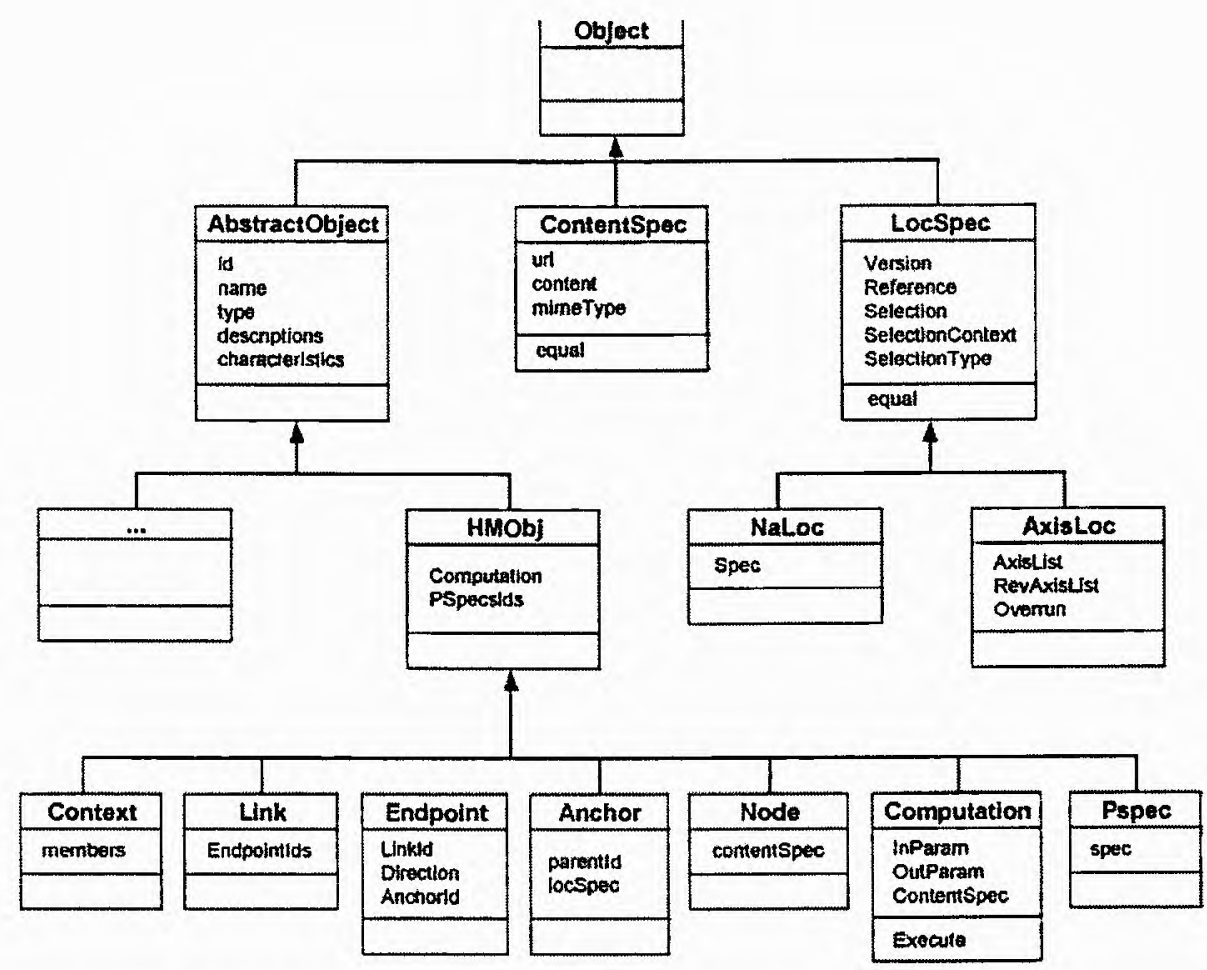

Figura 2.3: Modelo de dados navegacional segundo OHP (Grønbæk, 1998)

Âncoras contêm um atributo parentId, um identificador do objeto HMObject; isto permite a generalidade na qual tanto um objeto Link quanto um objeto Context podem ser pais de um objeto Anchor. LocSpec é uma classe que introduz o conceito de especificador de localização (Grønbæk and Trigg, 1996); um LocSpec corresponde ao valor de uma âncora no Modelo Dexter. Context é uma classe de objetos similar aos hipertextos no Modelo Dexter.

As subclasses PSpec e Computation possibilitam a especificação do comportamento de aplicações hipermídia habilitadas em tempo de apresentação. PSpec é uma classe que tipicamente armazena uma especificação de atributos peculiares a uma aplicação que regem a apresentação de um objeto hipermídia em tempo de execução. Já a classe Computation envolve objetos que armazenam código em alguma linguagem de programação para ser executado em tempo de execução por algum interpretador ou máquina virtual.

Segundo Grønbæk et al. (1999), os objetos hipermídia das classes especializadas de HMObj se associam através de relacionamentos 1:1, 1:N e $\mathrm{N}: \mathrm{N}$, e assim, representam as diversas formas de configuração dos objetos a serem manipulados em um OHS. 
O OHP pode ser implementado sob diversas formas. Uma implementação simples do OHP utiliza sockets TCP/IP usando a linguagem XML para codificar as mensagens c os parâmetros do protocolo que devem ser interpretados tanto por OHSs quanto por suas aplicações integradas. Este tipo de implementação do OHP ć encontrado no sistcma hipermídia aberto DHM. Maiores detalhes sobre a utilização do OHP no DHM podem scr encontrados na Seção 2.7.

Sob uma visão geral, existem mensagens do OHP que são enviadas unicamcntc pclo OHS e outras que são enviadas apenas pelas aplicações intcgradas a cstc. Basicamcntc, cxistcm quatro subconjuntos de mensagens definidos no OHP, segundo Grønbæk and Trigg (1999):

1. Subprotocolo de conexão: conjunto de mensagens responsávcl pelo estabclecimonto de conexões cntre OHSs c suas aplicações integradas.

2. Subprotocolo de ligação: conjunto de mensagens responsávcl pclo suportc à criação, rcmoção c percurso de ligaçõcs em documentos manipulados por aplicaçõcs integradas a OHSs.

3. Subprotocolo de navegação estendida: conjunto de mensagens que permitc a manipulação de estruturas hipcrmídia diretamente da interfacc das aplicaçõos integradas a OHSs. Este subprotocolo é opcional.

4. Subprotocolo multiusuário: conjunto de mensagens que fornccem suportc a bloqucios c notificações de eventos cm ambicnte multiusuários cooperativos.

\subsection{Principais OHSs}

Esta scção descreve alguns dos principais OHSs, sendo abordados o Serviço de Ligação da Sun (Pearl, 1989), o Microcosm (Lowe and Hall, 1999) e o Devise Hypermedia (Grønbæk and.Trigg, 1994). Embora existam outros OHSs na literatura, o Serviço de Ligação da Sun foi escolhido por ser considcrado a primeira implementação prática de um scrviço de ligações na história dos sistemas hipertexto, segundo Carr ct al. (1999). Microcosm c Devise Hypermedia complcmentam a lista de sistemas discutidos nesta scção pclo fato do seus projetistas screm os principais pesquisadores em sistemas hipermídia abcrtos. 


\subsubsection{SLS - Serviço de Ligação da Sun}

O Serviço de Ligação da Sun (Sun's Link Service) foi projetado em 1989 pela Sun Microsystems, sendo comercializado com o pacote de Software de Rede da Sun. O objetivo do SLS é integrar cada aplicação que roda em estações de trabalho da Sun através do fornecimento de ligações hipermídia.

O SLS deu início à implementação de sistemas e aplicações que utilizam a abordagem de OHSs. No entanto, é importante frisar que autores como Grønbæk et al. (1997) defendem que o sistema Intermedia (Meyrowitz, 1986) tenha sido o primciro sistema hipertexto a introduzir os primeiros conceitos de OHSs, como o suporte a ligações multiponto, bidirecionais c externas ao conteúdo de documentos.

O SLS inclui a especificação de um protocolo de comunicação com suas aplicaçõcs integradas, um software servidor de ligação, uma biblioteca para integração de novas aplicações e utilitários para o gerenciamento das bases de ligações. Como aplicações integradas ao SLS, têm-se os editores de texto textedit e vi dos sistemas da Sun c Unix, respectivamente. A Figura 2.4 descreve a arquitetura do SLS.

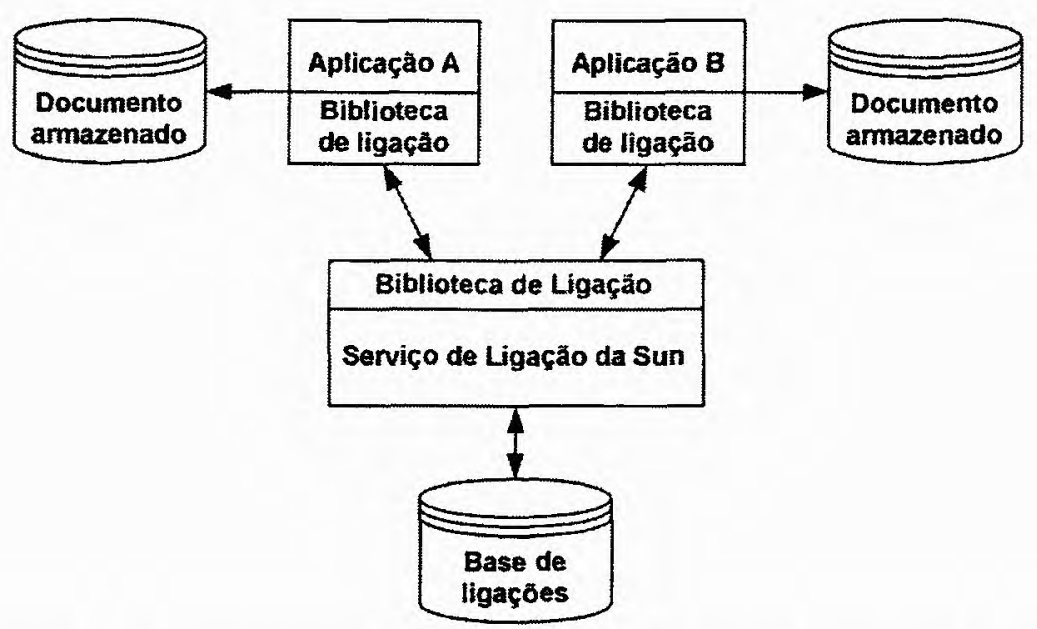

Figura 2.4: Arquitetura do Serviço de Ligação da Sun (Pearl, 1989)

A interface do usuário com o SLS se dá através de um painel de comandos principal, conforme mostra a Figura 2.5. Este painel consiste, em parte, do processo servidor de ligação que roda na máquina do usuário, servindo como mediador entre o SLS e suas apliçações integradas. Para criar uma ligação, o usuário deve selecionar um objeto cm uma aplicação integrada ao SLS c acionar as operações Start Link (que muda depois para End Link) e End Link para indicar os pontos finais fonte e destino da ligação, respectivamente. 
Por questões de consistência, o SLS fornece um ícone particular, conforme visto na Figura 2.5. Para percorrer a ligação criada, o usuário ativa a operação Display.

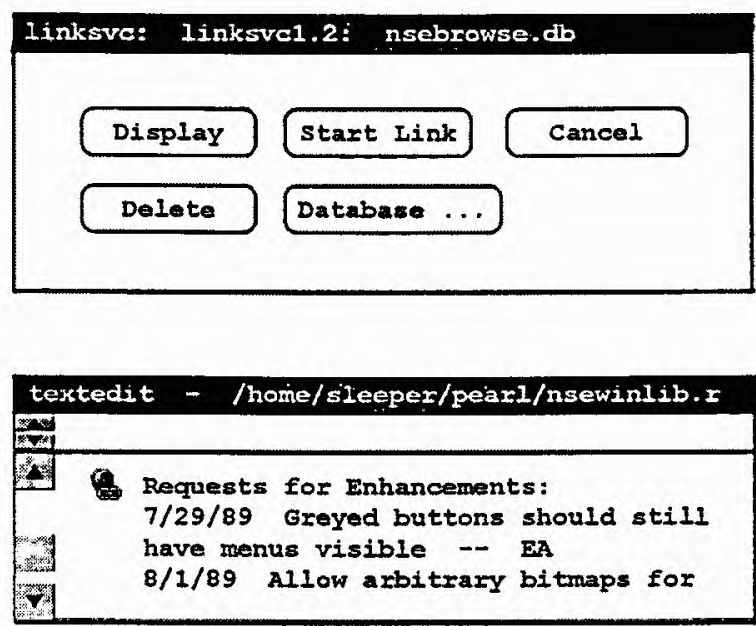

Figura 2.5: Painel de comandos do SLS e ligação na aplicação textedit (Pearl, 1989)

A biblioteca de ligação é utilizada pelas aplicações para que estas sejam integradas e se comuniquem com o SLS com mínimo esforço computacional. Esta biblioteca também faz parte do processo servidor de ligação. As aplicações se comunicam com o processo servidor de ligação central que controla o acesso às bases de ligações, como ilustra a Figura 2.4. Esta comunicação implementa o protocolo do SLS e envolve operações de criação, remoção e percurso de ligações. O SLS envia três tipos de mensagens a suas aplicações integradas: uma que forneça o identificador do objeto correntemente selecionado; uma que exiba o objeto com tal identificador e; outra que valide a existência desse objeto.

O modelo de ligações fornecido pelo SLS envolve ligações unidirecionais, não-valoradas e, normalmente binárias, podendo também serem n-árias. Neste caso, ao percorrer objetos que referenciam mais de um objeto, uma caixa de diálogo é mostrada ao usuário indicando os pontos finais daquela ligação, permitindo que este escolha o destino desejado.

Ligações hipertexto podem tornar-se inválidas, por exemplo, pela remoção de um de seus pontos finais. O SLS não suporta ligações inválidas, mas traz consigo dois mecanismos para identificar esta classe de ligaçōes: implícito e explícito. O mecanismo implícito ocorre quando o usuário tenta atravessar uma ligação cujo destino é inválido. O SLS informa ao usuário que a ligação não é mais válida e sugere a remoção da mesma. Porém, quando ambos os pontos finais de uma ligaçāo são inválidos, o SLS necessita do mecanismo explícito: um mecanismo de coleta de lixo que percorre todas as bases de ligações à procura de ligações inválidas, removendo-as quando as encontra. 


\subsubsection{Microcosm}

O sistema hipermídia aberto Microcosm foi desenvolvido na Universidade de Southampton, Inglaterra. O Microcosm consiste em um serviço de ligação desenvolvido, inicialmente, para fornecer a alunos e professores um ambiente hipertexto para a apresentação de bibliotecas de sons, imagens e vídeos, bem como de documentos textuais. A primeira aplicação a integrar-se ao Microcosm foi o Microsoft Word, devido a sua alta capacidade de programação fornecida pela linguagem Visual Basic. Além de ser utilizado na educação, o Microcosm foi integrado a aplicações do ramo da multimídia, engenharia, planilhas eletrônicas e sistemas gerenciadores de bancos de dados (Crowder and Hall, 1992).

O Microcosm utiliza uma abordagem diferente para o armazenamento de estruturas hipermídia: âncoras são embutidas no conteúdo do documento, enquanto ligações armazenam em bases de dados externas as informações referentes à posição física (expressa em número de bytes) das âncoras nesse documento (Davis et al., 1992).

A arquitetura do Microcosm consiste em duas camadas distintas, como mostra a Figura 2.6. Como descrito em Davis et al. (1992), a arquitetura do Microcosm não é cliente-servidor; há uma distribuição das várias funções hipertexto a uma cadeia de processos que se comunicam por passagem de mensagens. Visualizadores e editores de documentos são simplesmente instâncias específicas de processos hipertexto na cadeia de processos e, da mesma forma, comunicam-se por passagem de mensagens.

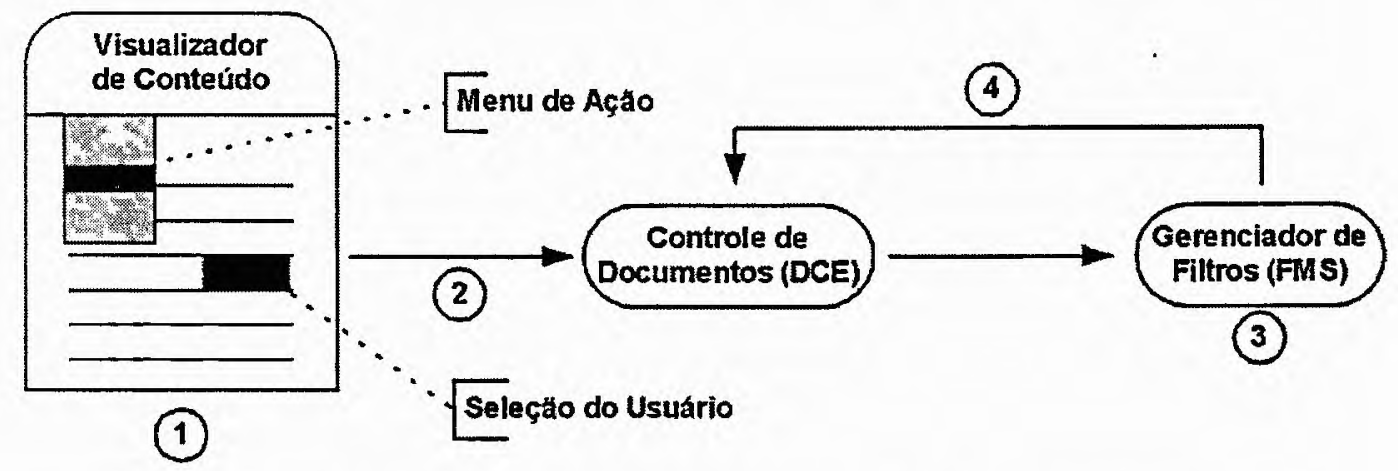

Figura 2.6: Arquitetura do Microcosm (Davis et al., 1994)

Segundo a Figura 2.6, usuários vêem a interface que corresponde a suas aplicações, referenciadas como visualizadores de conteúdo. A partir dessa interface, usuários podem fazer seleções e escolher uma ação a partir de um menu (por exemplo, a opção Follow Link), indicado por (1) na Figura 2.6. Uma aplicação tem por responsabilidades: 
1. cxibir um menu de ação (com operações Follow Link, Start Link, End Link, ctc.);

2. identificar a seleção realizada pelo usuário, bem como a posição física desta no conteúdo do documento;

3. identificar a posição física do documento correntc;

4. empacotar todas essas informações em uma mensagem; $e$

5. transmitir essa mensagem, indicada como (2) na Figura 2.6, ao Sistema de Controle de Documentos (DCS - Document Control System).

O DCS, ao receber a mensagem oriunda da aplicação, repassa-a ao Sistcma de Gcrenciamento de Filtros (FMS - Filter Management System) que decide que açõcs tomar (por excmplo, vcrificar que ligações estão disponíveis), indicado como (3) na Figura 2.6. Pequenos processos, chamados filtros, realizam a computação necessária e retornam ao FMS o resultado da ação solicitada pelo usuário. Se estes filtros têm uma ligação que conferc com a âncora-fonte na mensagem Follow Link, cles enviam uma mensagcm ao FMS que, por sua vez, direciona-a ao DCS, indicada como (4) na Figura 2.6, solicitando a exccução da aplicação apropriada para que o usuário possa visualizar o ponto final da ligação.

Fnquanto o DCS implementa um protocolo aberto para a coordenação de visões de documcntos, o FMS não implementa funções hipcrtcxto em si, mas ofercce um protocolo similar para o controle dos filtros que implementam funçöcs particularcs. Isto permitc o crescimento irrestrito das funcionalidades que o Microcosm pode fornccer. Três filtros sc destacam na arquitetura do Microcosm:

Filtros Linkbase. Comunicam-se diretamentc com as bases de ligaçõcs.

Filtro Linker. Manipula mensagens para criar e terminar ligações. A informação sobrc os pontos finais de ligações estão armazenadas $\mathrm{em}$ arquivos de bases de ligações.

Filtro Computed Linker. Utiliza um índice de um conjunto de arquivos de tcxto, criado previamente, para aplicar técnicas de recuperação de informação para fornecer ligaçōcs computadas.

O formato dos arquivos de bases de ligações é de fundamental importância por constituírcm o formato das mensagens do protocolo de comunicação com as aplicaçõcs intcgradas 
ao Microcosm. O formato desse arquivo representa cada ligação como um conjunto de marcações, que identificam cada arquivo referenciado pela ligação, assim como o contcúdo c posição das âncoras-fontc e destino. A ausência de algumas dessas informações no arquivo da base de ligações permite a configuração de ligações locais c globais.

Conclui-sc, assim, que o protocolo de comunicação entre o Microcosm c suas aplicaçõcs integradas consistc em:

1. exccutar aplicações para visualização de documentos que são pontos finais de destino de uma ligação;

2. cxibir âncoras em documentos segundo informaçõos de apresentação de aplicações integradas;

3. verificar a integridade de ligações; $\mathrm{c}$

4. responsabilizar aplicações quanto às habilidades que estas devem apresentar.

Uma vez que usuários podem editar documentos sem utilizar as funcionalidades hipermídia fornccidas pclo Microcosm, âncoras podem estar em novas posições nos seus respectivos documentos. Quanto à manutenção da consistência da base de ligaçõcs, o Microcosm utiliza o procedimento de comparação das datas de última modificação dos documentos c das ligações existentes sobre esses documentos, por exemplo, no caso de solicitação de uma operação Follow Link pelo usuário. As aplicações devem scr capazcs de reposicionar suas âncoras em caso de haver inconsistências para que, posteriormente, as bases de ligações possam ser atualizadas.

O OHS Microcosm foi implementado primciramente para a plataforma Windows, mas outras versõcs foram criadas para Macintosh, X-Windows e uma integrada à infra-cstrutura Wcb, chamada DLS Microcosm (Distributed Link Service) (Carr ct al., 1995).

O DLS Microcosm suporta bases de ligações mantidas em diferentes servidores, assim como mecanismos de localização dessas bases. O DLS é disponibilizado atravćs de um monu pop-up acoplado à barra de título do browser da Netscapc, como ilustra a Figura 2.7. Esse menu permite que usuários conectem as bases de ligaçõos do Microcosm à Intcrnet, possibilitando-lhes criar e percorrer ligações armazenadas externamente aos documentos Web. Antes que documentos scjam apresentados no browser, estes são processados pclo DLS para combiná-los com ligaçõcs externas. 


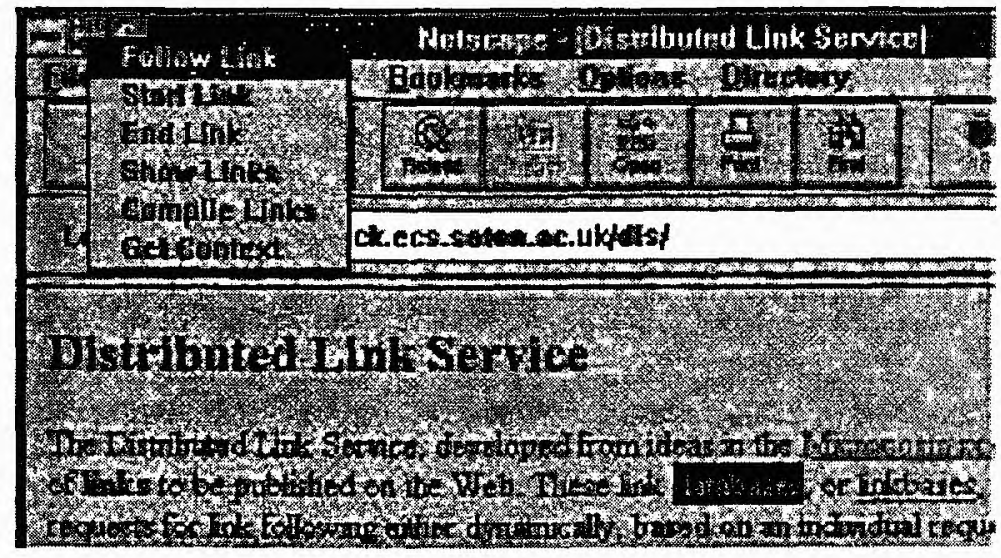

Figura 2.7: Percurso de ligação no DLS Microcosm (Carr et al., 1995)

O modelo de ligação do DLS segue o mesmo do Microcosm, isto é, ligações locais, genéricas, específicas e apenas unidirecionais. A heurística de detecção de inconsistências nas ligações também é igual à do Microcosm. As peculiaridades do DLS consistem na utilização de URLs para identificar documentos Web e do protocolo HTTP na comunicação entre aplicações c o DLS, uma vez que este se encontra no ambiente Web.

Recentemente, pesquisadores de Southampton estão trabalhando no desenvolvimento de um framework para OHSs distribuídos utilizando o DLS Microcosm como base, nomeado Microcosm TNG (Goose et al., 2000). Este framework visa atender a requisitos básicos de OHSs distribuídos: compartilhamento e organização de informação distribuída c serviços configuráveis distribuídos. As peculiaridades do Microcosm TNG residem na possibilidade de ligação entre aplicações de diferentes plataformas computacionais.

\subsubsection{DHM - Devise Hypermedia}

Pesquisadores da Universidade de Aarhus, Dinamarca, trabalharam em um projeto que desenvolvia ferramentas para fornecer suporte computacional a projetos de engenharia. As características cooperativas e abertas dos ambientes de projetos de engenharia criaram demanda alćm do tradicional percurso de ligações suportado pela hipermídia da época, o que incluía um banco de dados compartilhado, acesso multiplataforma, portabilidade, cxtensibilidade c adaptabilidade (Grønbæk and Trigg, 1994), ratificando as questõcs levantadas por Halasz (1988) para o projeto de futuros sistemas hipermídia.

O grupo de Aarhus utilizou o Modelo Dexter como ponto de partida e o transformou para uma visão orientada a objetos, gerando o protótipo de implementação DHM (Devise 
Hypermedia). O ambiente de programação utilizado consiste no Sistema Mjølner Beta com suporte à linguagem de programação orientada a objetos BETA. A Figura 2.8 descreve o Framework DHM, subdividindo-o em quatro camadas com suas respectivas responsabilidades.

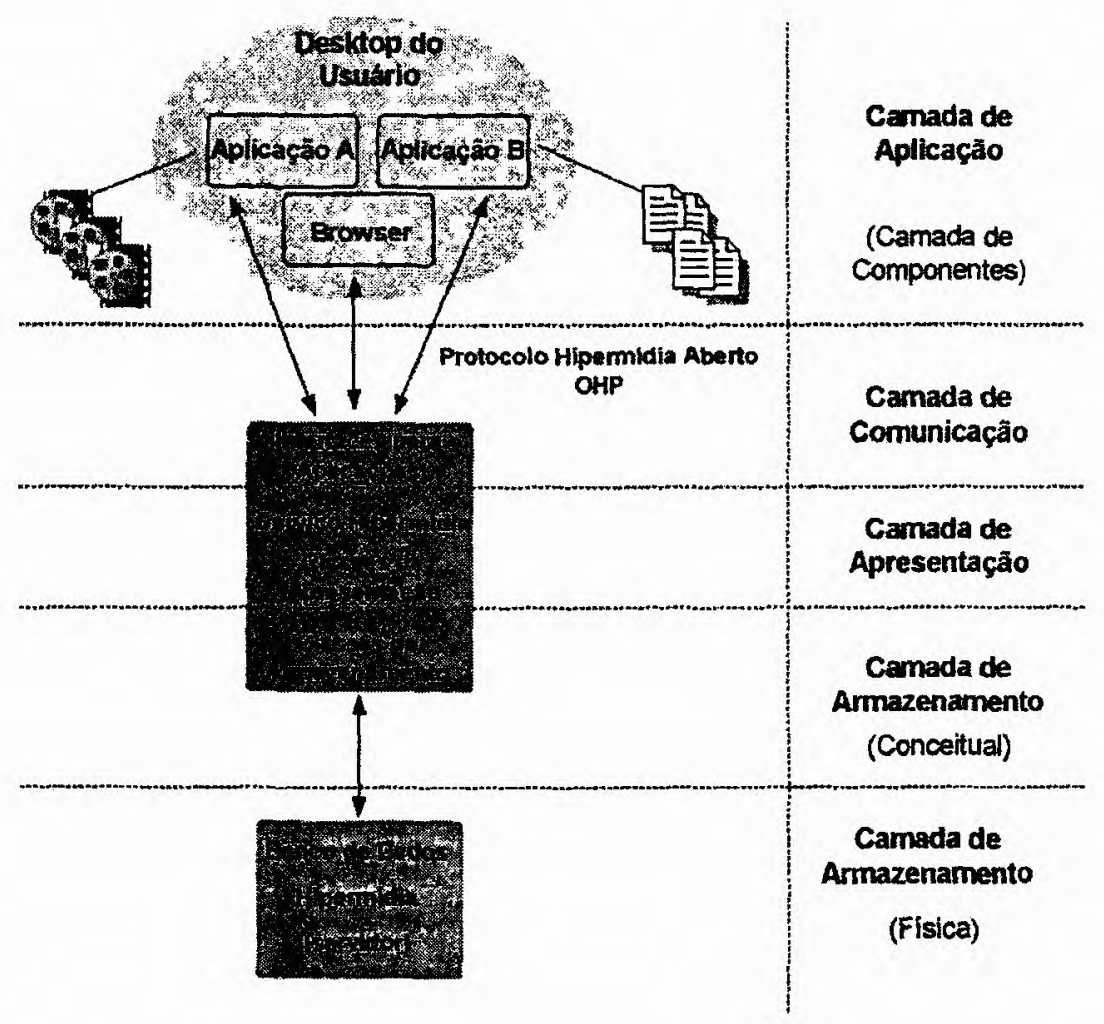

Figura 2.8: Framework DHM (Grønbæk and Trigg, 1999)

O Framework DHM, baseado em um sistema de objetos distribuídos, fornece vários tipos de processos cliente-servidor que correspondem às camadas descritas no Modelo Dextcr. São descritos em seguida, os processos envolvidos no Framework DHM. Cada classe de processos atua em uma camada do Framework DHM, exibido na Figura 2.8:

Processos editores. Manipulam as mídias suportadas pelo DHM (texto, gráficos c vídeo) que implementam a camada de componentes do Modelo Dexter;

Processos run-time. Fornecem o serviço hipermídia de ligaçāo e ancoragcm ao conjunto de processos editores utilizados pelo usuário. Tornam-se processos servidores para os processos editores, c clientes do servidor de banco de dados. Processos run-time implementam a camada de apresentação c parte da camada de armazenamento do Modelo Dexter. 
Processo servidor de banco de dados. Fornece o armazenamento físico permanente dos objetos hipermídia. Os objetos armazenados são instâncias das classes genéricas, implementando assim, os conceitos da camada de armazenamento do Modelo Dexter. O banco de dados utilizado no DHM foi melhorado com suporte a transações, técnicas de bloqueio e mecanismos de notificações de eventos.

O DHM estendeu o Modelo Dexter ao distinguir três tipos de âncoras independentemente do tipo de componente que as pertence: âncoras whole-component, quando o resultado do percurso de uma ligação é o componente inteiro; âncoras marcadas, quando um objeto está embutido no conteúdo do componente; e âncoras não-marcadas, quando sua localização deve ser calculada dentro de um componente.

Pesquisadores do DHM concluíram que os tipos de direção de ligação suportados pelo Modelo Dexter eram insuficientes para modelar a forma como as pessoas interpretam a direção de uma ligação. Assim, o DHM introduziu as noções de direção semântica, de percurso e de criação (Grønbæk and Trigg, 1994). Direção semântica corresponde ao relacionamento semântico entre os componentes ligados, por exemplo, quando uma ligação tem uma direção na qual é normalmente lida. Direção de criação corresponde à ordem na qual as extremidades das ligações foram criadas, isto é, a origem da ligação é a primeira extremidade criada. Por fim, direção de percurso especifica como a ligação pode ser percorrida. No DHM, ligações podem ser bidirecionais.

A Figura 2.9 apresenta a interface de uma das aplicações integradas ao DHM. À esquerda, o usuário está criando uma ligação (operação New Link) na extremidade de origem (Source); à direita, o usuário está percorrendo uma ligação (operação Follow Link) no sentido da origem para o destino (Forward).

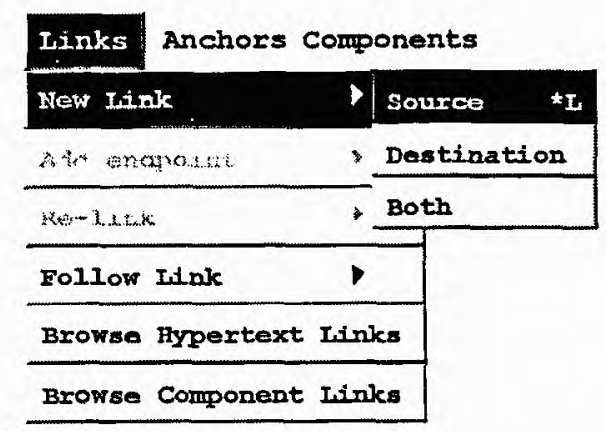

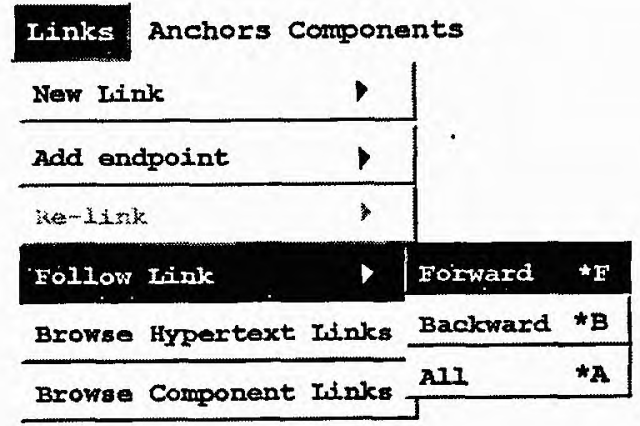

Figura 2.9: Criação e percurso de ligações no DHM (Grønbæk and Trigg, 1999) 
Em uma situação comum de ligação inválida no DHM, indesejável no Modelo Dexter, o OHS solicita ao usuário a remoção da ligação, ou a remoção do ponto final inválido, ou ainda a associação dessa ligação com outro destino. O DHM defende quatro diferentes situações que justificam a implementação de ligações inválidas:

1. um dos pontos finais da ligação está em um componente que foi removido;

2. uma âncora é removida;

3. objetos de dados relevantes ao conteúdo do componente estão indisponíveis; e

4. o valor da âncora é inválido, devido a edições fora do controle do OHS.

$\mathrm{Na}$ década de 90, surgiram implementações do DHM para várias plataformas operacionais, destacando-se as versões para Unix multiusuário, para Macintosh monousuário, em rede para Windows 95 e NT e integrada à infra-estrutura Web, chamada DHM/WWW (Grønbæk et al., 1997). Como evolução do DHM/WWW, pesquisadores de Aarhus criaram o OHS Webvise (Grønbæk et al., 1999), um dos tópicos estudados no Capítulo 4.

\subsection{Considerações Finais}

Este capítulo apresentou conceitos relativos à teoria de sistemas hipermídia abertos, com destaque para o Protocolo OHP e uma descrição de alguns dos principais OHSs Características necessárias a aplicações em OHSs nortearam o projeto e implementação do serviço de ligações WLS proposto neste trabalho, como a existência de um servidor de ligações que gerencie bases de estruturas hipermídia externas e forneça suporte a um modelo de ligação que estenda o tradicional modelo utilizado na Web.

O Modelo Dexter contribui com o desenvolvimento da infra-estrutura hipermídia do WLS à medida que delineia as responsabilidades de sistemas hipermídia e de suas aplicações integradas no tocante aos aspectos de armazenamento e apresentação.

O modelo de dados conceitual do WLS foi definido seguindo o modelo de dados navegacional do OHP apresentado na Figura 2.3. Para a definição da infra-estrutura hipermídia fornecida pelo WLS são utilizadas mensagens do protocolo OHP codificadas na linguagem XML, contribuições do DLS Microcosm e do DHM. 


\section{Capítulo 3}

\section{Papel de Padrões XML em OHSs}

\subsection{Considerações Iniciais}

Ao abstrair a entidade "documento", pode-se imaginá-la sob as seguintes dimensões: conteúdo, estrutura, apresentação, semântica, metadados ${ }^{1}$ e malha de hipertexto. ${ }^{2} \mathrm{Um}$ documento XML representa, basicamente, duas dimensões de informação: o conteúdo propriamente dito e a estrutura organizacional deste conteúdo. A Recomondação XML (Bray ct al., 1998) possibilitou a definição de especificações que represcntam as demais dimensões de informação de um documento.

Paralelamente ao trabalho do W3C (World Wide Web Consortium), desenvolveram-se várias pesquisas na comunidade de hipermídia aberta (OHSWG, 2001) que visavam estender a infra-estrutura da Web com serviços que armazenam as informações de ligação externamente ao conteúdo dos documentos. Para Carr and Hall (1998), OHSs como o DLS Microcosm e o DHM fizcram surgir questões relevantes para a comunidade de hipermídia aberta sobre serviços de ligação, como:

- Definição dos tipos de interface com o usuário para a apresentação de ligações;

- Variedade de comportamentos relacionados a ligações; e

- Semântica associada a conjuntos de ligações que interligam hiperdocumentos, etc.

\footnotetext{
${ }^{1}$ Por exemplo, bibliotecas usam como metadados: autor, título, assunto, editora e a localização física de cada livro.

${ }^{2}$ Reforências a sumário, índices de tabelas e figuras, notas de rodapé e bibliografia podem ser consideradas como malha de hipcrtexto sobre documentos, $\mathrm{cm}$ geral.
} 
Nesse contexto, o Grupo de Trabalho em Tecnologia XML do W3C c o OHSWG trabalham paralelamente com o objetivo de atingir a meta de projeto de OHSs: introduzir funcionalidades hipermídia em aplicações e componentes de ambientes computacionais, descnvolvendo-os gradualmente até atingirem o estado de um ambientc hipermídia unificado de alcance mundial c multiplataforma (van Ossenbruggen et al., 1998). Este capítulo apresenta as contribuições que a familia de padrõcs baseada na linguagem XML traz ao desenvolvimento de OHSs integrados à infra-cstrutura da Wcb, e à infra-estrutura do scrviço de ligações hipermidia WLS (Web Linking Service) proposto ncstc trabalho.

\subsection{XML - Linguagem de Marcação Extensível}

A linguagcm XML é apropriada para a representação de dados, documentos c demais entidades (relatório, protocolo, script, folha de estilo, ctc.), cuja essĉncia sc fundamenta na capacidade de agregar informações. Por conseguintc, aplicaçõcs podem associar semântica a dados e campos de documentos, e viabilizar o processamento automático de scus documentos manipulados. XML ć Recomendação W3C desde fevereiro de 1998.

Atualmentc, a linguagem XML é utilizada como formato padrão de intcrcâmbio de dados cstruturados na Web. Assim, evita-se que toda aplicação que envolve intercâmbio eletrônico de dados (EDI - Electronic Data Interchange) precise definir c implementar suas próprias cxtensões ao HTML. Ramos de ncgócios que utilizam XML como formato de intcrcâmbio de dados na Web incluem: comércio eletrônico, canais de notícias, scguradoras, bancos, etc. Aplicaçõcs de EDI precisam, cm gcral, de um mecanismo de validação das informaçõcs que estão sendo trocadas. Validação é um processo opcional no qual ć verificado se o conteúdo e a estrutura das informações XML segucm suas regras de formação definidas em sua gramática. Há dois tipos de gramáticas para XML, DTD (Document Type Definition) e Esquema XML (XMLSchcma, 2001). Embora cste tenha vantagcns sobre DTD quanto às regras de formação de entidades XML, gramáticas DTD são suportadas pelos principais browsers, enquanto que o Esqucma XML não.

Um documento XML, em sua forma básica, apresenta duas dimensõcs de informação: contcúdo c cstrutura. Apresentação, semântica, metadados e modelo de ligação hipertcxto são fornccidos por padrões derivados da linguagem XML, conforme aprescntado na Tabela 3.1. Isto sc deve à capacidade de XML fornecer rccursos para a definição de gramáticas que caractcrizam essas especificações para classes de documentos específicos com clcmentos, atributos e regras bem determinadas. 
Padrões baseados em XML são apresentados na Tabcla 3.1, que mostra o relacionamento entre HTML, SGML (ISO8879, 1986) e XML como padrões para documentos estruturados na Web. Segundo a Tabela 3.1, a maioria da informação contida cm um documento é codificada em XML. Dessa forma, o parser XML assume um papel de destaque em um OHS baseado $\mathrm{cm}$ XML, destituindo o browser do papel de aplicação mais importante em ambientes computacionais baseados na Web.

\begin{tabular}{|l|l|l|l|}
\hline & Tabela 3.1: Documentos estruturados na Wcb \\
\hline & Família HTML & Família XML & Família SGML \\
\hline \hline Marcação & HTML & XML & SGML \\
\hline Validação & DTD & DTD e Esquema XML & DTD \\
\hline Ligação & HTML & XLink & HyTimc \\
\hline Ancoragem & HTML & XPointer & TEI \\
\hline Semântica e metadados & HTML & RDF e Esquema RDF & DSSSL \\
\hline Estilo e apresentação & HTML e CSS & CSS e XSL & DSSSL \\
\hline
\end{tabular}

Várias pesquisas na comunidade de hipermídia aberta visam estender a infra-estrutura da Web com serviços que armazenam as informações de ligação externamente ao conteúdo de documentos. O sistema hipermídia aberto DHM utiliza a linguagem XML como formato de intercâmbio das estruturas de dados hipermídia por cle manipuladas. O OHS Webvise, versão para Web do DHM, também utiliza XML para a codificação de suas estruturas de dados (Grønbæk et al., 2000). O protocolo OHP XML do Webvise é visto cm detalhes no Capítulo 4.

\subsection{XSL - Linguagem de Folha de Estilo Extensível}

Documentos XML, em sua forma básica, não apresentam quaisquer informações relacionadas a sua apresentação. O domínio da forma de apresentação de documentos XML é de responsabilidade do XSL (Extensible Style Sheet Language). A linguagem XSL, Recomendação W3C desde outubro de 2001, consiste de três componentes: XPath (Clark and DeRose, 1999), XSLT (Clark, 1999) e XSL FO (XSL, 2001).

O principal propósito da linguagem XPath (XML Path Language) consiste em endereçar todos os elementos e respectivos atributos da árvore de documentos XML cm difcrentes níveis de granulosidade, a partir de uma sintaxe bascada em strings compacta c simples. A linguagem XPath é Recomendação W3C desde novembro de 1999.

XSLT (XSL Transformations) é uma linguagem para transformar documcntos XML 
em outros documentos XML de estrutura mais simples, ou em outro tipo de documento reconhecível por um browser, através de associações de regras de estilo a elementos da estrutura hierárquica de documentos XML. Por exemplo, XSLT permite transformar elementos XML em HTML. A linguagem XSLT é Recomendação W3C desde novembro de 1999.

Após a transformação de documentos XML por uma folha de estilo XSLT, pode-se associar um conjunto de objetos e propriedades de formatação que compõem a especificação XSL FO (XSL Formatting Objects). Assim, pode-se gerar, a partir de um único documento XML, vários formatos de documentos, como PostScript, Acrobat PDF, etc.

Sob uma perspectiva orientada a documentos, a combinação XML/XSL tem como vantagens a manipulação e transformação das estruturas de dados hipermídia de OHSs para outros formatos, o que possibilita uma maior variedade de tipos de documentos suportados por OHSs. Dessa forma, aspectos de apresentação podem ser fornecidos não somente por aplicações hipermídia habilitadas, mas também pelo serviço de ligações, se necessário.

Nesse mesmo contexto, a apresentação de documentos manipulados por aplicações integradas a OHSs colaborativos pode ser personalizada, segundo o usuário ou grupo de usuários que requisita esses documentos, por exemplo.

Uma vez que o browser assume um papel menos importante em OHSs, as transformações de documentos XML devem ocorrer, preferencialmente, no servidor. Isto permite a geração de um maior número de formatos de documentos participantes em OHSs.

\subsection{XLink - Linguagem de Ligação XML}

Com o objetivo de atender às necessidades de sistemas hipermídia mais robustos, dentre estes, os sistemas hipermídia abertos, a especificação XLink (Extensible Linking Language) (DeRose et al., 2001b) representa um dos componentes responsáveis pelo domínio da malha de hipertexto para documentos XML. XLink é Recomendação W3C desde junho de 2001. XLink é uma tecnologia que fornece a documentos XML construtores de hipertexto mais poderosos que aqueles fornecidos pelo simples modelo de ligação do HTML. Resumidamente, XLink fornece suporte a ligações externas, n-árias e multidirecionais. 
Ao armazenar a malha de hipertexto externamente ao conteúdo de documentos XML, XLink permite fazer filtragem, ordenação, análises e processamento de bases de ligações. Ainda, ligações podem ter títulos descritivos e papéis semânticos associados a cada um dos pontos finais interligados. Comportamentos associados ao percurso de ligações também são fornecidos por XLink, tratando-os como objetos de primeira classe. Maiores detalhes sobre XLink podem ser encontrados em DeRose et al. (2001b).

Como exemplo de aplicação da especificação XLink, foi desenvolvida pelo W3C a ferramenta de autoria e navegação Amaya (Amaya, 2001). Esta ferramenta é integrada ao serviço de anotações colaborativo Annotea (Kahan et al., 2001) que, por sua vez, permite criar anotações sobre objetos contidos nos documentos manipulados pelo Amaya sem modificar o conteúdo destes documentos. As anotações são apresentadas como ícones sobrepostos aos documentos Web com atributos XLink anexados a estes. Atualmente, Amaya suporta apenas ligações XLink simples, semelhantes às fornecidas pelo HTML.

A característica do XLink que o candidata a ser utilizado em OHSs consiste em seu suporte à separação explícita entre o conteúdo de documentos XML e devido a informações relacionadas ao grafo de hipertexto associado a estes documentos. Isto permite que aplicações usufruam de poderosos construtores de hipertexto oferecidos por essa especificação.

Segundo van Ossenbruggen et al. (1998), XLink é uma tecnologia que fornece suporte para a definição de um formato padrão para um serviço de ligações de OHS baseado em XML. Carr and Hall (1998) descrevem cenários de ambientes hipermídia onde os documentos são baseados em componentes XML. Em um desses cenários, documentos XML estão ligados a outros nós através de ligações externas fornecidas por um serviço de ligações baseado em XLink.

Halsey and Anderson (2000) demonstraram, através do applet LinkMap, que o XLink pode ser utilizado para capturar estruturas de ligações manipuladas por OHSs, no caso específico, o OHS Chimera. O LinkMap tem a capacidade de exibir imagens com ligações definidas pela especificação XLink.

Por fim, o projeto da especificação XLink teve importantes contribuições de padrões e sistemas hipermídia consagrados, dentre estes, a linguagem HTML, os padrões HyTime (DeRose and Durand, 1994) e TEI (Sperberg McQueen and Burnard, 1994), o Modelo Dexter (principal modelo de referência para OHSs), o OHS Microcosm e um dos sistemas precursores de OHSs, o Intermedia. 


\subsection{XPointer - Linguagem de Ponteiros XML}

O simples modelo de ligação $\mathbf{e}$ ancoragem hipertexto da Web permite somcntc a existência de ligações ponto-a-ponto e ponto-a-nó. Niveis de granulosidade mais refinados, como ligar a $1^{\mathrm{a}}$ sentença do $7^{\circ}$ parágrafo em um documento, requer que o usuário insira manualmente âncoras no arquivo de destino da ligação. Isto pode ser feito apenas se houver pcrmissão de escrita para o documento que se deseja referenciar. Para atender aos anseios de sistemas hipermídia avançados, dentre estes, os sistemas hipcrmídia abertos, - W3C desenvolveu a espccificação XPointer (Extensible Pointer Language), rcsponsávcl pelo: modelo de ancoragem de documentos XML (DeRose et al., 2001a). XPointer se encontra no estágio de "Last Call Working Draft" pelo W3C desde janeiro de 2001.

Embora seja responsável pelo domínio de ancoragem de documentos XML, XPointer não restringe a sintaxc ou semântica de referências por URIs (Universal Resource Identifier) a recursos de outros tipos de mídia. Ao suportar o endereçamento da cstrutura hierárquica de documentos XML, XPointer permite analisá-la c escolher suas partes internas baseado em várias propriedades, como:

- localizações internas específicas de documentos, mesmo quando seu autor não fornece quaisquer atributos identificadores a estas localizações;

- nível de endereçamento de fina granulosidade sobre elementos que compõem a cstrutura de documentos, utilizando-se de posicionamento relativo, selcção de cadcias de caracteres c contexto de seleção; e

- referência a elcmentos com atributo identificador $I D$.

A sintaxe da linguagem XPointer utiliza a sintaxe da linguagem XPath, adicionando-lhe algumas novas funcionalidades, tais como a introdução de funções de localização de strings. Dessa forma, o XPointer consegue endereçar toda a árvore de documentos XML. Maiores detalhes estão disponíveis em (DeRose et al., 2001a).

A forramenta Amaya utiliza a sintaxe do XPointer para o cndereçamento de anotações criadas sobre documentos Web. As informações dessas anotações são armazenadas em arquivos externos, não havendo a necessidade de cditar o conteúdo dos documentos. A seguir, tôm-se dois cxemplos de anotações feitas sobre o documento AmayaPage.html. O primciro excmplo retrata uma anotação que referencia todo o documento HTML; o segundo exemplo representa uma anotação realizada sobrc uma seleção de 3 caracteres 
cujo conteúdo é "W3C", localizada no primeiro parágrafo a uma distância de 11 caracteres do início do parágrafo em questão.

1. AmayaPage.html\#xpointer(/HTML[1])

2. AmayaPage.html\#xpointer(string-range(/HTML[1]/BODY[1]/DIV[1]/P[1], "W3C", 11,3))

A principal característica do XPointer que o candidata a ser utilizado em OHSs consiste em sua capacidade de endereçar toda a estrutura hierárquica de documentos XML, fornecendo variados níveis de granulosidade ao serviço de ligação utilizado.

van Ossenbruggen et al. (1999) destacam que, em virtude dos incompatíveis modelos de endereçamento existentes na Web, como âncoras HMTL, seletores CSS (CSS2, 1998) e XSL e notação XPointer, é imprescindível que o W3C desenvolva um modelo de endereçamento comum. Para van Ossenbruggen et al. (1998), XPointer é um forte candidato para a linguagem de ancoragem de documentos manipulados por aplicações em OHSs.

Assim como no projeto de XLink, os componentes de endereçamento de XPointer também tiveram contribuições substanciais de vários padrões e sistemas hipermídia estabelecidos, como a linguagem HTML, os padrões HyTime e TEI, o sistema Intermedia, o Modelo Dexter e o OHS Microcosm.

\subsection{RDF - Framework para Descrição de Recursos}

Ao não ser extensível, a linguagem HTML impede que desenvolvedores Web criem seus próprios elementos para refletir relações de semântica do conteúdo. Tarefas, como a utilização de um serviço de busca na Web, resultam em uma enorme quantidade de documentos cujos assuntos discutidos não estão intimamente relacionados ao tópico solicitado, necessitando de uma extenuante filtragem manual por parte do usuário. Isto se deve ao fato da linguagem HTML embutir informações com metadados. Se considerados em sua forma básica, documentos XML contêm pouca semântica e metadados sobre suas unidades de informação.

Com o objetivo de tornar a informação distribuída na Web compreensível não somente por humanos, mas também por máquinas e, conseqüentemente, facilitar a automatização de tarefas na Web, o W3C trabalhou no desenvolvimento de um mecanismo que permite a 
descrição de metadados relacionados a qualquer recurso Web: o RDF (Resource Description Framework), Recomendação W3C desde fevereiro de 1999 (Lassila and Swick, 1999). $\mathrm{O}$ estudo do RDF envolve três grandes componentes: modelo de dados, esquema c sintaxe para intercâmbio de metadados.

O modelo de dados do RDF consiste em três tipos de objetos: recursos, propriedades e declarações. Recursos são quaisquer objetos que possam ser referenciados por uma URI, por exemplo, páginas HTML. Propriedades são características utilizadas para descrever um recurso, por exemplo, a data de revisão de páginas HTML. Declarações são triplas formadas por recursos, propriedades e valores das propriedades, por exemplo, "a data de revisão de $h t t p: / / w w w . w 3 . o r g / X M L / S c h e m a \#$ dev possui valor 2001/06/14".

RDF é uma forma padronizada de representar grafos dirigidos rotulados, chamados de "diagramas de nós e arcos". Um recurso é normalmente representado por um nó oval; o valor da propriedade, por um nó retangular; e a propricdade, por um arco que conecta o recurso ao valor da propriedade. A Figura 3.1 apresenta a representação da declaração RDF descrita nesta seção.

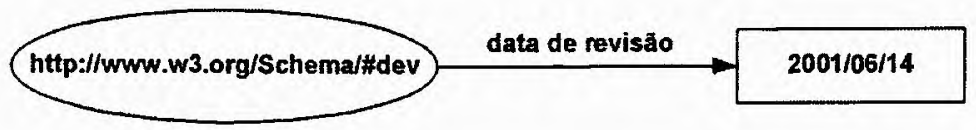

Figura 3.1: Declaração RDF segundo a representação de grafo

O modelo de dados do RDF não fornece qualquer mecanismo para declarar propriedades, nem para definir os relacionamentos existentes entre cstas propricdades c outros recursos. Comunidades de descrição de recursos, como o Dublin Core (DC, 1999), precisam de elementos que permitam descrevê-los: cste ć o papel da especificação Esquema RDF, Recomendação Candidata do W3C desde março de 2000 (Brickley and Guha, 2000). Esquema RDF oferece mecanismos para:

1. descrever a semântica de propriedades de recursos

2. definir as classes de recursos às quais essas propriedades pertencem;

3. restringir possíveis combinações de classes e rclacionamentos; e

4. detectar violações dessas restrições.

Atualmente, RDF e Esquema RDF são as principais especificações W3C que fazem parte de uma frente de pesquisa chamada Web Semântica (Berners-Lee ct al., 2001). 
A Web Semântica é uma extensão da Web atual na qual aplicações Web trocam c processam informações com semântica associada. Para isto, RDF utiliza XML como sintaxe para intercâmbio das descrições dos recursos Web, embora tais recursos possam scr XML ou não. A declaração "a data de revisão de http://www.w3.org/XML/Schema\#dev possui valor 2001/06/14" é representada segundo a sintaxe do RDF como segue:

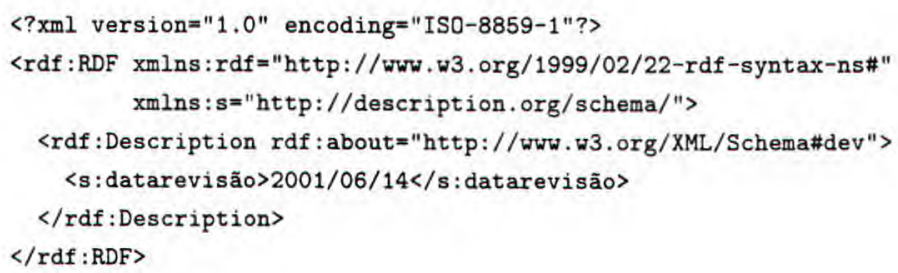

A descrição semântica do recurso, da propriedade e do relacionamento existente entre estes ć fornecida por uma especificação em Esquema RDF cujos detalhes não serão explicitados neste capítulo. O Capítulo 5, referente ao projeto e implementação do serviço WLS, descreve com detalhes a sintaxe, funcionalidade c utilização de Esquema RDF. Quando largamente utilizadas, as especificações W3C RDF e Esquema RDF garantirão interopcrabilidade entre aplicações diversas que trocam metadados, como aquelas que:

- fazem classificação de conteúdo, oferecendo melhores capacidades às máquinas de busca;

- realizam mapas de sites, para descrever o conteúdo e os relacionamentos de conteúdo disponíveis em um site Web particular, página ou biblioteca digital;

- trocam c compartilham conhecimento em redes semânticas, como agentes de software inteligentes;

- expressam as preferências de privacidade de um usuário, assim como as políticas de privacidade de um site Wcb, ctc.

Para Grønbrek et al. (2000), RDF c OHSs podem trabalhar em conjunto, uma vez que ambos são formas de descrever relacionamentos entre entidades de tipos quaisquer, são armazenados externamente aos documentos que se referem, além de fornccerem ao usuário um valor ou mecanismo de estruturação adicionais. Embora utilize um esquema de endereçamento limitado baseado cm URIs, RDF pode ser combinado com esquemas de endereçamento de níveis de granulosidade mais refinados, como XPointer, mais adaptado às necessidades de OHSs. 


\subsection{Considerações Finais}

Este capítulo apresentou o relacionamento existente entre a família de padrões XML e sistemas hipermídia abertos, especialmente no tocante aos aspectos de intercâmbio, apresentação, semântica, metadados, ligação e ancoragem hipertexto.

A família de padrões XML traz importantes contribuições ao projeto e implementação do serviço de ligações WLS proposto neste trabalho. Por ser uma meta-linguagem, XML é utilizada como formato de intercâmbio das mensagens do protocolo OHP que contêm as estruturas manipuladas pelo WLS. Cada uma destas mensagens são validadas segundo sua própria gramática. Embora XSL tenha um importante papel na apresentação de documentos XML em OHSs, o servidor de ligações WLS não a utiliza, dando às aplicações que utilizam o serviço a liberdade de apresentar seus respectivos documentos conforme desejado.

XLink contribui com o presente trabalho através de sua idéia de separação entre o conteúdo do documento e sua malha de hipertexto, premissa básica de OHSs, e a utilização de atributos que incorporam semântica às ligações e recursos ligados. XPointer é utilizado como modelo de endereçamento da estrutura interna dos documentos manipulados por aplicações integradas ao serviço de ligação WLS.

Por fim, a especificação RDF contribui com o projeto e implementação do serviço WLS através da definição dos relacionamentos entre as estruturas de dados manipuladas pelo WLS e os documentos gerenciados por aplicações, e do fornecimento de metadados referentes a essas estruturas e seus relacionamentos. 


\section{Capítulo 4}

\section{Implementações de Serviços de Ligação}

\subsection{Considerações Iniciais}

No início da década de 90, percebe-se uma mudança de projeto de sistemas monousuários e monolíticos para sistemas multiusuários, distribuídos e abertos. Esta transição foi fundamentalmente influenciada pela premissa básica do Modelo Dexter: a separação explícita entre a rede de hipertexto e o conteúdo dos documentos gerenciados por aplicações. Várias implementações de sistemas hipermídia abertos surgiram ao longo da história, sendo que muitas destas implementações foram integradas à infra-estrutura da Web, como os OHSs DLS Microcosm e DHM/WWW.

Paralelamente, a comunidade de pesquisa W3C desenvolveu duas especificações responsáveis por fornecer o domínio de ligação e ancoragem sobre documentos XML, denominadas XLink e XPointer, respectivamente. Estas especificações se utilizam de várias características desejáveis a OHSs, tornando-se candidatas à infra-estrutura de ligação e ancoragem de OHSs baseados em tecnologia XML. Este capítulo apresenta duas implementações de serviços de ligação, o Webvise e o XLip, descreve suas características de projeto e implementação e, por fim, discute as diferenças e contribuições desses serviços para com o serviço de ligações WLS. 


\subsection{Webvise}

O Webvise é um sistema hipermídia aberto que tem por objetivo expandir a infra-estrutura hipermídia da Web com serviços de OHSs (Grønbæk et al., 1999). O Webvise suporta a criação e manipulação de estruturas hipermídia armazenadas em bases de dados externas fundamentadas no Framework DHM (Grønbæk and Trigg, 1994). As estruturas hipermídia suportadas são contextos, nós, ligações, âncoras, anotações e roteiros guiados. ${ }^{1}$

Webvise é integrado a um conjunto de aplicações comumente utilizadas em um ambiente desktop sob plataforma Windows: o Microsoft Internet Explorer, o Microsoft Word e o Microsoft Excel. ${ }^{2}$ Dessa forma, é possível a criação de ligações entre documentos nos formatos suportados por essas aplicações, sem alterar o conteúdo de seus documentos. Ao longo desta seção, são descritas a arquitetura do OHS Webvise, a criação e manipulação de estruturas hipermídia suportadas por este, suas limitações e, por fim, suas principais características.

\subsubsection{Arquitetura do Webvise}

O OHS Webvise consiste de dois componentes principais: o Webvise-servidor (Webvise Server) e o Webvise-cliente (Webvise Client). O núcleo da arquitetura do OHS Webvise é a aplicação Webvise-cliente que permite que os usuários usufruam de funcionalidades hipermídia a partir da interface de suas aplicações integradas. O Webvise-cliente roda na estação do usuário atuando como uma camada de software intermediária entre suas aplicações integradas e um ou mais servidores de estruturas que acessam diretamente as bases de estruturas hipermídia, conforme mostra a Figura 4.1.

A criação e apresentação de âncoras em documentos manipulados pelas aplicações integradas ao Webvise é dependente da capacidade de programação destas aplicações. A técnica utilizada para integrar o Webvise-cliente às aplicações MSIE, Word e Excel foi a Automação OLE (Object Linking and Embedding) da plataforma Windows. O Webvise-cliente expõe os serviços hipermídia abertos através de uma interface COM (Component Object Model), chamada de IWebviseApplObj. Maiores detalhes sobre esta interface podem ser encontrados em (Grønbæk et al., 1999). A interface IWebviseApplObj pode ser utilizada por quaisquer aplicações que suportem Automação OLE.

\footnotetext{
${ }^{1}$ Roteiros guiados são nós de composição que contêm outros nós e um grafo que os conecta.

${ }^{2}$ Por motivos de simplificação, tais aplicaçōes serão chamadas de MSIE, Word e Excel.
} 


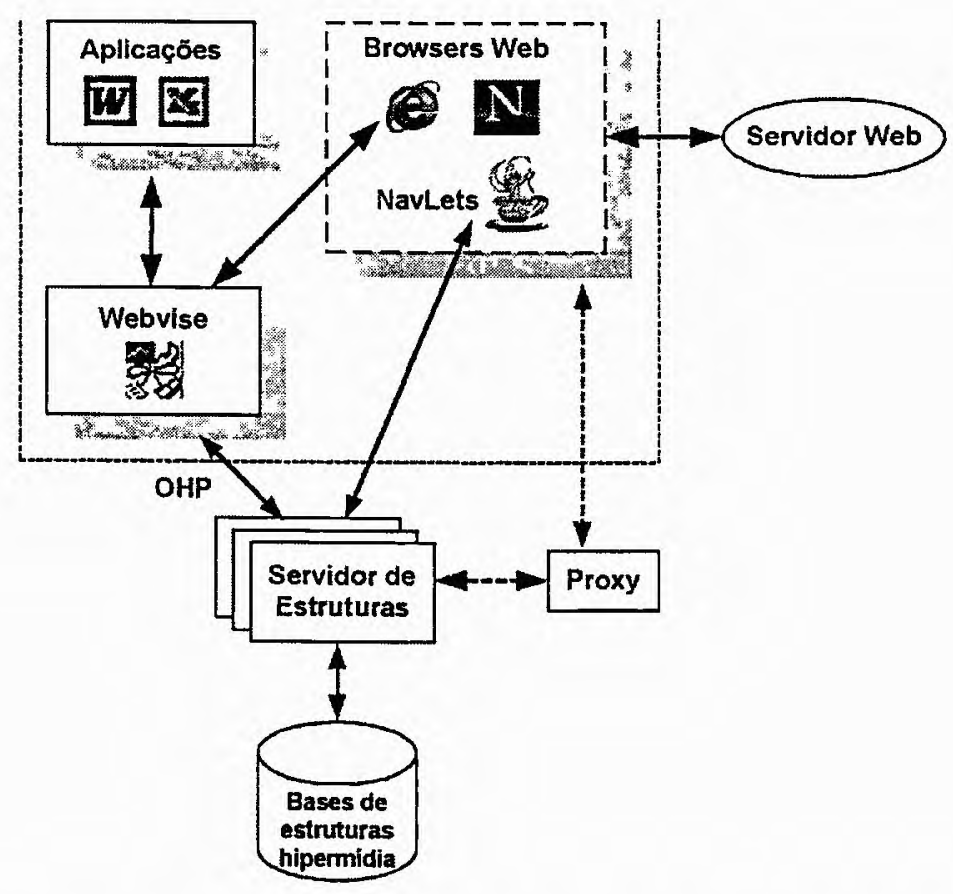

Figura 4.1: Arquitetura do OHS Webvise, adaptado de (Grønbæk et al., 1999)

Applets Java, chamados Navlets, foram implementados para acesso direto aos servidores de estruturas sem a comunicação com o Webvise-cliente. Por serem miniaplicativos Java, estes podem ser embutidos em documentos Web manipulados tanto pelo MSIE quanto pelo browser Netscape Navigator.

A comunicação entre o Webvise-cliente e o(s) servidor(es) de estrutura(s) é fornecida por uma API cliente que implementa as operações necessárias para enviar solicitações a um ou mais servidores de estruturas, e para receber notificações dos servidores de estruturas. A troca de mensagens necessária a essa comunicação é compatível com o protocolo OHP, implementado como protocolo textual sobre TCP/IP, no qual as mensagens são codificadas utilizando XML. O Webvise-servidor necessita de conexão com a Internet para validar as mensagens XML trocadas entre o Webvise-cliente e os servidores de estruturas. O processo de validação desse conjunto de mensagens é realizado mediante uma gramática em DTD.

Para cada aplicação integrada ao Webvise, a aplicação Webvise-cliente implementa uma aplicação wrapper que trata da comunicação com sua aplicação correspondente. Isto inclui: rodar a aplicação e solicitar a esta a abertura e exibição de um documento. $O$ MSIE é a aplicação que melhor se integra ao Webvise-cliente devido às interfaces do 
Modelo de Objeto de Documentos (DOM - Document Object Model) (DOM, 1998). A principal funcionalidade oferecida pelo DOM é tratar cada elemento HTML como um objeto programável, associando-lhe estados e operações, alćm de um conjunto de eventos associados. Isto permite que o Webvise-cliente solicite informaçõcs de âncoras de documentos HTML diretamente via DOM. Portanto, quando um documento Web é carregado, um evento é gerado e, se uma ligação deve ser inserida no documento, ela é inserida pelo Webvise-cliente percorrendo a árvore DOM, encontrando a localização apropriada e inserindo a ligação dinamicamente.

As bases de estruturas hipcrmídia do OHS Webvise foram implementadas a partir de seu modelo de dados conceitual, definido com base na especificação dos relacionamentos entre os objetos do modelo navegacional do protocolo OHP. Para que as estruturas criadas pelo Webvise-cliente possam ser acessadas por quaisquer browsers Web, essa comunicação pode se dar através de um servidor proxy. O usuário deve configurar seu browser Web para sempre acessar o servidor proxy que fornece as seguintes funcionalidades:

- inserção de elementos $<A>$ da linguagem HTML para representar os pontos finais de uma ligação criados com o Webvise-cliente;

- inserção de código JavaScript para permitir a exibição de anotações criadas com o Webvise-cliente em uma jancla pop-up sobre o texto anotado;

- busca de ponto final de ligação global bascada em uma seleção de texto; c

- reestruturação da hierarquia de frames na qual o documento referenciado se encontrava quando estruturas foram criadas.

O servidor proxy verifica em cada documento navegado pelo browser Web a existência de estruturas externas a screm sobrepostas. Se tais estruturas são encontradas, estas são compiladas no documento, conforme suas funcionalidades anteriormente citadas. $\mathrm{O}$ servidor proxy não suporta ligações entre documentos locais do Word e do Excel, apenas entre documentos Web manipulados diretamente por browsers Web. Para isso, cstes documentos teriam de ser copiados de um servidor Web e manipulados através do Webvise-cliente. 


\subsubsection{Webvise-cliente e Aplicações Integradas}

A interface da aplicação Webvise-cliente pode ser visualizada na Figura 4.2. É importante observar que a versão do Webvise utilizada neste trabalho é a 3.0 para Windows $98 / \mathrm{NT} / 2000 .^{3}$ Dessa forma, pode haver algumas diferenças entre as interfaces das aplicações envolvidas apresentadas nas figuras desta subseção e as provenientes de versões anteriores do Webvise.

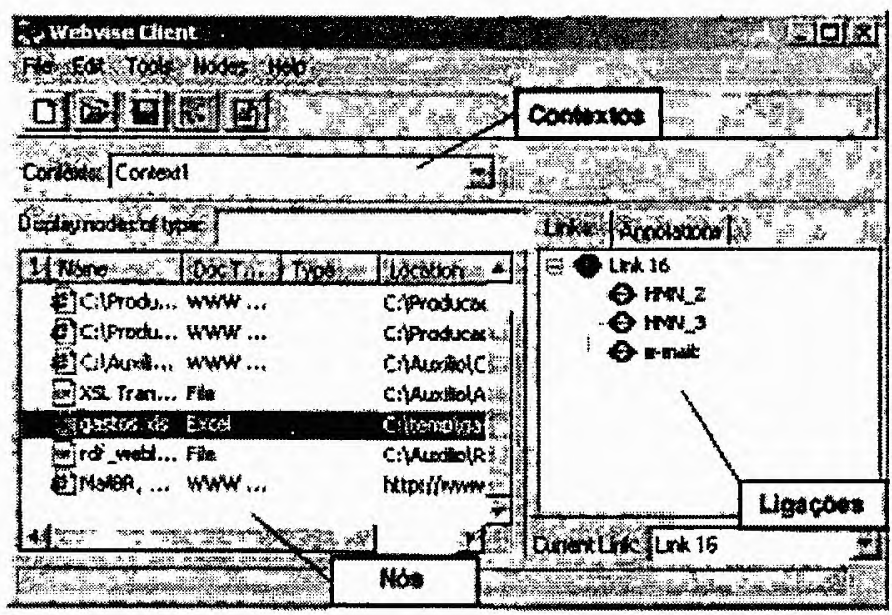

Figura 4.2: Interface da aplicação Webvise-cliente

A partir da interface do Webvise, contextos podem ser criados e editados. Contextos abertos estão disponíveis na caixa de listagem Contexts. Os nós hipermídia contidos no contexto corrente são listados no quadro Node. Nós são inseridos nesse quadro através do acionamento da opção Create Node na interface das aplicações integradas, ou através do menu Nodes. Um duplo clique sobre o nome do nó ativa sua aplicação associada e seu conteúdo é exibido. Para mostrar as ligações que referenciam um dado nó, o usuário deve acionar a opção Links - Show Links do menu exibido ao se clicar com o botão direito sobre o nó hipermídia. As ligações são exibidas no quadro Link. Roteiros guiados são também criados a partir do menu Nodes no Webvise-cliente.

Nós, ligações e âncoras são criados a partir das interfaces das aplicações MSIE, Word e Excel, em virtude do conjunto de extensões escrito para cada aplicação integrada ao Webvise. Essas aplicações suportam tipos de estruturas hipermídia específicos. O MSIE, por exemplo, foi estendido com um menu para criar ligações ancoradas, globais e anotações, conforme indicado na Figura 4.3. O processo de criação de ligações ancoradas

\footnotetext{
${ }^{3}$ Disponível para download em http://www.daimi.aau.dk/les/webvisestuff.htm.
} 
no MSIE é bastante simples. A partir da interface do MSIE, o usuário deve:

1. selecionar o texto que servirá de ponto final de origem para a ligação;

2. clicar com o botão direito sobre a seleção e acionar a opção New Link. A seleção é dinamicamente marcada como uma âncora HTML tradicional;

3. selecionar outros textos que servirão de pontos finais de destino no mesmo ou em outro documento;

4. clicar com o botão direito sobre a seleção e acionar a opção Add Anchor;

Após esses passos, o usuário pode percorrer a ligação de forma semelhante às ligações HTML tradicionais, ou através da opção Follow Link ao clicar com o botão direito sobre a seleção do ponto final de origem.

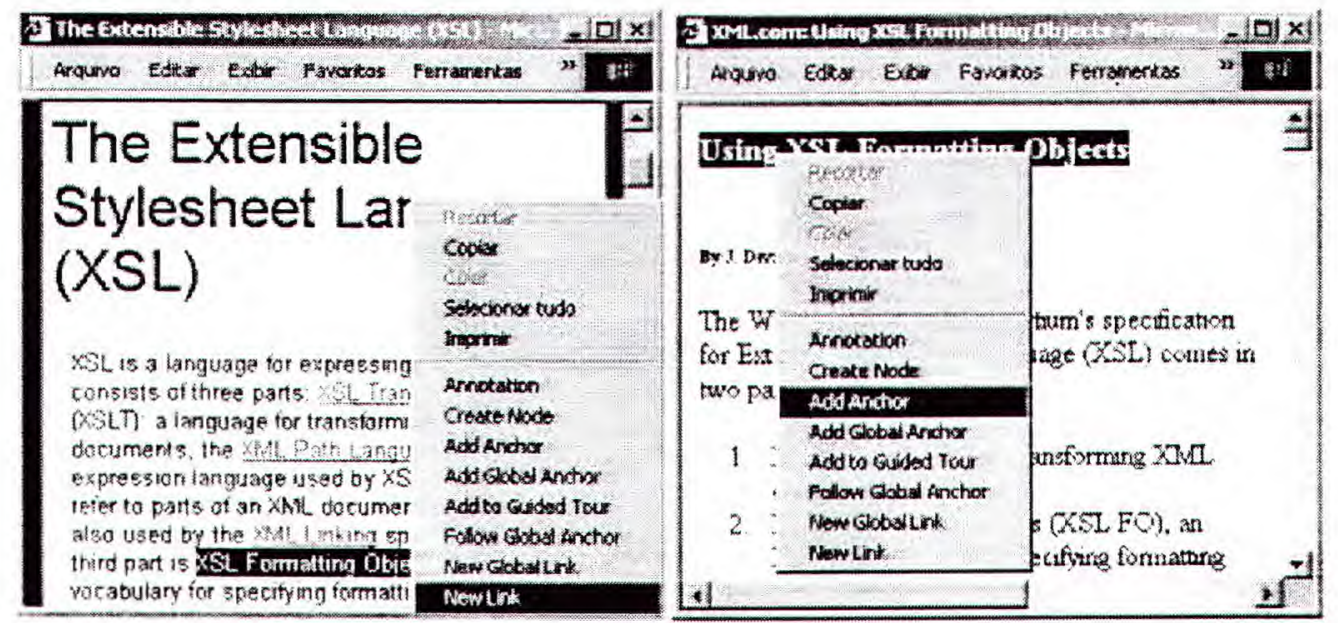

Figura 4.3: Criação de ligação ancorada no MSIE

Funcionalidades hipermídia no Excel e no Word são disponibilizadas ao usuário através da inclusão de menus e barras de ferramentas às suas interfaces. Enquanto que no Excel apenas ligações ancoradas são suportadas, no Word podem ser criadas ligações ancoradas e globais, herança do OHS Microcosm. O processo de criação de ligações globais no Word é bastante simples. Como indicado na Figura 4.4, ao utilizar a interface do Word, o usuário deve:

1. selecionar o texto que servirá de ponto final de destino para a ligação; 
2. clicar com o botão direito sobre a seleção e acionar a opção New Link - Global do menu. Isto cria automaticamente o ponto final de destino e a ligação global;

3. selecionar cada um dos textos que servirão de pontos finais de origem no mesmo ou em outro documento;

4. clicar com o botão direito sobre cada seleção e acionar a opção Add Anchor - Global;

Para percorrer uma ligação global, o usuário deve selecionar um dos pontos finais de origem e acionar a opção Follow Link - Global do menu Hypermedia. Cada um dos pontos finais de origem selecionados apontam para a seleção do ponto final de destino.

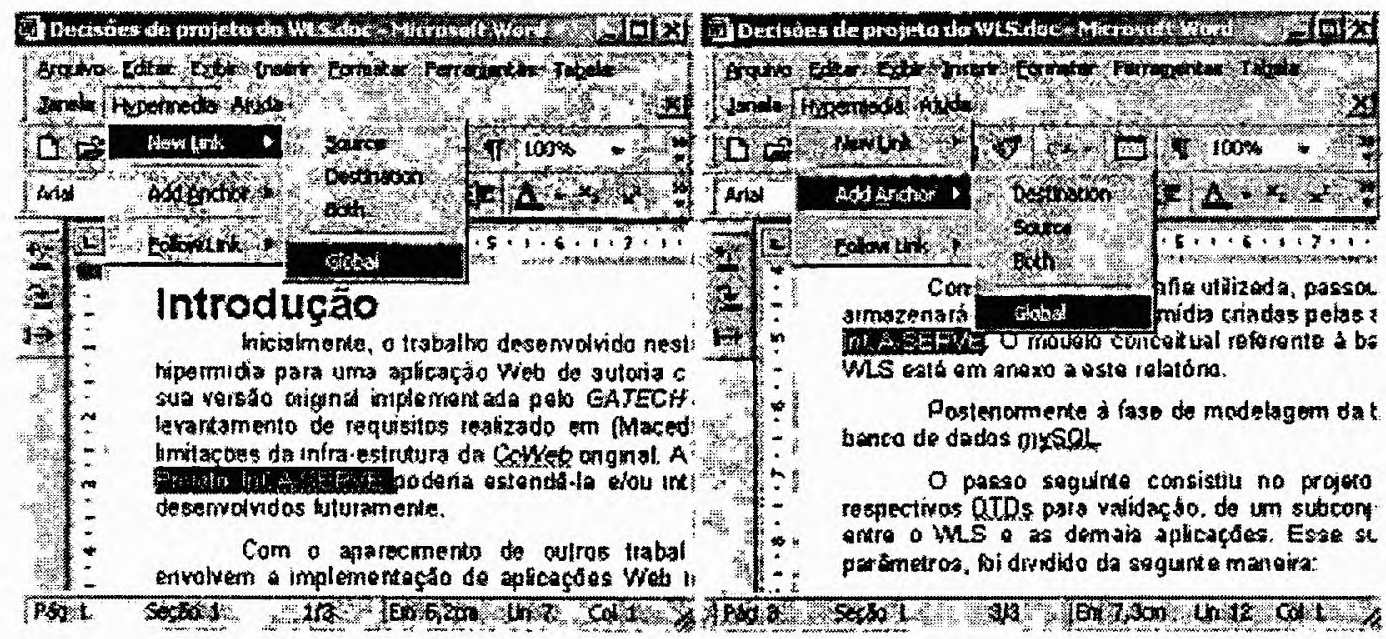

Figura 4.4: Criação de ligação global no Microsoft Word

\subsubsection{Protocolo OHP XML}

A partir do modelo de dados do protocolo OHP, foi derivada uma gramática DTD para a validação das mensagens XML trocadas entre o Webvise-cliente e o(s) servidor(es) de estrutura(s). Dessa forma, quaisquer parsers em conformidade com o padrão XML conseguem exportar e importar as estruturas hipermídia gerenciadas pelo Webvise.

O formato de dados derivado do protocolo OHP é chamado de OHIF (Open Hypermedia Interchange Format) (Grønbæk et al., 2000). Cada arquivo OHIF representa um objeto Contexto do modelo de dados do OHP. Um contexto é uma coleção indexada de objetos hipermídia (nós, âncoras, ligações e pontos finais). Assim, o Webvise permite que o objeto Contexto seja ancestral direto de todos os demais objetos. 
$\mathrm{O}$ ponto mais importante do protocolo XML do Webvise consiste na representação de suas ligações. Ligações hipermídia no OHIF são, normalmente, relacionamentos N:M, portanto, uma coleção de pontos finais. A seguir, é mostrada a representação de um trecho de um arquivo OHIF ilustrando uma ligação entre dois pontos finais representados por seus respectivos identificadores. Cada ponto final tem atribuído a si os identificadores da ligação e da âncora às quais pertencem e a direção associada à ligação (fonte, destino ou bidirecional). A remoção explícita de pontos finais de ligações, quer sejam nós ou âncoras, não provoca a remoção automática dessas ligações.

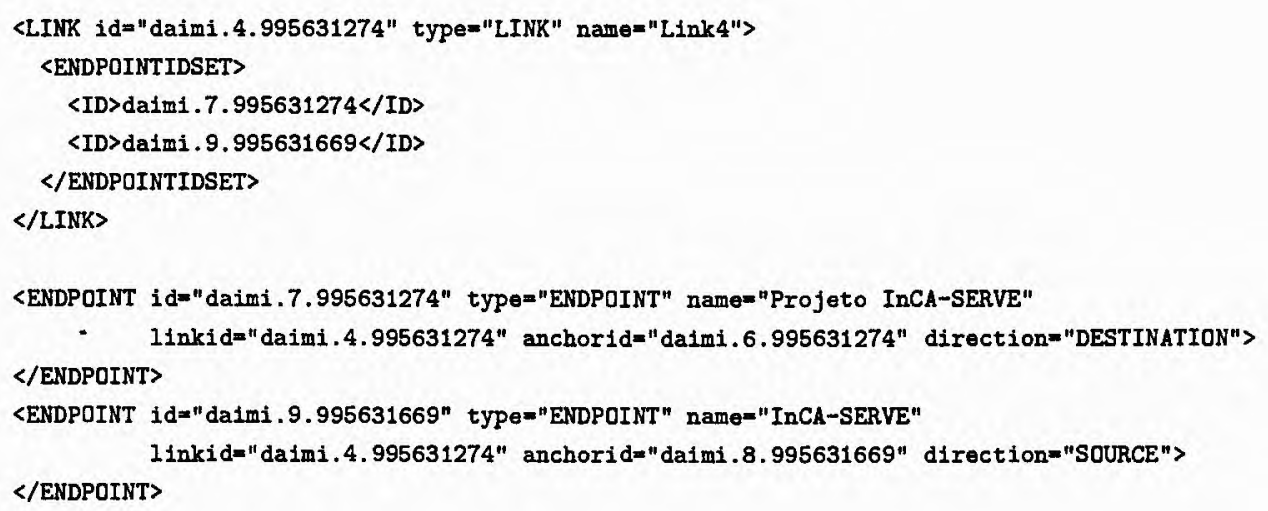

Âncoras representam localizaçõcs internas no conteúdo de nós hipermídia. Uma âncora pode ser, ao mesmo tempo, ponto final de origem e destino de diferentes ligações. Como técnica de armazenamento de informações de âncoras, o Webvise utiliza os atributos Seleção, que corresponde à seleção textual realizada pelo usuário para criação de âncoras; e Contexto da Seleção, atributo que armazena a porção de texto que envolve o conteúdo de Seleção. Com base nessas informações, o Webvise consegue gerenciar a integridade entre o conteúdo do documento e as estruturas hipermídia externas relacionadas, cvitando o problema de âncoras inconsistentes e ligações inválidas. Na verdade, apenas a informação Seleção ć suficiente para determinar uma localização no conteúdo de um documento. No entanto, para detectar a âncora com maior precisão, utiliza-se a informação redundante Contexto da Seleção, uma vez que Seleção pode ocorrer mais de uma vez no documento (Da̛⿱is, 1998). Apresenta-se, a seguir, uma representação de âncora no formato OHIF.

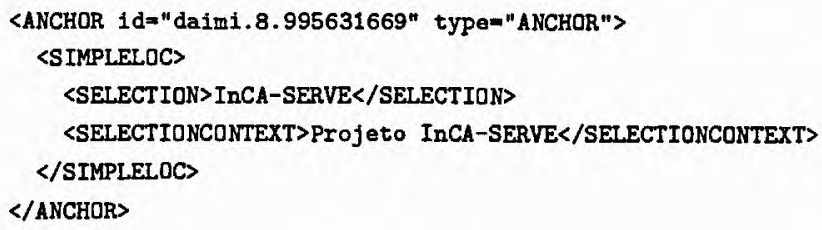


Por fim, o Webvise suporta o compartilhamento de estruturas hipermídia ao utilizar o protocolo WebDAV (World Wide Web Distributed Authoring and Versioning) (Goland et al., 1999). O WebDAV consiste em um conjunto de extensões ao protocolo HTTP que possibilita a colaboração assíncrona sobre documentos Web. Dessa forma, arquivos OHIF (contextos) são enviados a um servidor Web que contém o módulo do WebDAV embutido. O Webvise e suas aplicações integradas ${ }^{4}$ funcionam como aplicações-clicnte para o servidor WebDAV ao enviar solicitações de bloqueio, desbloqueio, recuperação de propriedades e alteração do conteúdo dos contextos compartilhados.

\subsubsection{Características do Webvise}

Bascado nas funcionalidades oferecidas pelo OHS Webvisc a suas aplicações intcgradas, as scguintes caractcrísticas podem ser identificadas:

- atua como servidor de ligações e anotações hipermídia;

- estende o modelo OHP ao fornecer nós de composição do tipo rotciro guiado;

- permite que estruturas hipermídia atuem como camadas transparcntcs, sobrcpostas a documentos no momento de sua apresentação;

- pcrmite a variabilidade de formatos de documentos $\mathrm{cm}$ seu ambientc computacional;

- permite que usuários criem ligações sem escrever comandos HTML cm documontos cuja autoria não lhes pertence; c

- pcrmite que usuários compartilhem suas estruturas hipermídia.

Apcsar de suas muitas funcionalidades, o OHS Webvise apresenta a limitação de ser restrito à plataforma Windows. Outra limitação consiste na aprescntação de uma âncora, por exemplo, após o percurso de uma ligação, por basear-se na $1^{2}$ ocorrência do par de atributos Seleção e Contexto de Seleção. Erroncamente, ć possívcl obtcr a localização de uma âncora cujo texto é idêntico ao armazenado em Seleção, c o texto quc o envolvc também igual a Contexto de Seleção. Isto ocorre quando usuários editam documentos fora do gerenciamento do Webvise e insercm o texto igual ao anteriormente sclccionado antes deste, por exemplo.

\footnotetext{
${ }^{4}$ As aplicações Word c Excel, a partir da versão 2000, suportam o protocolo WcbDAV.
} 


\subsection{XLip}

O processador XLip é uma implementação, desenvolvida pela Fujitsu Ltd., das especificações W3C XLink e XPointer (XLip, 2000). Atualmente, o XLip pode ser adquirido em conjunto com a aplicação XLink Tree, um browser Java que serve de interface do processador XLip com o usuário. ${ }^{5}$ Tanto o XLip quanto o XLink Trce foram escritos na linguagem Java podendo, assim, serem executados em várias plataformas computacionais que suportam o Ambiente de Execução Java (JRE - Java Runtime Environment) com pacote JDK (Java Development Kit) versão 1.2.2 ou superior. Ao longo desta seção, são apresentados excmplos de implementação do XLip referente a funcionalidades oferecidas pelas cspecificaçõcs XLink e XPointer, assim como serão discutidas limitações do XLip na implementação dessas especificações $\mathrm{e}$ as principais caractcrísticas destc processador.

\subsubsection{XLip e Ligação/Ancoragem XML}

O processador XLip está em conformidade com as especificações XLink c XPointer quando cstas se encontravam no estágio de Recomendação Candidata pelo W3C cm 2000. Quanto ao modelo de ligação de documentos XML provido pelo XLip, tem-se o suporte ao percurso de ligações simples e estendidas com seus respectivos atributos. Ligações simples são semelhantes às ligações encontradas na Web, enquanto que as estendidas podem ser multidirecionais. Bases de ligações e elementos dos tipos locator, resource, arc c title, todos com seus respectivos atributos, também são suportados pelo XLip.

Quanto ao modelo de ancoragem de documentos XML fornecido pelo XLip, têm-se o suporte à forma de endereçamento de elementos com atributos do tipo ID (através da função $i d$ ) e à forma de endereçamento que simula o percurso da cstrutura de árvore de documentos XML (sequiência de inteiros separados por barras). Maiores detalhes sobre cstas duas formas de endereçamento podem ser encontradas em (DeRose et al., 2001a).

O XLip é integrado ao XLink Tree cuja interface é mostrada na Figura 4.5. Para navegar cm documentos XML no XLink Tree, o usuário deve acionar o botão Open a File. Assim que o arquivo XML é aberto, vê-se a árvore que representa a disposição hicrárquica de ş̣us clementos. Os subelementos de um nó podem ser visualizados ao serem clicados duas vezes. Ainda segundo a Figura 4.5, nós que apresentam informaçõcs de ancoragem c ligação estendem a jancla da aplicação para exibir tais informações. Para percorrer uma

\footnotetext{
${ }^{5}$ Disponível para download em http://www.labs.fujitsu.com/free/xlip/en/download.html.
} 
ligação, o usuário deve selecionar o nó que representa o ponto final de origem de uma ligação (ícone de cor vermelha) e acionar a opção Traversal.

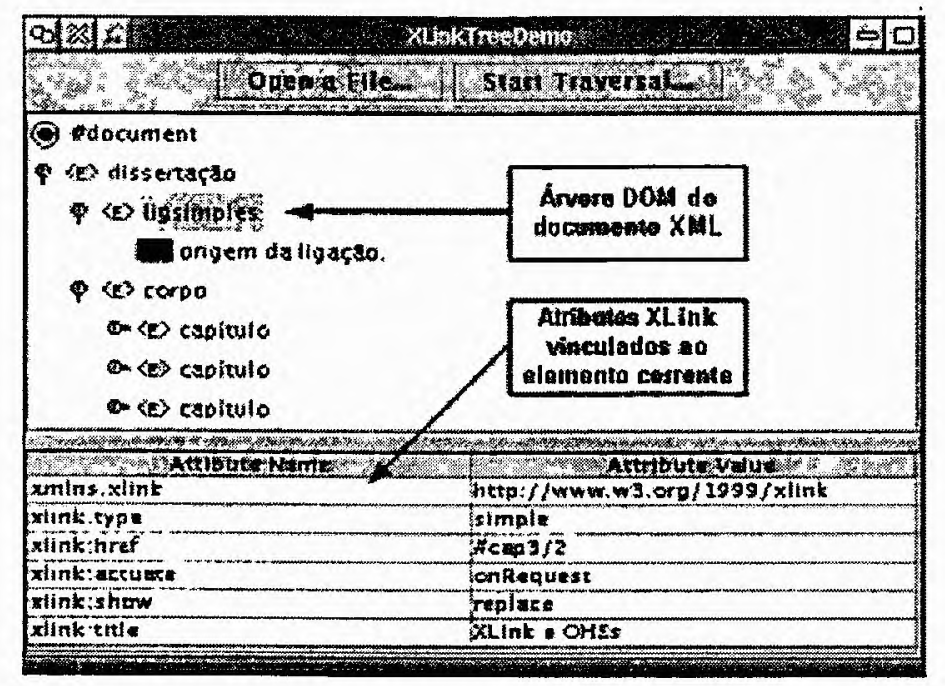

Figura 4.5: Interface da aplicação XLink Tree

O processador XLip realiza o processamento de XLink e XPointer com DOM, o que o permite trabalhar com qualquer processador ou parser XML que trate elementos de documentos como objetos programáveis, na condição de que uma intèrface apropriada entre o XLip e esse processador seja implementada.

Um exemplo de ligação simples da especificação XLink é apresentado na Figura 4.6. À esquerda, o XLink Tree apresenta a estrutura hierárquica do documento XML destacando o ponto final de origem, (texto "a partir daqui"). O comportamento de percurso da ligação é determinado pela ativação da opção Traversal, com o ponto final de origem sendo substituído pelo de destino (à direita), definida pelo atributo XLink show= "replace". Um pequeno trecho desta ligação simples em XLink é apresentada a seguir.

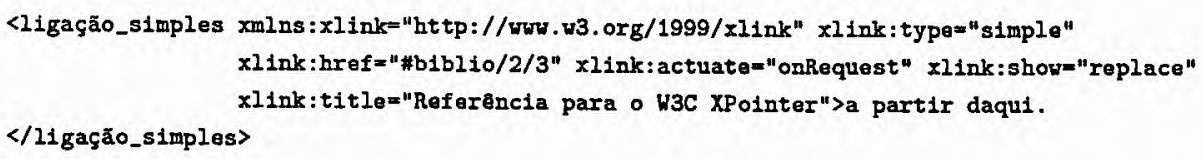

Segundo a notação do XPointer, o ponto final de origem aponta para o terceiro elemento de informação, filho do segundo elemento cujo pai tem como identificador biblio, identificado pelo atributo $\times$ link:href="\#biblio/2/3". Neste caso, o ponto final de destino é representado por $<$ ref $>$ http://www.w3.org/TR/xptr $</$ ref $>$, conforme indicado na Figura 4.6 (à direita). 


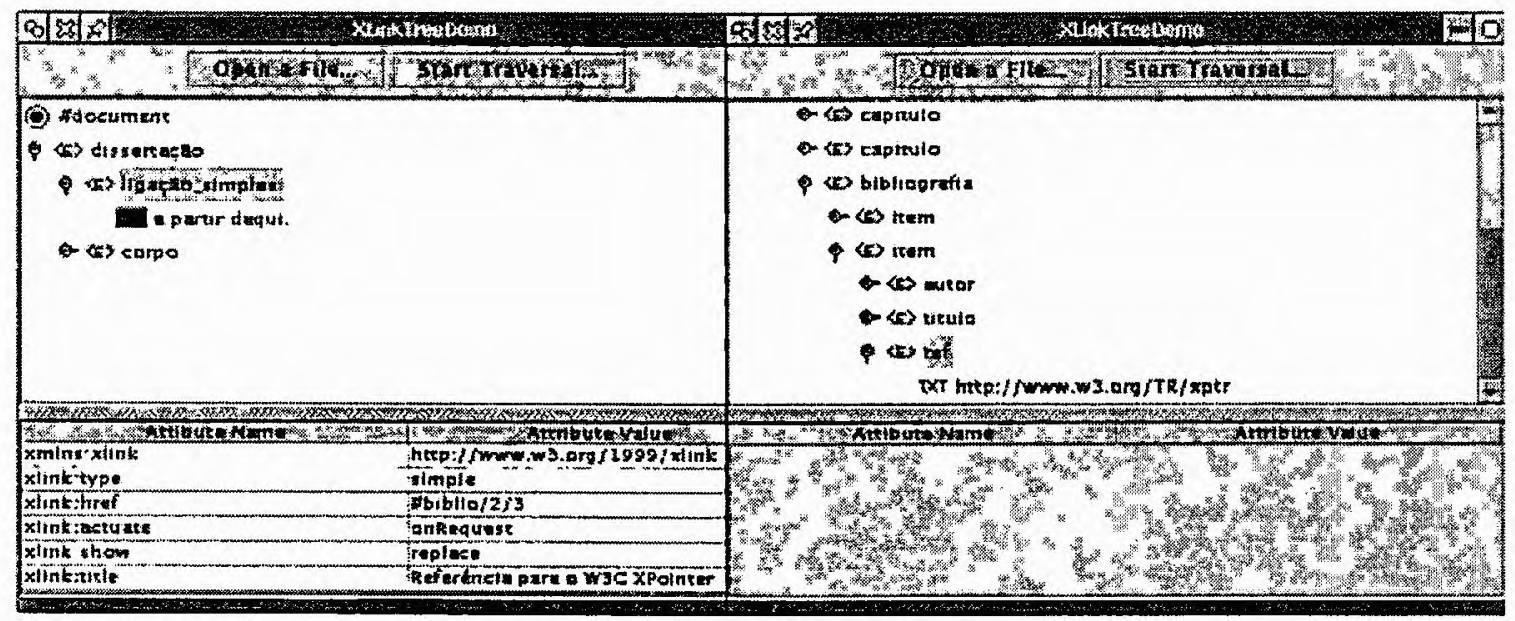

Figura 4.6: Percurso de ligação simples interna com XLip/XLink Tree

Um exemplo de ligação estendida bidirecional externa é apresentado na Figura 4.7. Imediatamente após ser carregado, o arquivo "dissertação.xml" obtém seu conjunto de âncoras e ligações armazenado no arquivo "base_ligação.xml". A noṭação XLink correspondente ao carregamento da base de ligações de "dissertação.xml" armazenada no elemento carregaBase é mostrada a seguir.
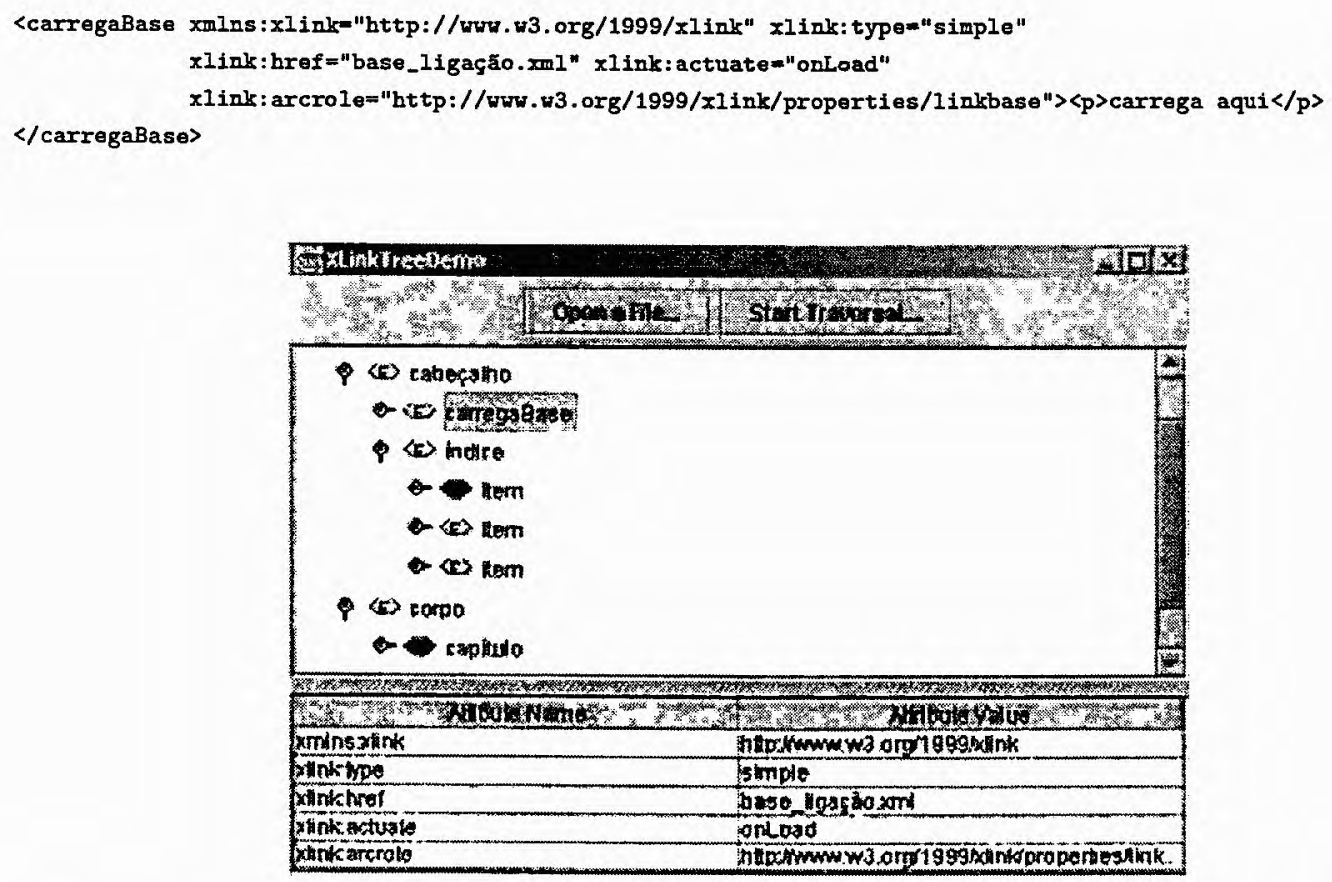

Figura 4.7: Percurso de ligação estendida bidirecional externa com XLip/XLink Tree 
Em "base_ligação.xml" são definidos os pontos finais da ligação bidirecional definida sobre "dissertação.xml". Esta ligação é obtida ao inverter seus pontos finais, não havendo, assim, distinção entre origem e destino. Seguindo o exemplo da Figura 4.7, a ligação ć percorrida do primeiro elemento de <índice> para o primeiro nó do elemento <corpo> e vice-versa, ambos destacados na Figura 4.7. Os pontos de ancoragem dos respectivos ponțos finais são toc1 e cap1, conforme mostra a notação XLink seguinte:

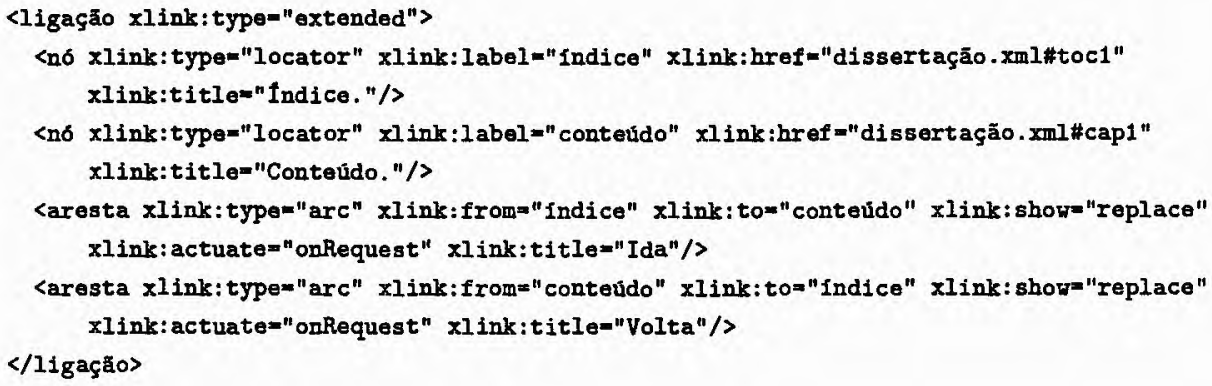

\subsubsection{Características do XLip}

Baseado nas funcionalidades oferecidas pelo processador XLip, as seguintes características podem ser identificadas:

- atua como servidor de ligação hipermídia;

- é multiplataforma, por ter sido escrito na linguagem Java;

- é compatível com as Recomendações Candidatas XLink/XPointer;

- faz processamento de XLink e XPointer com DOM; e

- não é restrito apenas a fornecer ligações a documentos XML.

Embora o XLip seja, atualmente, um dos principais processadores para as cspccificações XLink e XPointer, o XLip apresenta algumas limitações quanto a sua implcmentação, como seu suporte parcial ao conjunto de comportamentos especiais para o percurso de ligações fornecido pelo XLink e às capacidades de enderç̧amento de documentos XML fornccidas pelo XPointer. 


\subsection{Considerações Finais}

Este capítulo apresentou duas implementações de serviços de ligação que se encontram no mesmo contexto do serviço de ligações WLS proposto neste trabalho. Embora apresentem diferentes propósitos, Webvise, XLip e WLS gerenciam estruturas hipermídia armazenadas externamente aos documentos referenciados. O XLip permite também utilizar especificações XLink internas aos documentos XML relacionados.

Assim como o XLip, o WLS se preocupa em gerenciar ligações e âncoras hipermídia, abstendo-se de fornecer anotações como objetos de primeira classe, como o Webvise o faz. No contexto do projeto InCA-SERVE, há um serviço específico para fornecimento de anotações hipermídia chamado GroupNote (Izeki, 2001). Embora não tenha sido implementado em Java como o XLip, o WLS não é restrito a uma plataforma computacional, contrariamente ao Webvise, este restrito à plataforma Windows.

O modelo de dados conceitual do WLS, assim como do Webvise, seguem o modelo de dados do OHP. No entanto, o modelo de dados do Webvise estende o OHP ao dar suporte a nós de composição, enquanto o WLS não os provê. O WLS não apresenta uma interface com o usuário, assim como Webvise e XLip. As funcionalidades hipermídia fornecidas pelo WLS são acessadas através da interface de suas aplicações integradas.

Uma vez que o objetivo do WLS consiste em fornecer funcionalidades hipermídia a aplicações baseadas em tecnologia XML, o WLS, assim como o XLip, utiliza o XPointer para o endereçamento da estrutura hierárquica dos documentos gerenciados por suas aplicações integradas.

O WLS não precisa ser ciente da especificação XPointer, como o XLip, mas deve armazenar as informações referentes ao endereçamento das âncoras dos documentos manipulados por suas aplicações integradas, e ser capaz de detectar e atualizar as âncoras que, porventura, venham a tornar-se inconsistentes. 


\section{Capítulo 5}

\section{Projeto e Implementação do WLS}

\subsection{Considerações Iniciais}

A partir de sua experiência com o sistema Notecards, Halasz (1988) contribuiu com sete questões de projeto a serem consideradas no desenvolvimento da futura geração de sistemas hipertexto. A infra-estrutura hipermídia da Web foi concebida sobre um conjunto de protocolos e padrões simples, como a sintaxe e o modelo de ligação fornecidos pela linguagem HTML. Contudo, questões como suporte à colaboração e versionamento não foram introduzidas na Web. Posteriormente, Bieber et al. (1997) discutiam os benefícios oriundos da adição de funcionalidades hipermídia a aplicações de sistemas de informação, bem como da extensão da infra-estrutura hipermídia da Web a partir de sua integração com sistemas hipermídia abertos.

O serviço de ligações hipermídia WLS, proposto neste trabalho, visa prover funcionalidades hipermídia a aplicações XML em ambiente Web que desejem tornar-se hipermídia habilitadas, e possibilitar sua integração com essas aplicações formando um ambiente computacional aberto baseado em padrões XML. Este capítulo apresenta as questões de projeto que nortearam a definição da infra-estrutura do serviço de ligações WLS, assim como os principais aspectos envolvidos em sua implementação. 


\subsection{Modelagem do WLS}

Uma abordagem de sistemas hipermídia abertos foi utilizada como fundamentação teórica para o projeto e implementação do WLS utilizando como arquitctura de refcrĉncia o Modelo Dexter e suas extensões (Grønbæk and Trigg, 1994; Halasz and Schwartz, 1994). A principal contribuição do Modelo Dexter para o WLS consiste na separação de responsabilidades do serviço de ligações WLS e de suas aplicações integradas. Scgundo o modelo de três camadas de sistemas hipertexto proposto pelo Modelo Dextcr, o gercnciamento da rede de estruturas é de incumbência do WLS, enquanto que o armazcnamento c apresentação de documentos ficam sob a alçada de suas aplicaçõcs integradas.

O modclo de dados conceitual do WLS foi definido seguindo o modelo navegacional do OHP, descrito na Seção 2.6. A definição dos relacionamentos entre os objetos das classcs cspccializadas de HMObj consideram o suporte aos requisitos específicos do modelo de dados do WLS, representado em UML (Unified Modeling Language) na Figura 5.1.

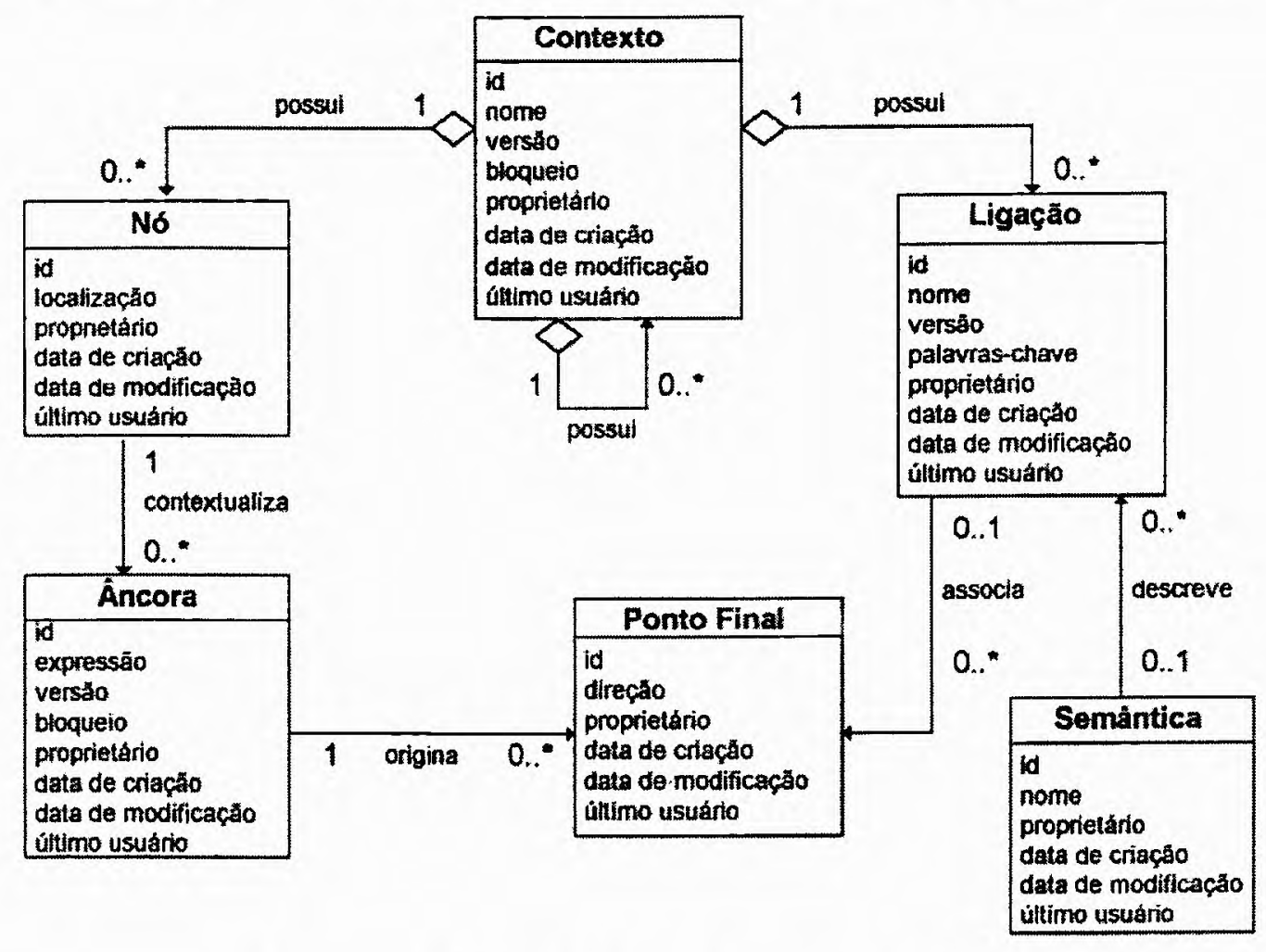

Figura 5.1: Modelo de dados conceitual do WLS 
Todas as classes especializadas de HMObj definidas no modelo navegacional do OHP, exceto PSpec e Computation, foram incorporadas ao modelo conceitual do WLS. As classes PSpec e Computation são utilizadas para especificar o comportamento de uma aplicação hipermídia em tempo de apresentação. Embora seja uma característica interessante, optou-se por não suportá-la, uma vez que o enfoque do WLS não reside sobre aspectos de apresentação de documentos gerenciados por suas aplicações integradas.

Grønbæk and Trigg (1999) afirmam que, para ambientes colaborativos, objetos hipermídia devem incluir informações que indiquem, por exemplo, seus respectivos criadores e últimos modificadores, além do momento em que foram criados e modificados pela última vez. Dessa forma, foram incluídas as propriedades proprietário, data de criação, data de modificação e último usuário a todas as classes do modelo conceitual do WLS. Tais extensões no modelo navegacional do OHP são garantidas, uma vez que o OHP foi definido como um modelo aberto, o que permite a especialização de novas classes de objetos e a introdução de novas propriedades às classes do modelo.

No WLS, a classe Contexto representa uma agregação de objetos hipermídia, como nós, ligações e contextos aninhados. Esta classe possibilita que diferentes ligações hipermídia sejam aplicadas sobre um mesmo conjunto de informações, além do reuso de contextos criados previamente. A propriedade bloqueio foi introduzida às classes Contexto e Âncora para armazenar informações relativas ao bloqueio de estruturas hipermídia em diferentes níveis de granulosidade. Dessa forma, é possível o trabalho colaborativo não apenas sobre os documentos manipulados por aplicações hipermídia habilitadas, mas também sobre âncoras localizadas nesses documentos. Uma abordagem de OHS que fornece suporte à colaboração assíncrona sobre estruturas hipermídia foi implementada no OHS Webvise.

Para suportar o histórico de modificações em estruturas hipermídia para posterior recuperação, foi incluída a propriedade versão às classes Contexto, Âncora e Ligação. O versionamento de estruturas hipermídia compreende um dos requisitos do OHS HyperDisco (Wiil, 1995).

A classe Nó corresponde aos documentos manipulados por aplicações hipermídia habilitadas. Esta classe possui a propriedade localização, que armazena a posição física de um documento, como URLs ou caminhos em sistemas de arquivos. Vale destacar que poucas informações sobre documentos precisam ser tratadas, já que o WLS representa um serviço de ligações hipermídia, não um sistema de hiperbase. ${ }^{1}$

\footnotetext{
${ }^{1}$ Sistema de hiperbase é um banco de dados que gerencia o armazenamento de objetos hipermídia e, às vezes, seus respectivos conteúdos (Grønbæk and Trigg, 1999).
} 
Ligações entre nós hipermídia são definidas através das classes Âncora, Ponto Final e Ligação. A classe Âncora define uma localização interna no conteúdo de um nó hipermídia sobre o qual uma ligação é criada. Uma vez que o serviço WLS visa fornecer estruturas hipermídia a aplicações XML, seu modelo de ancoragem utiliza a especificação XPointer. A propriedade expressão armazena a localização de âncoras na sintaxe do XPointer.

Mediante a modelagem dos relacionamentos entre as classes Âncora, Ponto Final e Ligação, o modelo do WLS oferece suporte a ligações n-árias e multidirecionais. A classe Ligação identifica associações existentes entre pontos finais. Ponto Final corresponde a cada extremidade de uma ligação com sua respectiva direção (fonte, destino ou bidirecional), expressa pela propriedade de mesmo nome. Segundo os relacionamentos definidos entre as classes Âncora e Ponto Final, uma âncora pode estar associada a vários pontos finais de ligações. Esta abordagem de projeto é relevante uma vez que esses tipos de ligações são suportados pelos principais OHSs, como Microcosm, DHM e Webvise.

A classe Ligação foram acrescentadas propriedades que lhe incorporam semântica, tais como nome, título descritivo para a ligação, e palavras-chave, conjunto de palavras que auxilia na descrição do relacionamento existente entre os nós ligados. Em virtude da possibilidade de extensão do modelo navegacional do OHP, foi inserida no modelo conceitual do WLS a classe Semântica. Esta classe tem como propósito fornecer os relacionamentos semânticos entre os pontos finais de ligações de forma explícita que, na maioria das vezes, não ocorre na Web. O WLS oferece aos usuários alguns tipos semânticos pré-definidos para ligações, influência direta de sistemas linguagens e aplicações hipermídia, conforme mostra a Tabela 5.1.

Tabela 5.1: Tipos semânticos pré-definidos para ligações no WLS

\begin{tabular}{|l|l|}
\hline Tipo Semântico & Contribuição \\
\hline \hline conselho, comentário, explicação e pergunta & Serviço Annotea (Kahan et al., 2001) \\
\hline bibliografia, citação, direitos autorais, email e índice & Linguagem HTML (Bieber et al., 1997) \\
\hline anotação e mudança & Sistema Guide (Brown, 1986) \\
\hline exemplo e informações adicionais & Sistema MacWeb (Nanard and Nanard, 1991) \\
\hline
\end{tabular}

Atributos e tipos semânticos a ligaçōes podem ser utilizados para diversos fins computacionais, como buscas baseadas em estrutura de hipertexto, uma das melhorias sugeridas por Halasz (1988) e Bieber et al. (1997). Buscas baseadas em conteúdo de nós (como na Web) ignoram a estrutura de hipertexto. Todavia, buscas baseadas em estrutura examinam a rede de hipertexto procurando alguma sub-rede que atenda a um determinado padrão. Por exemplo, uma simples consulta poderia ser procurar por nós que sejam conectados por ligações que tenham como palavras-chave "XML" e "nível básico". Em um 
cenário educacional, o conjunto de nós que atendem a essa consulta auxiliariam professores e alunos na condução de seus papéis no processo de ensino-aprendizagem. Um outro exemplo de possível consulta à base de ligações do WLS seria procurar por dois nós conectados por uma ligação do tipo semântico anotação onde o ponto final de origem contém a palavra $O H S$.

Permitir associações semânticas explícitas entre nós hipermídia é de fundamental importância para o uso de hipermídia na educação, uma vez que humanos pensam e aprendem por associação. Segundo Lewis et al. (1999), ao fornecer as associações devidas entre os componentes de seu material didático hipermídia, o professor proporciona aos alunos um aprendizado mais profundo deste material através da navegação entre tais associações. É importante destacar que o serviço de ligações WLS não fornece um sistema de busca baseada em estrutura de hipertexto; o WLS apenas fornece uma infra-estrutura que suporta buscas dessa natureza.

\subsection{Arquitetura do WLS}

O presente trabalho está inserido no contexto do Projeto InCA-SERVE que envolve o desenvolvimento de um conjunto de aplicações de caráter de CSCL (Computer-Supported Collaborative Learning). O WLS tem a incumbência de gerenciar uma base externa de âncoras e ligações a partir da qual oferece funcionalidades hipermídia a essas aplicações que compõem o ambiente computacional do Projeto InCA-SERVE.

A Figura 5.2 apresenta a arquitetura do WLS e sua comunicação com aplicações XML do Projeto InCA-SERVE. Aplicações que desejem tornar-se hipermídia habilitadas enviam mensagens ao WLS, baseado no protocolo OHP, de tal forma a solicitar operações, como criação e percurso de ligações sobre seus documentos gerenciados. Portanto, a arquitetura do serviço de ligações WLS compreende uma base externa de estruturas hipermídia, um protocolo de comunicação com suas aplicações integradas e um conjunto de operações na forma de uma API que gerencia essa base de dados. 


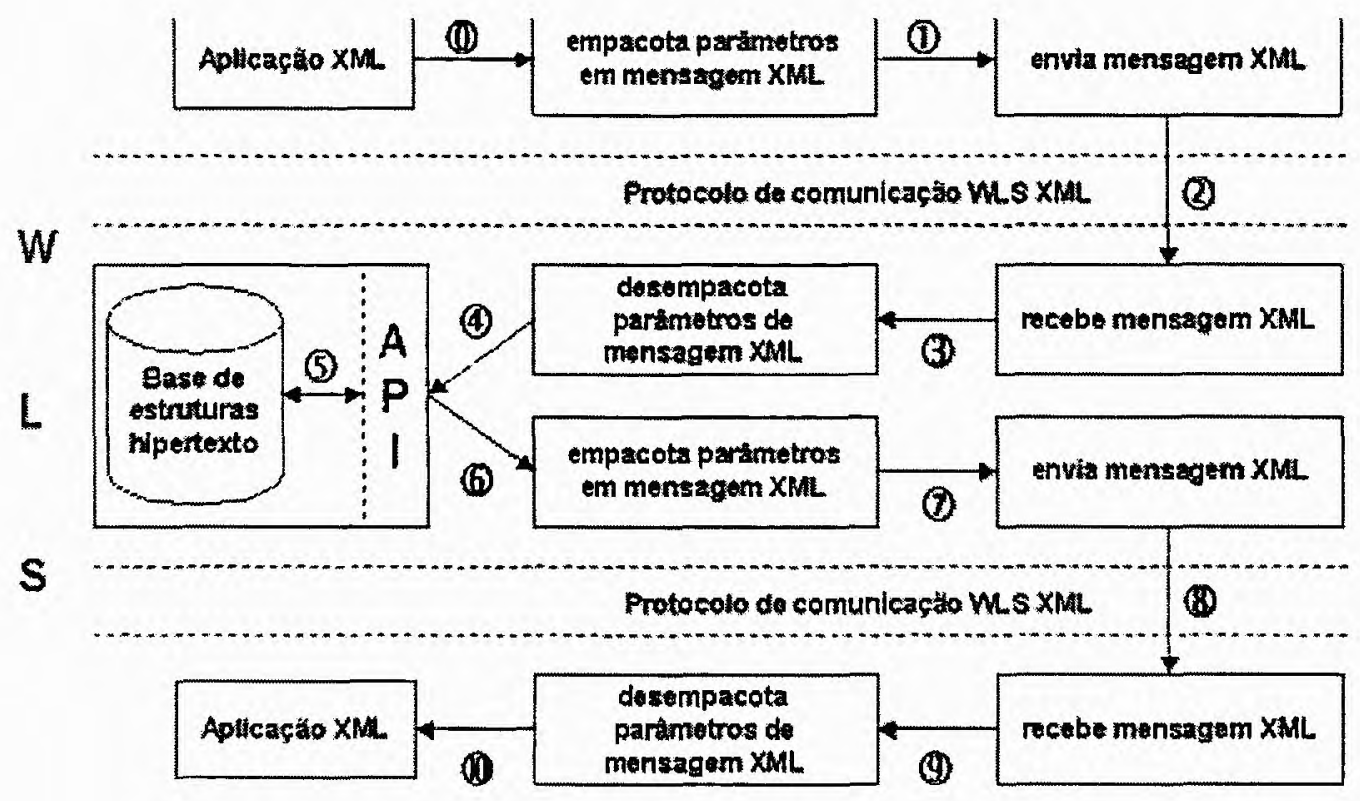

Figura 5.2: Arquitetura do WLS e comunicação com aplicações XML

Aplicações do Projeto InCA-SERVE podem usufruir do serviço de ligações fornecido pelo WLS. A CoWeb é um ambiente de autoria assíncrona colaborativa (Guzdial, 1999) utilizada como ferramenta de CSCL no ICMC-USP. A partir de um estudo realizado pelo autor deste trabalho (Macedo et al., 2001), foram levantados requisitos para a melhoria de sua infra-estrutura no suporte à autoria e ao ensino colaborativos. Com base nesses requisitos, foi implementada a ferramenta CoTeia com tecnologias baseadas na linguagem XML para estruturação e apresentação de páginas Web (Arruda Jr and Pimentel, 2001).

O WebNote consiste em um serviço colaborativo de anotações manipuladas como objetos de primeira classe, de modo a possibilitar o compartilhamento de anotações entre aplicações que compreendem o ambiente computacional do projeto InCA-SERVE (Izeki, 2001). Na implementação do WebNote são utilizadas tecnologias baseadas em XML para a estruturação, apresentação, controle de concorrência e fornecimento de semântica e metadados aos seus documentos gerenciados.

As aplicações CoTeia e WebNote (e outras aplicações XML) podem usufruir das funcionalidades oferecidas pelo WLS através de trocas de mensagens baseadas no protocolo OHP especificadas no formato XML. Cada uma destas mensagens corresponde a uma operação disponibilizada pela API (Application Programming Interface) do WLS que acessa diretamente a base de ligações hipermídia. 
A palavra-chave na abordagem de OHSs empregada no serviço de ligações WLS é integração. Assim, para que aplicações XML sejam integradas ao WLS, é necessário que estas sejam estendidas, como mostra a Figura 5.2, de forma a:

1. fornecer a localização de cada um de seus documentos gerenciados;

2. identificar e codificar âncoras em seus documentos no formato XPointcr;

3. empacotar e desempacotar essas informações em mensagens no formato XML;

4. interpretar e validar os parâmetros associados a cada operação definida na API do WLS; c

5. fornecer as funcionalidades hipermídia do WLS em suas interfaces com o usuário.

\subsection{Implementação do WLS}

Uma primeira decisão para o desenvolvimento do WLS foi sua disponibilização na forma do uma API simples, extensível c aberta para aplicaçõcs XML. Simples, quanto à lcgibilidade de suas funções e parâmetros; extensível, ao permitir que outros tipos abstratos de dados sejam inseridos com pouca ou nenhuma reescrita de código e; aberta, à medida que csta interface de comunicação é tornada pública. A utilização de uma API como abordagcm de implcmentação possibilita o reuso do WLS em diferentes contcxtos, rcduzindo o csforço de autoria de aplicações XML.

A plataforma de software utilizada na implementação do WLS inclui o sistcma opcracional Linux, o servidor Web Apache integrado a um interpretador PHP (Hypertext Preprocessor $)^{2}$, o banco de dados $\mathrm{MySQL}^{3}$ e especificações bascadas na linguagem XML. A implementação das operações projetadas na API do WLS foram escritas na linguagem PHP com acesso à base de âncoras c ligações implementada sobre o MySQL. MySQL e PHP compreendem as principais tecnologias utilizadas, atualmente, no descnvolvimento de aplicações para o ambientc Web. MySQL é um servidor de banco de dados compacto que apresenta uma API para a linguagem PHP que permitc o acesso de clicntes ao banco de dados. O banco de dados MySQL e interpretadorcs PHP estão disponívcis para diversas plataformas computacionais, desde Unix/Linux até Windows 95/98/2000. Sendo assim, o WLS não ć rcstrito a uma plataforma computacional.

\footnotetext{
${ }^{2}$ http://www.php.net

${ }^{3}$ http://www.mysql.com
} 
Por ser uma meta-linguagem, XML foi utilizada como formato de intercâmbio das mensagens do protocolo de comunicação entre o WLS e suas aplicações integradas. Dessa forma, cada solicitação das aplicações a operações do WLS é codificada em XML, bem como a resposta a cada solicitação. Associada a cada mensagem do protocolo de comunicação entre o WLS e suas aplicações integradas, há uma especificação gramatical em DTD. Esquema XML poderá ser utilizado para validação de mensagens do protocolo assim que for plenamente suportado pelos principais browsers do mercado. Portanto, o WLS e suas aplicações integradas devem apresentar parsers validadores para a checagem da sintaxe e validação das mensagens XML trocadas.

O modelo de ancoragem da estrutura interna de documentos gerenciados por aplicaçōes integradas ao WLS é baseado na especificação XPointer. Aplicações integradas ao WLS precisam codificar a posição de âncoras segundo a sintaxe do XPointer, e transmití-la em uma mensagem XML ao WLS para posterior armazenamento na base de estruturas. $O$ WLS não precisa entender a sintaxe do XPointer, apenas deve armazenar as informações referentes ao endereçamento de âncoras.

Visto que os documentos gerenciados por aplicações estão fora do gerenciamento do WLS, é possível a falta de sincronização entre o conteúdo destes documentos (em virtude de edições posteriores) e as informações sobre âncoras e ligações destes documentos. $O$ WLS tem scripts responsáveis pela deteç̧ão e atualização de informações de âncoras e ligações que, porventura, venham a tornar-se inconsistentes. A técnica utilizada é semelhante à empregada no OHS Microcosm: a comparação das datas de última modificação de ligações e documentos. Se uma aplicação integrada ao WLS solicita o percurso de uma determinada ligação, o processo se daria da seguinte forma, em resumo:

1. o WLS é solicitado pela aplicação para verificar SE o documento que serve como destino da ligação é válido;

(a) se o documento é válido, o WLS verifica SE a data de última modificação da ligação é menor que a data de última modificação do documento encontrado (âncoras podem estar inconsistentes). Se este for o caso:

i. a aplicação deve reposicionar as âncoras (se puder); e

ii. o WLS deve atualizar a base de ligações.

(b) SENÃO, caso o documento não tenha sido modificado sem conhecimento do WLS, a aplicação abre o documento de destino da ligação e posiciona o cursor na âncora que serve de ponto final de destino da ligação a ser percorrida. 
2. SENÃO, caso o documento não seja válido, a aplicação solicita ao usuário que tome a providência de apagar a ligação, ou deixá-la inválida para posterior reuso.

Por fim, as especificações W3C RDF e Esquema RDF foram utilizadas para o fornecimento de semântica e metadados às estruturas hipermídia manipuladas pelo WLS. Para Chang (1998), a partir de um modelo de classes UML, é possível gerar uma representação equivalente em Esquema RDF. Dessa forma, dado o modelo conceitual do WLS na notação UML, foi possível especificar um Esquema RDF para o serviço de ligações WLS que se encontra no Apêndice A deste trabalho. Esse mesmo Esquema RDF pode ser encontrado na URL http://coweb.icmc.sc.usp.br/WLSProject-ns\#.

Um parser RDF entende a semântica de cada um dos elementos de um documento RDF ao consultar o vocabulário de metadados definido pela URI do espaço de nomes deste vocabulário. Segundo Bray et al. (1999), um espaço de nomes é uma coleção de nomes usada em documentos XML que compartilham um mesmo local, funcionando como um sistema de nomes para elementos e atributos XML. A URI para o Esquema RDF do WLS representa o espaço de nomes que funciona como um ponteiro para detalhes adicionais sobre informações de definição da semântica dos objetos que compõem a base de dados do WLS. Toda a descrição semântica contida no Esquema RDF do WLS se encontra no idioma inglês, portanto, os nomes das classes e propriedades descritas no modelo conceitual do WLS na Seção 5.2 podem diferir daqueles encontrados no espaço de nomes definido para o Esquema RDF do WLS. É apresentado, a seguir, uma breve explicação desse Esquema RDF.

Em um modelo de classes, classes são normalmente organizadas sob uma forma hierárquica; este tipo de relacionamento é transmitido pela propriedade rdfs:subClassOf. Por definição, tudo descrito por expressões RDF é considerado um recurso e, consecutivamente, uma instância da classe rdfs:Resource. Foi criada uma classe geral de objetos hipermídia, chamada HMObject, herança do modelo navegacional do OHP. Portanto, a classe HMObject é uma subclasse da superclasse Resource. Todas as classes que pertencem ao modelo conceitual do WLS são subclasses de HMObject; por exemplo, a classe Context. O relacionamento entre classes e propriedades é expresso por $r d f s$ :domain; por exemplo, a propriedade expression está relacionada à classe Anchor.

Embora ainda limitado, foi utilizado o sistema de tipagem de dados do Esquema RDF expresso por rdfs:range; por exemplo, a propriedade descriptions é um repositório do tipo Bag, uma lista não-ordenada de recursos cujos valores podem ser duplicados. Nesse caso, descriptions armazena uma lista de, no máximo, três palavras-chave para caracterização 
do papel semântico da ligação. Ainda quanto à tipagem de dados do Esquema RDF, podem ser criadas classes com valores específicos de uma determinada propriedade; por exemplo, para a propriedade direction, pertencente à classe EndPoint, foi criada uma classe valueOfDirection cujos valores assumidos são from, to e bi. Dessa forma, consegue-se expressar que as possíveis direções de um ponto final de ligação.

Há propriedades do modelo do WLS que já foram definidas semanticamente pelo Dublin Core (DC, 1999); por exemplo, a propriedade creator. Nesse caso, é feito um ponteiro para o espaço de nomes do Dublin Core que contém a semântica desejada através da declaração $r d f s: i s D e f i n e d B y ~ r d f: r e s o u r c e=~ " h t t p: / / p u r l . o r g . d c / e l e m e n t s / 1.1 /$ ". Existem outras propriedades definidas pelo Dublin Core com a mesma semântica, porém com nome diferente daquele definido no modelo do WLS; por exemplo, a propriedade created tem o mesmo significado que a propriedade date definida pelo Dublin Core. Por esta razão, created é uma subpropriedade (rdfs:subPropertyOf) de date.

De acordo com Chang (1998), propriedades RDF também representam relacionamentos entre classes de um modelo de classes UML. Assim, foram definidas propriedades para representar relacionamentos entre classes do modelo conceitual do WLS, tais como a propriedade anchors OfNode, para o relacionamento entre as classes Node e Anchor, e a propriedade linkType, para o relacionamento entre as classes Link e Semantics. Como ambas as propriedades foram definidas no contexto do WLS, suas definições semânticas apontam para o espaço de nomes que contém o Esquema RDF para o WLS, através da declaração rdfs:isDefinedBy rdf:resource= "http://coweb.icmc.sc.usp.br/WLSProject-ns\#". Com a definição de relacionamentos entre as classes do modelo conceitual do WLS através das especificações W3C RDF e Esquema RDF, é possível gerar um mapa do hipertexto que engloba um conjunto de documentos ligados pela infra-estrutura do WLS.

Portanto, quanto à utilização do Modelo, Sintaxe e Esquema RDF na infra-estrutura do serviço de ligações WLS, conclui-se que, ao associar metadados e semântica aos objetos componentes da base de dados gerenciada pelo WLS:

1. buscas baseadas em estruturas de hipertexto podem ter seus índices de recuperação e precisão melhorados, o que minimiza o árduo trabalho de usuários em garimpar os resultados provenientes de suas buscas; e

2. é possível o mapeamento do hiperespaço que envolve a rede de hipertexto sob gerência do WLS e os documentos manipulados por suas aplicações integradas, o que auxilia usuários na navegação em um site Web, por exemplo. 


\subsection{Operações Suportadas pelo WLS}

No trabalho de Miotto (2001) é apresentado o modelo OXHMBS (Open eXtended Hypermedia Model based on Statecharts), uma extensão do modelo formal para especificação de aplicações hipermídia XHMBS (Paulo et al., 1998). O modelo OXHMBS tem como objetivo oferecer suporte formal para a especificação de aplicações em OHSs através da utilização da técnica Statecharts (Harel, 1987).

Em OXHMBS, as operações associadas às mensagens dos subprotocolos de conexão, ligação e multiusuário do OHP foram formalmente definidas. Essas especificações formais nortearam a identificação do conjunto de operações associadas às classes do modelo de dados conceitual do WLS. Este conjunto de operações forma a API do WLS. O modelo OXHMBS também contribuiu para a implementação do WLS, já que a utilização de uma abordagem formal possibilita garantir a consistência e confiabilidade das operações componentes da API.

Para cada classe do modelo conceitual do WLS foram definidas e implementadas operações conforme descrito na Tabela 5.2. A definição completa da API do WLS, bem como maiores detalhes de sua implementação, podem ser encontrados no site Web do Projeto InCA-SERVE. ${ }^{4} \mathrm{Na}$ documentação da interface das operações de cada classe que compõe o modelo conceitual do WLS, existe uma breve descrição textual da tarefa executada pela operação e seus respectivos parâmetros de entrada e saída na ordem em que devem ser tratados.

Tabela 5.2: Algumas operações definidas na API do WLS

\begin{tabular}{|l|l|}
\hline Classe & Operações permitidas \\
\hline \hline Contexto & insere, remove, valida, obtém membros, obtém RDF, obtém XML \\
\hline Nó & insere, remove, valida, apresenta, inspeciona, obtém RDF, obtém XML \\
\hline Ligação & insere, remove, inspeciona, percorre, obtém RDF, associa semântica \\
\hline Âncora & insere, remove, inspeciona, obtém RDF, atualiza, obtém lista de âncoras \\
\hline Ponto final & insere, remove, referencia nó, referencia âncora \\
\hline Semântica & insere, remove, valida, altera tipo \\
\hline
\end{tabular}

É importante destacar as operações que combinam RDF e Esquema RDF (operações obtémRDF) para obter metadados referentes a objetos da base de dados manipulada pelo WLS. Ao solicitar alguma dessas operações, é gerado, por exemplo, o seguinte modelo RDF com metadados para o objeto Link:

\footnotetext{
${ }^{4}$ Disponível em http://coweb.icmc.sc.usp.br/incaserve/
} 


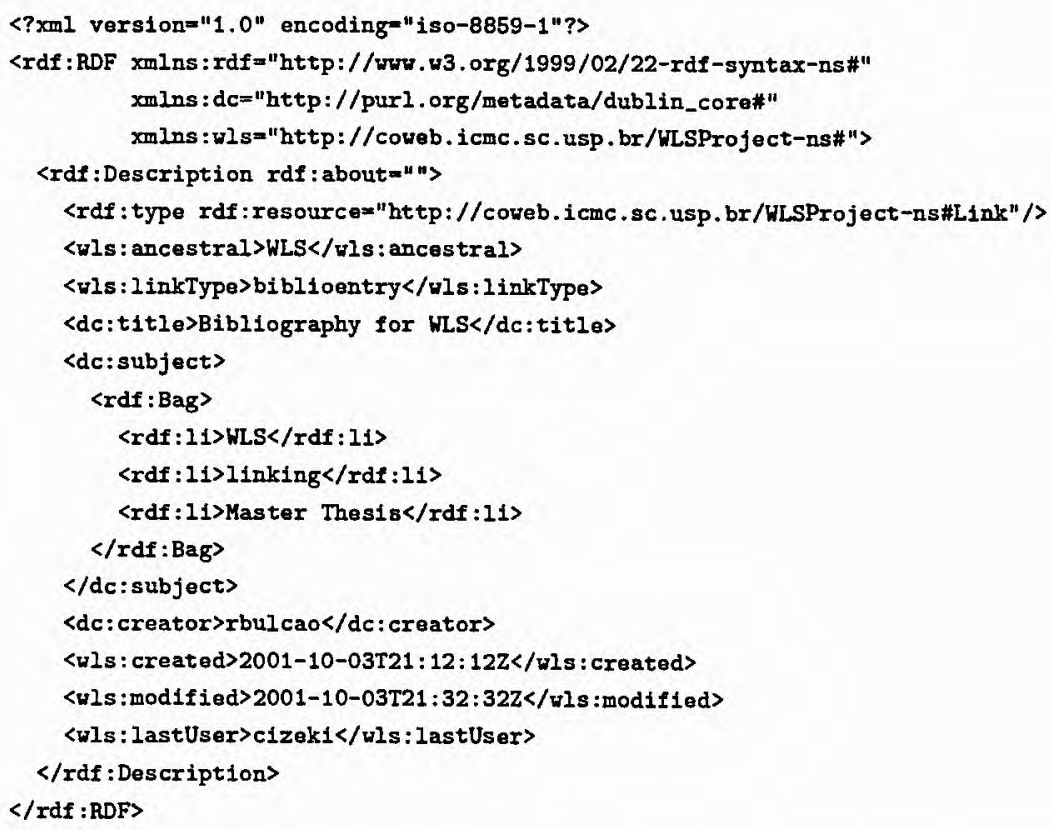

Segundo a sintaxe XML/RDF apresentada, como o objeto Link nằo tem uma URI que o identifique, rdf:about está vazio. Este objeto tem como ancestral o objeto Context cujo nome é "WLS". O tipo semântico associado a essa ligação é do tipo "biblioentry" e tem como título "Bibliography for $W L S$ ". Algumas palavras-chave foram associadas a essa ligação: "WLS", "linking" e "Master Thesis". Portanto, essa ligação aponta para a referência bibliográfica do WLS, no caso, uma dissertação de mestrado. Informações sobre quem e quando essa ligação foi criada e modificada pela última vez são também fornecidas como metadados; no caso, o usuário "rbulcao" é o autor da ligação e "cizeki", o último usuário que modificou alguma propriedade referente à ligação corrente. Conforme trabalho realizado em Pimentel et al. (2001), ao utilizar RDF e Esquema RDF em conjunto com a linguagem XSLT, é possível apresentar metadados definidos para cada objeto do modelo do WLS através das interfaces com o usuário de aplicações integradas ao WLS.

Com o objetivo de entender o processo de criação de ligações utilizando a infra-estrutura hipermídia do WLS integrada a uma aplicação XML integrante do Projeto InCA-SERVE, é apresentado, a seguir, um exemplo desse processo de criação de ligações. Se um usuário na aplicação WebNote deseja criar uma ligação entre duas anotações, o WebNote tem de ser estendido, primeiramente, de forma a fornecer essa funcionalidade em sua interface com o usuário. O WebNote deve ainda identificar o ponto de ancoragem indicado pelo usuário e transformá-lo para a sintaxe do XPointer. A mensagem XML apresentada a seguir mostra o valor de uma âncora na sintaxe do XPointer que representa a seqüência 
de 5 caracteres cujo valor é "teste", que fica a 45 caracteres do início do corpo de uma página HTML. Esta informação é associada à localização da anotação, provavelmente uma URL, e à direção da ligação corrente, provavelmente um ponto final de origem. Todas essas informações devem ser estruturadas (empacotadas) em uma mensagem newLink no formato XML segundo uma gramática DTD e enviadas ao WLS, conforme ilustrado a seguir.

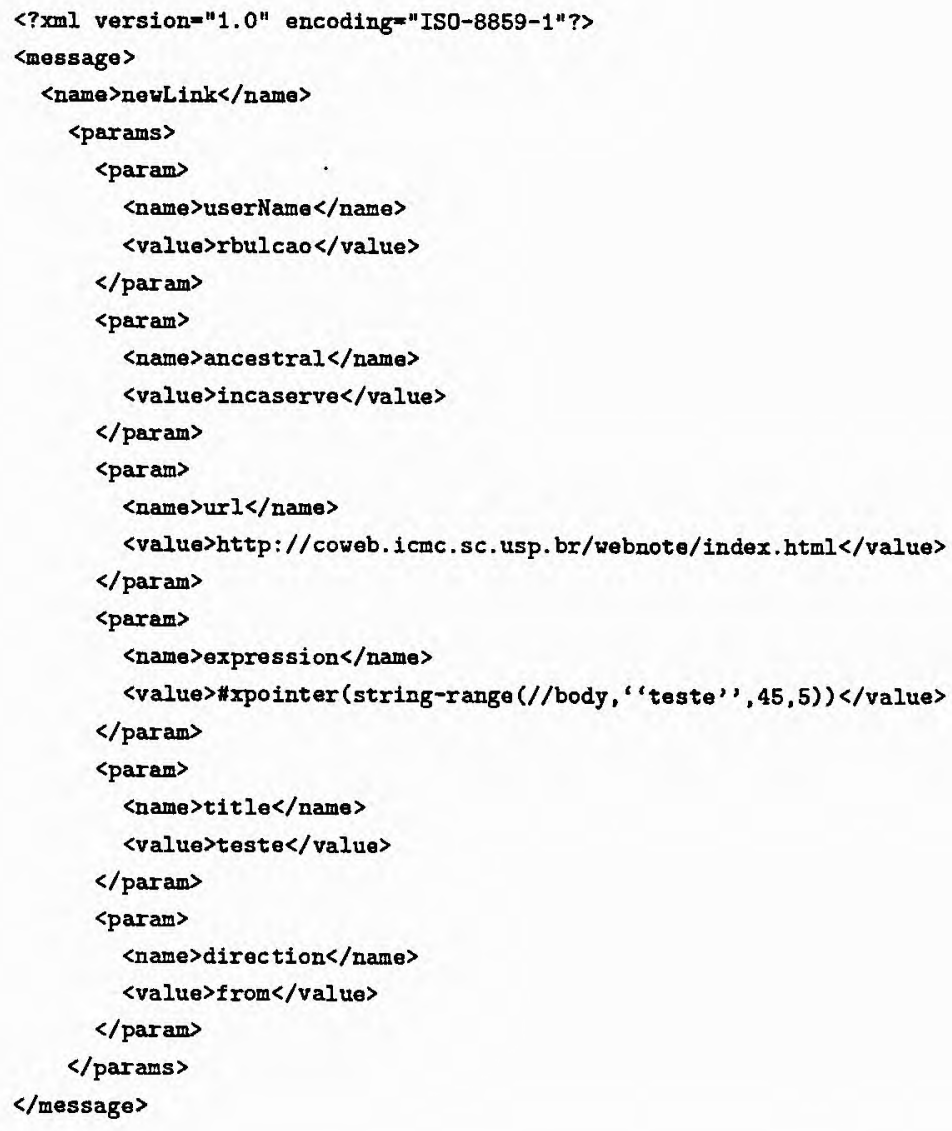

Ao receber esta mensagem XML, o WLS extrai (desempacota) o nome da operação que está sendo solicitada e a invoca passando-lhe os demais parâmetros na ordem em que estes aparecem na mensagem XML. A operação correspondente realiza o devido processamento e retoma em uma mensagem XML os respectivos resultados. No caso da operação newLink, esta se conecta à base de ligaçōes, cadastra a ligação corrente e retorna à aplicação WebNote os identificadores da ligação e do ponto final da ligação criados em uma mensagem XML. De posse do identificador da ligação, o usuário pode inserir pontos finais de destino para esta ligação através da solicitação da operação addEndPoint, o que permite a extensão do modelo de ligação utilizado na Web. 


\subsection{Considerações Finais}

Este capítulo apresentou aspectos de projeto e implementação do serviço de ligações WLS proposto neste trabalho. Foram destacadas as contribuições que a filosofia de sistemas hipermídia abertos e os padrões baseados em XML trouxeram ao projeto e implementação do trabalho proposto, caracterizando-o como um serviço aberto de ligações hipermídia para Web baseado em XML.

O projeto de serviços de ligação sob a ótica de OHSs considera um conjunto de requisitos básicos, dentre os quais, destacam-se: o gerenciamento de bases externas de ligações, o fornecimento de funcionalidades hipermídia a aplicações, a divisão de responsabilidades entre serviços de ligação e suas aplicações integradas, e o suporte a um modelo de ligação que possibilite estender o tradicional modelo utilizado na Web.

A arquitetura do serviço de ligações WLS é composta por uma base independente de estruturas hipermídia, o protocolo de comunicação XML com suas aplicações integradas e um conjunto de scripts que gerenciam essa base de dados com a responsabilidade de fornecer serviços hipermídia a aplicações e manter a consistência e integridade de âncoras e ligações. 


\section{Capítulo 6}

\section{Conclusões}

Este trabalho apresentou a definição da infra-estrutura do serviço aberto de ligações hipermídia para Web, chamado WLS (Web Linking Service). O WLS gerencia uma base independente de âncoras e ligações e fornece funcionalidades hipermídia a quaisquer aplicações XML que desejem tornar-se hipermídia habilitadas.

Como fundamentação teórica para o projeto e implementação do WLS foi utilizada uma abordagem de sistemas hipermídia abertos e padrões baseados na tecnologia XML. A infra-estrutura hipermídia do WLS atende aos seguintes requisitos:

1. disponibilização de funcionalidades hipermídia a aplicações XML que queiram usufruir de funcionalidades hipermídia através da implementação de mensagens, instanciadas como operações, do Protocolo OHP;

2. integração de um conjunto em aberto de aplicações XML hipermídia habilitadas através da implementação do WLS na forma de uma API simples, pública e extensível; e

3. disponibilização de seu serviço em ambiente Web através da utilização de padrões baseados na tecnologia XML.

Em suma, desenvolvedores de aplicações XML devem considerar a navegação e estruturação hipermídia para organizar, relacionar e dar a seus usuários acesso flexível às informações disponibilizadas. Um grande desafio ao fornecer funcionalidades hipermídia segundo a ótica de OHSs está nas mudanças na interface das aplicações hipermídia habilitadas com o usuário e em sistemas de autoria que adotam essa filosofia. 


\subsection{Contribuições}

As contribuições que o presente trabalho traz à comunidade de pesquisa $\mathrm{cm}$ hipcrmídia consistcm em:

1. disponibilizar publicamente a implementação do conjunto de opcraçõcs que intcgram a API do serviço de ligações WLS, operações cstas responsávcis pclo accsso e geronciamonto da basc independente de estruturas hipermídia;

2. reduzir o csforço de autoria de aplicações XML no que diz respcito ao fornecimento de funcionalidades hipcrmídia;

3. possibilitar a intcgração e cxtensão de aplicações XML atravós da API fornccida polo serviço de ligações WLS;

4. pcrmitir buscas baseadas cm cstruturas de hipcrtcxto ao associar metadados c scmântica às estruturas de dados gorenciadas pelo scrviço de ligaçõcs WLS;

5. fornecer um cstudo detalhado das decisões de projeto que nortcaram o desenvolvimento do scrviço de ligações WLS; e

6. explorar a utilização de especificações XML no contexto do OHSs.

\subsection{Trabalhos Futuros}

Como trabalhos futuros para o scrviço de ligações WLS, cstão scndo investigadas:

- a intcgração de sua infra-estrutura com aplicaçõcs XML no contcxto do Projeto InCA-SERVE, como a CoTeia e o WebNotc;

- a cxtensão de sua infra-cstrutura para dar suportc às cspecificaçõos do padrão XLink;

- a cxportação de estruturas hipcrtcxto computadas ao utilizar as cspccificaçõcs W3C RDF c Esquema RDF;

- a utilização do WLS para ligação do informações multimídia sincronizadas, por cxcmplo, da Rccomendação W3C SMIL (Synchronized Multimedia Integration Language) (SMIL, 2001); 
- a colaboração assíncrona sobre suas estruturas hipertexto gerenciadas atravćs do protocolo WebDAV (Goland ct al., 1999);

- o versionamento de estruturas hipcrtcxto ao utilizar a aplicação VcrsionWcb (Soarcs ct al., 2000);

- o suportc ao intercâmbio de estruturas hipermídia em ambientc distribuído atravćs do protocolo SOAP (Simple Object Access Protocol) (Gudgin et al., 2001); c

- a cxtcnsão da base de dados gercnciada pelo WLS com novos métodos de armazcnamento de informações da estrutura hicrárquica de documentos XML cm bascs de dados rclacionais, como o método XRcl (Yoshikawa ct al., 2001).

\subsection{Considerações Finais}

Apcsar da importância rcconhecida dos OHSs, as implcmontaçõcs atuais não são públicas, o que dificulta sua cxtcnsão ou utilização fora dos contcxtos nos quais foram descnvolvidas. A implcmentação do WLS sob a forma de uma API aberta permitc que scu scrviço scja utilizado não somente no contexto do Projcto InCA-SERVE, mas para qualquer conjunto de aplicações XML. Embora o WLS tenha utilizado o Modelo Dextcr como modelo conccitual do hiperdocumento, extensõcs ao scrviço WLS podem scr investigadas no sentido de explorar outros modclos conceituais de hipcrdocumentos, tais como o Modclo de Contcxtos Aninhados (Soares ct al., 1996).

O WLS possui um importantc papcl no contcxto do Projeto InCA-SERVE, uma vez que elc sc configura como um serviço de ligaçõcs que pcrmitc a integração das diversas aplicaçõcs que virão a fazer parte dessa infra-estrutura. 


\section{Referências Bibliográficas}

Amaya (2001). Amaya Home Page - W3C Editor/Browser. on-line in World Wide Web. http://www.w3.org/Amaya.

Arruda Jr, C. R. E. and Pimentel, M. G. C. (2001). Projeto e implementação de um sistema colaborativo de edição. Revista Eletrônica de Iniciação Científica da Sociedade Brasileira de Computação, 2. a publicar em Novembro.

Berners-Lee, T., Hendler, J., and Lassila, O. (2001). The Semantic Web. on-line in World Wide Web. http://www.scientificamerican.com/2001/0501issue/0501berners-lee.html.

Bieber, M., Vitali, F., Ashman, H., Balasubramanian, V., and Oinas-Hukkonen, H. (1997). Fourth generation hypermedia: some missing links for the World Wide Web. International Journal of Human-Computer Studies, 47(1):31-65.

Bray, T., Hollander, D., and Layman, A. (1999). Namespaces in XML, W3C Recommendation. on-line in World Wide Web. http://www.w3.org/TR/REC-xml-names/.

Bray, T., Paoli, J., and Sperberg McQueen, C. M. (1998). Extensible Markup Language 1.0, W3C Recommendation. on-line in World Wide Web. http://www.w3.org/TR/REC-xml.

Brickley, D. and Guha, R. V. (2000). Resource Description Framework Schema Specification, W3C Candidate Recommendation. on-line in World Wide Web. http://www.w3.org/TR/rdf-schema/.

Brown, P. J. (1986). Interactive documentation. Software: Practice and Experience, pages 291-299.

Bush, V. (1945). As we may think. The Atlantic Monthly, 176:101-108.

Carr, L. and Hall, W. (1998). The implications of XML for open hypermedia. In Proceedings of OHS Workshop 4.0 at ACM Hypertext'98 Conference, pages 22-26, Pittsburgh, PA. ACM Press. 
Carr, L., Hall, W., and Roure, D. D. (1999). The evolution of hypertext link services. ACM Computing Surveys, 31(4).

Carr, L., Roure, D. D., Hall, W., and Hill, G. (1995). The Distributed Link Service: a tool for publishers, authors and readers. In Proceedings of the Fourth Third International World Wide Web Conference: The Web Revolution, pages 647-656, Boston, MA.

Chang, W. W. (1998). A discussion of the relationship between RDF-Schema and UML, W3C Note. on-line in World Wide Web. http://www.w3.org/TR/1998/NOTE-rdf-uml-19980804/.

Clark, J. (1999). Extensible Style Sheet Language Transformations (XSLT). on-line in World Wide Web. http://www.w3.org/TR/xslt/.

Clark, J. and DeRose, S. (1999). XML Path Language (XPath), W3C Recommendation. on-line in World Wide Web. http://www.w3.org/TR/xpath.

Crowder, R. and Hall, W. (1992). The use of interactive media as a training and operational interface in the advanced factory. In Proceedings of the Third International Conference on Factory 2000, pages 106-110, University of York, UK.

CSS2 (1998). Cascading Style Sheets 2 (CSS2), W3C Recommendation. on-line in World Wide Web. http://www.w3.org/TR/REC-CSS2/.

Davis, H. (1998). Referential integrity of links in open hypermedia systems. In Proceedings of Hypertext'98 of ACM Conference, pages 207-216, Pittsburgh, PA. ACM Press.

Davis, H., Hall, W., Heath, I., Hill, G., and Wilkins, R. (1992). Towards an integrated information environment with open hypermedia systems. In Proceedings of the Fourth ACM Conference on Hypertext, pages 181-190, Milan, Italy. ACM Press.

Davis, H., Knight, S., and Hall, W. (1994). Light hypermedia link services: a study of third-party applications integration. In Proceedings of ECHT'94: European Conference on Hypertext Technologies, pages 41-50, Edinburgh, Scotland. ACM Press.

Davis, H., Lewis, A., and Rizk, A. (1996). OHP: A draft proposal for a standard Open Hypermedia Protocol. In Proceedings of Hypertext'96: the 2nd Workshop on Open Hypermedia Systems, pages 27-53, Washington DC. ACM Press.

DC (1999). Dublin Core Metadata Initiative. on-line in World Wide Web. http://purl.org/dc/. 
DeRose, S. and Durand, D. (1994). Making HyperMedia Work: A.User's Guide to HyTime. Kluwer Academic Publishers, Boston, MA.

DeRose, S., Maler, E., and Daniel, R. (2001a). XML Pointer Language (XPointer), Last Call Working Draft. on-line in World Wide Web. http://www.w3.org/TR/xptr.

DeRose, S., Maler, E., and Orchard, D. (2001b). XML Linking Language (XLink), W3C Recommendation. on-line in World Wide Web. http://www.w3.org/TR/xlink.

DOM (1998). Document Object Model Level 1 Specification, W3C Recommendation. on-line in World Wide Web. http://www.w3.org/TR/REC-DOM-Level-1.

Engelbart, D. (1984). Authorship provisions in Augment. In Proceedings of 28th IEEE International Conference, pages 465-472, San Francisco, CA.

Goland, Y., Whitehead, E., Faizi, A., Carter, S., and Jensen, D. (1999). HTTP Extensions for Distributed Authoring - WebDAV. Internet Proposed Standard RFC 2518.

Goose, S., Hall, W., and Reich, S. (2000). Microcosm TNG: a framework for distributed open hypermedia. IEEE Multimedia, 7(3):52-60.

Grønbæk, K. (1998). Interoperability - issues beyond the protocol. In Proceedings of the OHS Workshop 4.0 at ACM Hypertext'98 Conference, pages 33-38, Pittsburgh, PA.

Grønbæk, K., Bouvin, N., and Sloth, L. (1997). Designing Dexter-based hypermedia services for the World Wide Web. In Proceedings of ACM Hypertext'97 Conference, pages 146-156, Southampton, UK.

Grønbæk, K., Hem, J., Madsen, O., and Sloth, L. (1994). Cooperative hypermedia systems: a Dexter-based architecture. Communications of the ACM, 37(2):64-75.

Grønbæk, K., Sloth, L., and Bouvin, N. (2000). Open hypermedia as user controlled meta data for the Web. In Proceedings of the Ninth International World Wide Web Conference, Amsterdam, The Netherlands.

Grønbæk, K., Sloth, L., and Orbæk, P. (1999). Webvise: browser and proxy support for open hypermedia structuring mechanisms on the WWW. In Proceedings of the Eighth International World Wide Web Conference, pages 253-267, Toronto, Canada.

Grønbæk, K. and Trigg, R. (1994). Design issues for a Dexter-based hypermedia system. Communications of the ACM, 37(2):41-49. 
Grønbæk, K. and Trigg, R. (1996). Toward a Dexter-based model for open hypermedia: unifying embedded references and link objects. In Hypertext'96 Seventh ACM Conference on Hypertext, pages 149-160, Washington DC. ACM Press.

Grønbæk, K. and Trigg, R. (1999). From Web to Workplace: Designing Open Hypermedia Systems (Digital Communication), volume 1. MIT Press, Boston, Ma. 386 p.

Gudgin, M., Hadley, M., Moreau, J. J., and Nielsen, H. F. (2001). Simple Object Acess Protocol (SOAP) version 1.2 - W3C Working Draft. on-line in World Wide Web. http://www.w3.org/TR/soap12/.

Guzdial, M. (1999). Supporting learners as users. The Journal of Computer Documentation, 23(2):3-13.

Halasz, F. (1988). Reflections on Notecards: seven issues for the next generation of hypermedia systems. Communications of the ACM, 31(7):345-365.

Halasz, F. and Schwartz, M. (1990). The Dexter Hypertext Reference Model. In Proceedings of the NIST Hypertext Standardization Workshop Gaithersburg, pages 95-133. National Institute of Standards and Technology Special Publications.

Halasz, F. and Schwartz, M. (1994). The Dexter hypertext reference model. Communications of the $A C M, 37(2): 30-39$.

Hall, W., Hill, G., and Davis, H. (1993). The Microcosm link service. In Proceedings of ACM Hypertext'93, pages 256-259, Toronto, Canada. ACM Press.

Halsey, B. and Anderson, K. (2000). XLink and open hypermedia systems: a preliminary investigation. In Proceedings of the ACM Hypertext'2000, pages 212-213, San Antonio, TX. ACM Press.

Harel, D. (1987). Statecharts: a visual formalism for complex systems. Science Computer Programming, 8(3):231-274.

ISO8879 (1986). Information Processing - Text and Office Systems - Standard Generalized Markup Language (SGML) - ISO 8879. on-line in World Wide Web. http://www.iso.ch/cate/d16387.html.

Izeki, C. A. (2001). Anotações Colaborativas como Hiperdocumentos de Primeira Classe na Web Semântica. Dissertação, Instituto de Ciências Matemáticas e de Computação da USP, São Carlos, São Paulo. 
Kahan, J., Koivunen, M., Prud'Hommeaux, E., and Swick, R. R. (2001). Annotea: an open RDF infrastructure for shared web annotations. In Proceedings of the $W W W 10$ Intermational Conference, Hong Kong.

Lassila, O. and Swick, R. R. (1999). Resource Description Framework (RDF) Model and Syntax Specification, W3C Recommendation. on-line in World Wide Web. http://www.w3.org/TR/REC-rdf-syntax.

Leggett, J. and Schnase, J. (1994). Viewing Dexter with open eyes. Communications of the $A C M, 37(2): 76-86$.

Lewis, P., Hall, W., Carr, L., and Roure, D. D. (1999). The significance of linking. ACM Computing Surveys, 31(4):1-6.

Lowe, D. and Hall, W. (1999). Hypermedia and the Web - An Engineering Approach. John Wiley \& Sons, Chichester, UK. 626 p.

Macedo, A. A., Bulcão Neto, R. F., and Pimentel, M. G. C. (2001). Autoria colaborativa na Web: experiências e reflexões sobre a Coweb. Revista Brasileira de Informática na Educação - RBIE, 9.

Malcolm, K., Poltrock, S., and Schuler, D. (1991). Industrial strength hypermedia: requirements for a large engineering enterprise. In Proceedings of Hypertext'91: Third ACM Conference on Hypertext, pages 13-24. ACM Press.

Meyrowitz, N. (1986). Intermedia: the architecture and construction of an object-oriented hypermedia system and applications framework. In ACM Conference on Object-Oriented Programming Systems, Languages and Applications, pages 186-201, Portland, Oregon. ACM Press.

Miotto, A. M. M. (2001). Especificação de um Modelo Formal para Aplicações em Sistemas Hipermídia Abertos. Dissertação, Instituto de Ciências Matemáticas e de Computação da USP, São Carlos, São Paulo.

Nanard, J. and Nanard, M. (1991). Using structured types to incorporate knowledge in hypertext. In Proceedings of ACM Hypertext'91, pages 329-344, San Antonio, TX. ACM Press.

Nelson, T. (1974). Computer Lib/Dream Machines. Mindful Press.

OHSWG (2001). Open Hypermedia Systems Working Group. on-line in World Wide Web. http://www.csdl.tamu.edu/ohs/. 
Paulo, F., Turine, M., Oliveira, M., and Masiero, P. (1998). XHMBS: a formal model to support hypermedia specification. In Proceedings of Hypertext'98: The Ninth ACM Conference on Hypertext and Hypermedia, pages 161-170. ACM Press.

Pearl, A. (1989). Sun's link service: a protocol for open linking. In Proceedings of ACM Hypertext '89, pages 137-146, Pittsburgh, PA. ACM Press.

Pimentel, M. G. C. and Abowd, G. (1999). Development and understanding of automated capture environments to support long-term use. Projeto de Cooperação Internacional Aprovado junto ao ProTeM-Cc-CNPq/Brasil e ao NSF-EUA.

Pimentel, M. G. C., Izeki, C. A., and Arruda Jr, C. R. E. (2001). An XML-based infrastructure supporting collaborative annotations as first-class hyperdocuments. In Anais do VII Simpósio Brasileiro de Sistemas Multimídia e Hipermídia, pages 173-186, Florianópolis, SC.

Raggett, D., Hors, A. L., and Jacobs, I. (1998). HTML 4.01 Specification, W3C Recommendation. on-line in World Wide Web. http://www.w3.org/TR/html401/.

Rizk, A. and Sauter, L. (1992). Multicard: an open hypermedia system. In Proceedings of the ACM Conference on Hypertext (EHCT'92), pages 4-10, Milano, Italy. ACM Press.

SMIL (2001). Synchronized Multimedia Integration Language (SMIL 2.0), W3C Recommendation. on-line in World Wide Web. http://www.w3.org/TR/smil20/.

Soares, L., Casanova, M., and Souza, G. (1996). Anchors and links for nested composite nodes. In Third International Conference on Multimedia Modelling, pages 21-34, Toulouse, França.

Soares, M., Fortes, R., and Moreira, D. (2000). VersionWeb: a tool for helping Web pages version control. International Conference on Internet Multimedia Systems and Applications, pages 275-280.

Sperberg McQueen, C. and Burnard, L. (1994). Guidelines for Electronic Text Encoding and Interchange. Text Encoding Initiative, Chicago.

Trigg, R. and Grønbæk, K. (1997). Heterogeneity, structure and CSCW: three challenges for open hypermedia. In Proceedings of the 3rd Workshop on Open Hypermedia Systems, pages 131-136, Southampton, UK. ACM Press.

van Ossenbruggen, J., Eliëns, A., and Rutledge, L. (1998). The role of XML in open hypermedia systems. In Proceedings of the 4th Workshop on Open Hypermedia Systems, pages 63-67, Pittsburgh, PA. 
van Ossenbruggen, J., Hardman, L., and Rutledge, L. (1999). Interoperability on the World Wide Web. In Proceedings of OHS Workshop 5.0 at ACM Hypertext'9g Conference, pages 48-51, Darmstadt, Germany.

Wiil, U. (1995). HyperDisco: an object-oriented hypermedia framework for flexible software system integration. In Proceedings of IEEE COMPSAC'95, pages 298-305, Dallas, TX.

Wiil, U. (1997). Open hypermedia: systems, interoperability and standards. Journal of Digital Information - JoDI, 1(2).

XLip (2000). Fujitsu XLink Processor (XLip). on-line in World Wide Web. http://www.labs.fujitsu.com/free/xlip/en/.

XMLSchema (2001). XML Schema Language, W3C Recommendation. on-line in World Wide Web. http://www.w3.org/XML/Schema.

XSL (2001). Extensible Style Sheet Language (XSL), W3C Recommendation. on-line in World Wide Web. http://www.w3.org/TR/xsl/.

Yoshikawa, M., Amagasa, T., Shimura, T., and Uemura, S. (2001). XRel: a path-based approach to storage and retrieval of XML documents using relational databases. ACM Transactions on Internet Technology, 1(1):110-141. 


\section{Apêndice A}

\section{Esquema RDF para o WLS}

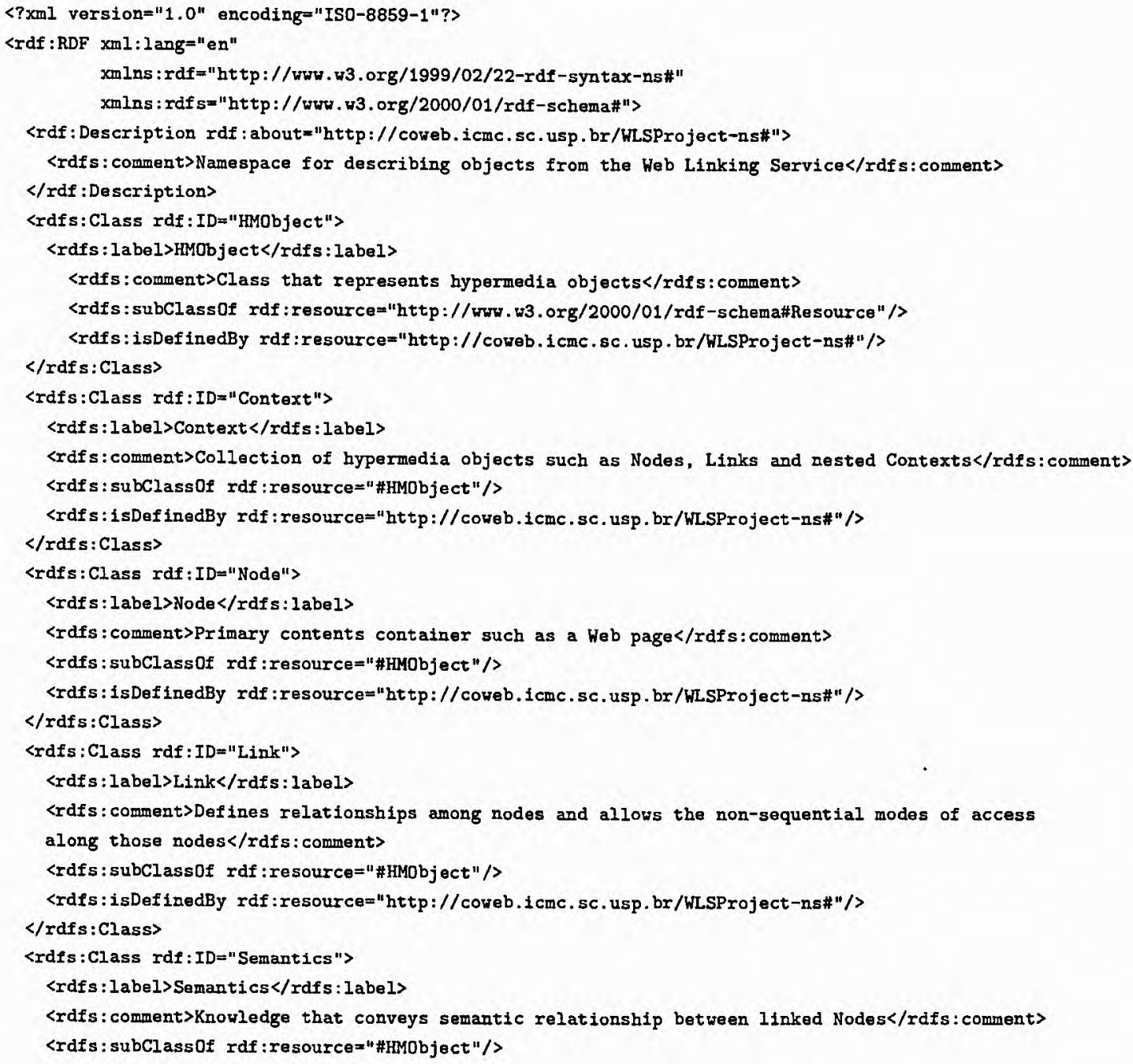




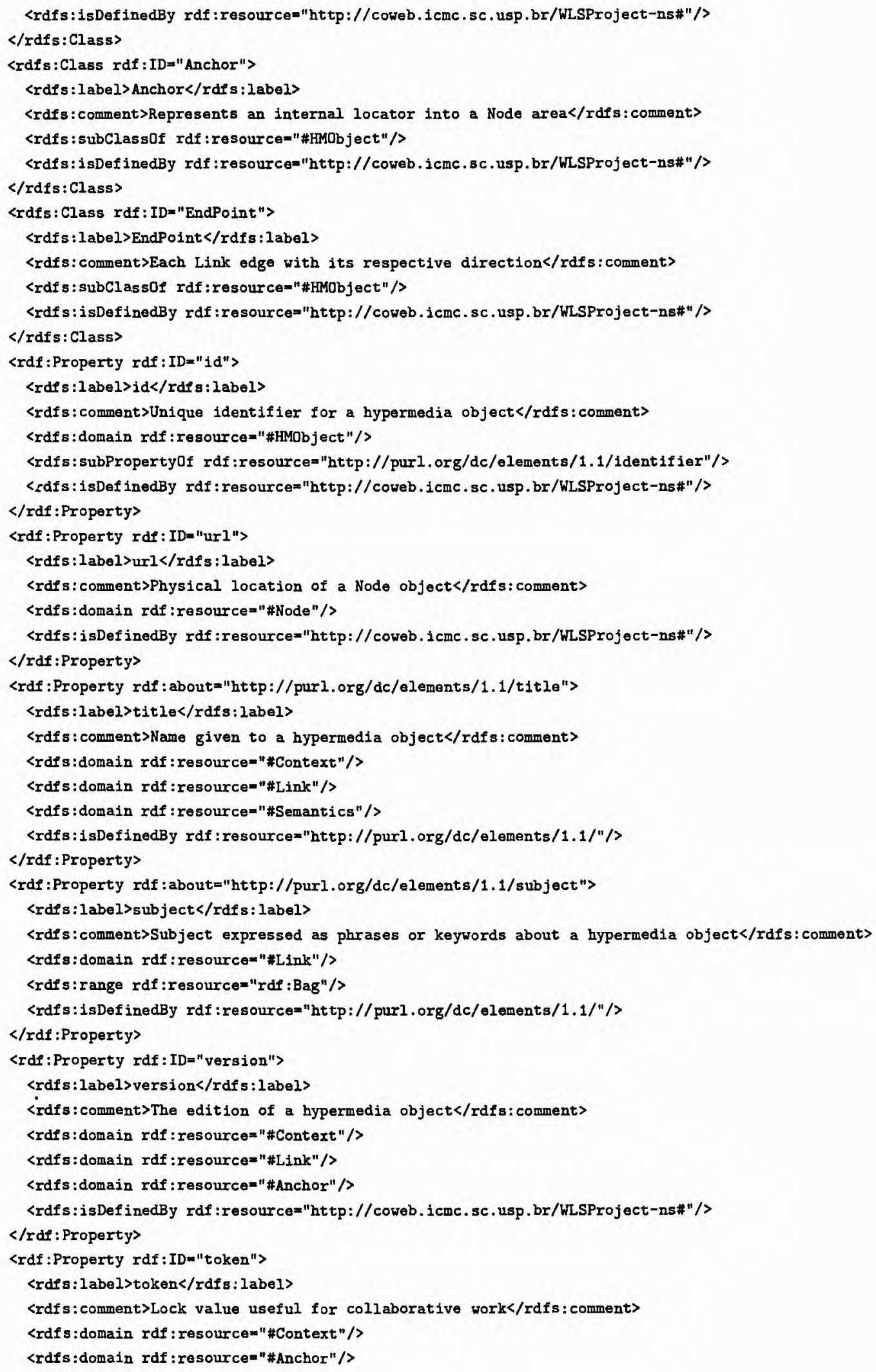


〈rdfs:isDefinedBy rdf:resource="http://coweb.icmc.sc.usp.br/WLSProject-ns\#"/>

$</$ rdf:Property $>$

〈rdf : Property rdf : ID="expression"〉

〈rdfs: label>expression</rdfs:label>

〈rdfs:comment>Anchor value in an understandable syntax by applications</rdfs:comment>

<rdfs:domain rdf: resource="\#Anchor"/>

〈rdfs:isDefinedBy rdf:resource="http://coweb.icmc.sc.usp.br/WLSProject-ns\#"/>

$\langle/$ rdf:Property $\rangle$

$\langle r d f:$ Property rdf : ID="direction"〉

〈rdfs:label>direction</rdfs : label>

〈rdfs:comment>Direction of each EndPoint</rdfs:comment>

〈rdfs: domain rdf : resource="\#ndPoint"/>

〈rdfs:range rdf : resource=" \#valuedfDirection"/>

〈rdfs:isDefinedBy rdf:resource="http://coweb.icmc.sc.usp.br/WLSProject-ns\#"/>

$\langle/$ rdf: Property $>$

〈rdfs:Class rdf:ID="valueDfDirection"/>

<value0fDirection $\mathrm{rdf}: \mathrm{ID}=" \mathrm{from}$ "/>

<valueOfDirection rdf:ID="to"/>

<valueofDirection rdf : ID="bi"/>

〈rdf:Property rdf : about="http://purl.org/dc/elements/1.1/creator"〉

$\langle$ rdfs: label>creator</rdfs : label>

〈rdfs: comment>User name who created a hypermedia object</rdfs:comment>

<rdfs: domain rdf : resource="\#HMObject"/>

$<$ rdfs:isDefinedBy rdf:resource="http://purl.org/dc/elements/1.1/"/>

$</$ rdf:Property $\rangle$

〈rdf:Property rdf:ID=" created"〉

〈rdfs : label>created</rdfs:label>

$\langle$ rdfs:comment>Date and time on which a hypermedia object was created. $\langle/ \mathbf{r d f s}$ :coment>

<rdfs: domain rdf : resource=" \#HMObject"/>

〈rdfs : subPropertyof rdf:resource="http://purl.org/dc/elements/1.1/date"/>

<rdfs: isDefinedBy rdf:resource="http://coweb.icmc.sc.usp.br/WLSProject-ns\#"/>

$\langle/$ rdf:Property $\rangle$

〈rdf : Property rdf : ID="modified"〉

$\langle$ rdfs: label>modified</rdfs: label〉

〈rdfs:comment>Date and time on which a hypermedia object was last modified.〈/rdfs:comment>

<rdfs: domain $r$ df : resource="\#HMObject"/>

〈rdfs:subPropertyof rdf : resource="http://purl.org/dc/elements/1.1/date"/>

<tdfs: isDefinedBy rdf :resource="http://coweb.icmc.sc.usp.br/WLSProject-ns\#"/>

$\langle/$ rdf:Property $\rangle$

〈rdf : Property rdf : ID="lastUser"〉

$\langle$ rdfs:label>lastUser $\langle/$ rdfs: label>

〈rdfs:comment>User name who last modified a hypermedia object</rdfs:comment>

<rdfs: domain rdf: resource="\#HMObject"/>

<rdfs: subPropertyof rdf : resource="http://purl.org/dc/elements/1.1/creator"/>

〈rdfs:isDefinedBy rdf:resource="http://coweb.1cmc.sc.usp.br/WLSProject-ns\#"/>

$\langle/$ rdf: Property $\rangle$

〈rdf:Property rdf:ID="ancestral">

$\langle$ rdfs:label>ancestral</rdfs:label>

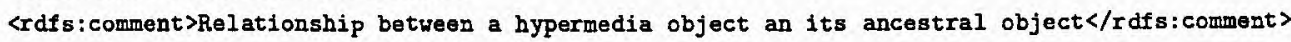

〈rdfs: domain rdf: resource="\#Context"/>

〈rdfs:domain rdf: resource="\#Node"/>

<rdfs: domain rdf : resource="\#Link"/>

<rdfs: domain rdf: resource=" Anchor"/>

〈rdfs:range rdf:resource="rdf:Literal"/>

〈rdfs:isDefinedBy rdf:resource="http://coweb.icmc.sc.usp.br/WLSProject-ns\#"/> 


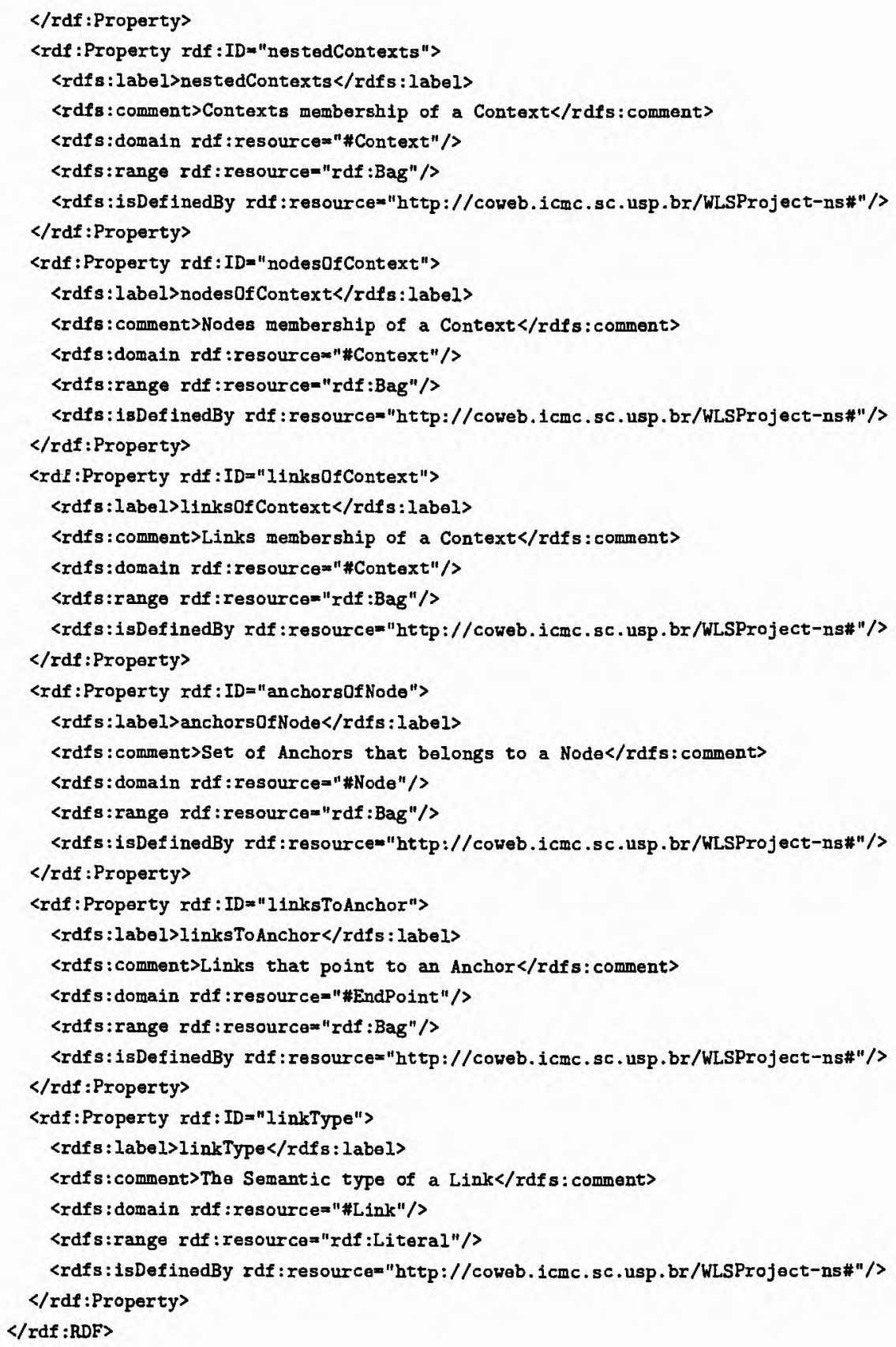

